FABRICIA LEALZAGANEU

\title{
Avaliação da linfangiogênese intratumoral em carcinoma precoce do colo de útero
}

Tese apresentada à Faculdade de Medicina da Universidade de São Paulo para obtenção do título de Doutor em Ciências

Programa de Obstetrícia e Ginecologia

Orientador: Prof. Dr. Jesus Paula Carvalho

\section{São Paulo}

2010 
Dados Internacionais de Catalogação na Publicação (CIP)

Preparada pela Biblioteca da

Faculdade de Medicina da Universidade de São Paulo

Creprodução autorizada pelo autor

\section{Zaganelli, Fabricia Leal}

Avaliação da linfangiogênese intratumoral em carcinoma precoce do colo do útero / Fabricia Leal Zaganelli. -- São Paulo, 2010.

Tese(doutorado)--Faculdade de Medicina da Universidade de São Paulo.

Programa de Obstetrícia e Ginecologia.

Orientador: Jesus Paula Carvalho.

Descritores: 1.Neoplasias do colo do útero 2.Histerectomia 3.Linfagiogênese 4.Podoplanina 5.Marcadores biológicos de tumor 6.Metástase neoplásica

USP/FM/DBD-256/10 
"Deus nos fez perfeitos,

Ele não escolhe os mais capacitados, e sim capacita os escolhidos." 


\section{Agradecimentos}

Deus - em primeiro lugar, pois sem Ele seria impossível chegar até aqui. Peço perdão por minhas inseguranças, que foram muitas. "Agradeço todas as dificuldades que enfrentei, pois se não fosse por elas, eu não teria saído do lugar. As facilidades nos impedem de caminhar." Chic o Xavier

Prof. Dr. Jesus Paula Canalho, meu onientador - meus mais sinceros respeito e admiração e obrigada por ter sido muito mais do que um orientador, despertando em mim a vontade de fazer. Agradeço por sua capacidade de transformar cada momento do seu dia em reflexões positivas para que eu, aluna que iniciava a vida acadêmica, visse que as dificuldades existem, mas que existem também ferramentas para superálas. O senhor é um exemplo de professor.

\section{Magnífico Reitor da Universidade Federal do Espínito Santo, Doutor Rubens} Sérgio Rasseli - agradeço pelo carinho que sempre teve comigo e que me proporcionou a continuidade nos estudos até a chegada a este doutorado. Meus eternos agradecimentos.

Profa. Dra. Margareth Vetis Zaganelli - sua extrema generosidade comigo em vários momentos da minha vida ajudaram-me a prosseguir e a lutar por meus ideais. A senhora é muito mais do que uma tia querida, é um exemplo de profissional. Obrigada.

Prof. Dr. João Alvécio Sossai - admirável e generoso, pois consegue ajudar não só seus alunos próximos, mas também os que estão distantes. Obrigada. 
Prof. Dr. João Carlos Sampaio Góes - um exemplo profissional para alunos que iniciam a vida acadêmica. Obrigada por ter me aberto portas que estão fazendo toda a diferença na minha vida.

Dra. Renata Sampaio Goes - obrigada por ser uma amiga tão querida.

Prof. Dr. Edmund C. Baracat - meu eterno agradecimento por esta oportunidade. "Tudo o que um sonho precisa para ser realizado é alguém que acredite nele." Roberto Shinya shiki

Prof. Dr. Marcelo A. Calil - pela disponibilidade irrestrita e por possibilitar com que este trabalho se concretizasse.

Profe Dra. Filomena Manino Carvalho - seus gestos de carinho, atenção e delicadeza foram muito além das funções de uma professora, demonstrando-se uma mãe que me fez perceber o quanto é uma pessoa especial na sua forma de ser. Saiba como foram bem-vindos seus ensinamentos e ações, os puxões de orelha que sempre ocorreram na hora certa e seus sorrisos quando acertávamos o dever de casa. Muito obrigada!

Prof. Dr. Altamiro Dias - por me acolher em seu ambulatório e dividir o conhecimento diário com paciência e amizade.

Dra. Eoá Muniz de Freitas Alves - pela paciência e carinho quando estávamos afobados devido aos prazos e só a senhora, com seu jeitinho doce, nos ajudou a conseguir. Obrigada.

Meus pais - quando iniciava os primeiros passinhos nas areias de Conceição da Barra, vocês já me encorajavam a superar os desafios da vida e a utilizar os tropeços como um trampolim para chegar mais longe. O que me tornei só foi possível por ser um pedacinho de vocês. 
Meu esposo - amado e companheiro, você esteve comigo em momentos extremamente difíceis que transcorreram ao mesmo tempo desta tese e, apesar de tudo, você foi minha força. Amo você!

Meus imãos - Juninho, nunca vou me esquecer daquele dia quando fui me matricular na Faculdade de Direito e você não permitiu. Olhe só aonde chegamos. Adriana, amada cunhada, o que seria de mim sem sua "ajudinha" com a informática? Fred, obrigada pelo carinho, alegria e, acima de tudo, pela paz que me trouxe em suas visitas. Aninha, minha cunhada tão querida, conseguimos rir muito decifrando o endnote. Irmãos, como vocês fazem a vida valer a pena!

Vovô Galdino e vovó Elisa - tudo começou com vocês e, hoje, fruto desse grande amor, nasceram filhos e agora netos, que se espelham em vocês a cada dia para dar orgulho a esses avós tão maravilhosos.

Aos amigos do IBCC - tantos amigos (Fernanda e Gislei, Noemi e Andréa, Vera e Marli, enfermeira Luciana, Janete), que foram fundamentais para que conseguisse esta vitória.

Aos amigos do Centro de Referência da Mulher - Prof. Dr. Luiz Henrique Gebrim, Prof. Dr. José Carlos Pascalicchio e Dr. Alisson Zanatta, por acreditaram em mim quando ainda não havia conquistado este título.

Aos amigos - que fiz durante o curso, pela verdadeira amizade que construímos e, em particular, àqueles que estavam sempre ao meu lado.

A todos, registro minha gratidão. 
Esta dissertação ou tese está de acordo com as seguintes normas, em vigor no momento desta publicação:

Referências: adaptado de Intemational Committee of Medical Joumals Editors (Vancouver)

Universidade de São Paulo. Faculdade de Medicina. Serviço de Biblioteca e Documentação. Guia de apresentação de dissertações, teses e monografias.

Elaborado por Anneliese Carneiro da Cunha, Maria Julia de A. L. Freddi, Maria F. Crestana, Marinalva de Souza Aragão, Suely Campos Cardoso, Valéria Vilhena. 2a ed. São Paulo: Serviço de Biblioteca e Documentação; 2005.

Abreviaturas dos títulos dos periódicos de acordo com list of Joumals Indexed in Index Medicus. 
Lista de Abreviaturas e Siglas

Lista de Símbolos

Lista de Figuras

Lista de Gráficos

Lista de Tabelas

Resumo

Summary

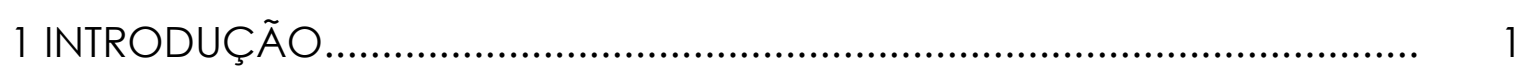



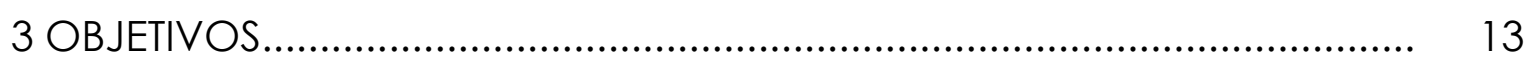

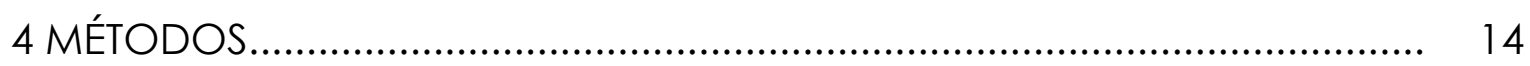

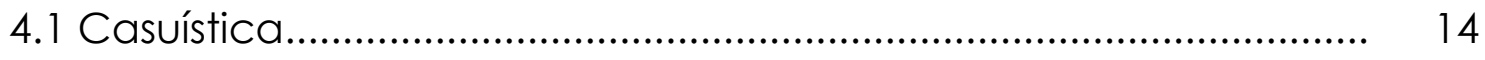

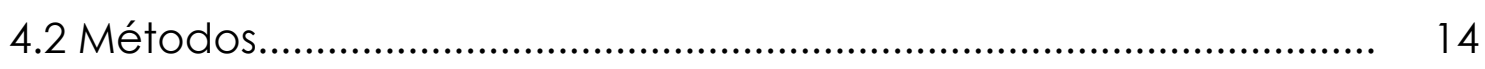

4.2.1 Análise dos prontuários...................................................... 14

4.2.2 Método anatomopatológico................................................ 15

4.2.3 Construção dos blocos de microarranjos de tecidos (TMA).. 16

4.2.4 Técnica de imunoistoquímica..................................................... 19

4.2.5 Interpretação imunoistoquímica.............................................. 21

4.2.6 Método de avaliação da microdensidade vascular............. 24

4.3 Análise estatística................................................................................... 27

5 RESULTADOS...................................................................................... 28

5.1 Análise comparativa dos grupos segundo o comprometimento dos linfonodos e desfecho.......................................................... 29

5.2 Comparação dos métodos de avaliação da linfangiogênese.... 40

5.3 Associações entre MDVL e características clínico-patológicas.... 42

5.4 Análise multivariada com inclusão da MDVL na previsão do desfecho das pacientes..

\footnotetext{
${ }^{1}$ Este trabalho foi revisado de acordo com as novas regras ortográficas.
} 
5.5 Associação entre a MDVL e a expressão da podoplanina pelas células neoplásicas e células fibroblásticas do estroma intratumoral

5.6 Associação entre expressão de podoplanina em células neoplásicas com comprometimento vascular, acometimento de linfonodos e desfecho.

5.7 Avaliação da expressão da podoplanina em células fibroblásticas do estroma intratumoral.

5.8 Análise multivariada incluindo a MDVL, expressão de podoplanina pelas células neoplásicas e em células fibroblásticas do estroma para previsão do acometimento dos linfonodos e no desfecho das pacientes.

6 DISCUSSÃO

7 CONCLUSÕES. 64

8 ANEXOS. 66

9 REFERÊNCIAS. 69 APÊNDICE 


\section{Lista de Abreviaturas e Siglas}

ANOVA Análise de variância

cAmp AMP cíclico

CAPPesq Comissão de Ética para Análises de Projetos de Pesquisa

CEL Expressão da podoplanina em célula intratumoral

CLEC-2 Receptor-2 lecitina-like tipo C

DAB 3-3'-diaminobenzamidina

DVL Densidade linfovascular

DVP Densidade vascular ponto

DVT Densidade vascular traço

DVV Densidade vascular vaso

EMT Transição epitélio-mesenquimal

EVL Embolização vascular linfática

FIGO Federação Internacional de Ginecologia e Obstetrícia

GI Grau de liberdade

IBCC Instituto Brasileiro de Controle do Câncer

INCA Instituto Nacional do Câncer

ITS Estroma intratumoral

LMVD Microdensidade densidade vascular linfática

LYVE 1 Receptor endotelial de vaso linfático (lymphatic vessel endothelial receptor-1)

MDVL Microdensidade densidade vascular linfática

OMS Organização Mundial da Saúde

p Probabilidade de erro alfa

PBS Tampão fosfato de sódio

$\mathrm{pH} \quad$ Potencial de Hidrogênio

PLAG Agregação plaquetária

TMA Microarranjo de tecidos

TTS Tempo de sobrevida total

VEGF Fator de crescimento endotelial vascular (vascular endothelial growth factor)

VEGFR Receptor de crescimento endotelial vascular (vascular endothelial growth factor receptor) 


\section{Lista de Símbolos}

$\begin{array}{ll}\mathrm{H}_{2} \mathrm{O}_{2} & \text { Água Oxigenada } \\ \% & \text { Porcentagem } \\ \mu \mathrm{m} & \text { Micrômetro } \\ \mathrm{mm} & \text { Milímetro } \\ \chi^{2} & \text { Qui-quadrado }\end{array}$




\section{lista de Figuras}

Figura 1 Instrumento de precisão para construção de microarranjos de tecidos, do fabricante Beecher Instruments, Silver Spring, MD..... 17

Figura 2 (A) Transferência do bloco doador, (B) Bloco receptor................... 17

Figura 3144 casos tornaram-se apenas cinco lâminas de TMA.................... 18

Figura 4 Bloco de TMA (A), corte histológico de TMA corado pela Hematoxilina-Eosina (B)................................................................. 19

Figura 5 Detalhe de um dos casos de (A) adenocarcinoma e (B) carcinoma de células escamosas, presentes em bloco de TMA. 19

Figura 6 Imunocoloração para podoplanina em vasos linfáticos intratumoral em caso de carcinoma de células escamosas...........

Figura 7 Expressão de podoplanina em células neoplásicas com mais intensidade de coloração na interface com o estroma intratumoral circunjacente (exame imunoistoquímico, D2-40, aumento original 100X).

Figura 8 Expressão forte de podoplanina em células fibroblásticas do estroma intratumoral (exame imunoistoquímico, D2-40, aumento original 400X)

Figura 9 Ki 67 positivo em $>50 \%$ das células neoplásicas em casos de adenocarcinoma grau 1 .

Figura 10 (A) Quantificação da densidade vascular (DVL), (B) cálculo da DVL pelo método morfométrico de Weibel com gratículo 10 linhas e 10 pontos e (C) representação histológica da expressão da podoplanina em fibroblastos do estroma intratumoral. 


\section{Lista de Gráficos}

Gráfico 1 Curvas de sobrevida (Kaplan-Meyer) segundo 0 acometimento dos linfonodos, utilizando estatística de Breslow. 38

Gráfico 2 Correlação entre os resultados dos métodos para avaliação da densidade vascular..................................................................... 


\section{Lista de Tabelas}

Tabela 1 Características clínico-patológicas de carcinomas de colo de útero submetidos a tratamento cirúrgico primário no período de 2000 a 2008

Tabela 2 Estadiamento clínico segundo o comprometimento dos linfonodos

Tabela 3 Estadiamento clínico segundo desfecho das pacientes 29

Tabela 4 Tipo histológico segundo o comprometimento dos linfonodos...... 30

Tabela 5 Tipo histológico segundo o desfecho das pacientes...................... 30

Tabela 6 Distribuição do acometimento de paramétrio nos grupos............. 31

Tabela 7 Distribuição do acometimento de paramétrio segundo o desfecho das pacientes.

Tabela 8 Distribuição do acometimento da vagina segundo o comprometimento dos linfonodos.

Tabela 9 Distribuição do acometimento de vagina segundo o desfecho das pacientes

Tabela 10 Distribuição do acometimento do útero segundo o comprometimento dos linfonodos.

Tabela 11 Distribuição do acometimento do útero segundo o desfecho das pacientes

Tabela 12 Distribuição do grau histológico segundo o comprometimento dos linfonodos.

Tabela 13 Distribuição do grau histológico nos grupos segundo o desfecho das pacientes

Tabela 14 Distribuição do comprometimento vascular segundo o comprometimento dos linfonodos.

Tabela 15 Distribuição do comprometimento vascular segundo o desfecho das pacientes.

Tabela 16 Distribuição da expressão do Ki-67 segundo o acometimento dos linfonodos. 
Tabela 17 Distribuição da expressão do Ki-67 segundo o desfecho das pacientes.

Tabela 18 Comparativo de médias segundo o comprometimento dos linfonodos.

Tabela 19 Comparações das médias segundo o desfecho das pacientes... 37

Tabela 20 Associação entre comprometimento de linfonodos e desfecho das pacientes.

Tabela 21 Distribuição conjunta da classificação entre os métodos DVV e DVP.

Tabela 22 Distribuição conjunta da classificação entre os métodos DVV e DVT...

Tabela 23 MDVL segundo a faixa etária das pacientes.

Tabela 24 MDVL segundo o estadiamento clínico das pacientes. 42

Tabela 25 MDVL segundo o tipo histológico. 43

Tabela 26 MDVL e tamanho do tumor. 43

Tabela 27 MDVL e acometimento de paramétrio. 44

Tabela 28 MDVL e acometimento de vagina 44

Tabela 29 MDVL e acometimento de linfonodos. 45

Tabela 30 MDVL e grau histológico. 45

Tabela 31 MDVL e comprometimento vascular. 46

Tabela 32 MDVL e profundidade de invasão 46

Tabela 33 MDVL e expressão do Ki-67 47

Tabela 34 MDVL e desfecho das pacientes. 47

Tabela 35 Resultados do modelo para o desfecho, incluindo a MDVL 48

Tabela 36 Resultados do modelo para o desfecho. 48

Tabela 37 Resultados do modelo para o acometimento dos linfonodos, incluindo a MDVL 49

Tabela 38 Resultados do modelo para o acometimento dos linfonodos....... 49

Tabela 39 MDVL e expressão de podoplanina em células neoplásicas......... 50

Tabela 40 MDVL e a expressão da podoplanina no estroma intratumoral.... 50

Tabela 41 Expressão da podoplanina em células neoplásicas e comprometimento vascular. 
Tabela 42 Expressão da podoplanina em células neoplásicas e estado dos linfonodos.

Tabela 43 Expressão da podoplanina em células neoplásicas e desfecho das pacientes

Tabela 44 Expressão da podoplanina em células neoplásicas e expressão da podoplanina no estroma intratumoral.

Tabela 45 Resultados do ajuste do modelo saturado para a expressão da podoplanina no estroma.

Tabela 46 Resultados do ajuste do modelo final para a expressão de podoplanina no estroma.

Tabela 47 Expressão da podoplanina em células fibroblásticas do estroma intratumoral e comprometimento de linfonodos.

Tabela 48 Expressão da podoplanina em células fibroblásticas do estroma intratumoral e desfecho.

Tabela 49 Modelo inicial para acometimento de linfonodos incluindo expressão da podoplanina nas células neoplásicas.

Tabela 50 Modelo final para previsão de acometimento de linfonodos........

Tabela 51 Modelo inicial para acometimento dos linfonodos incluindo expressão da podoplanina no estroma intratumoral

Tabela 52 Modelo quase final para o acometimento dos linfonodos incluindo expressão da podoplanina no estroma intratumoral.....

Tabela 53 Modelo inicial para previsão do desfecho incluindo a expressão da podoplanina nas células neoplásicas.

Tabela 54 Modelo final para o desfecho incluindo a expressão da podoplanina nas células neoplásicas.

Tabela 55 Modelo inicial para previsão do desfecho incluindo a expressão da podoplanina no estroma intratumoral.

Tabela 56 Modelo final para previsão de desfecho incluindo a expressão da podoplanina no estroma intratumoral. 
Zaganelli FL. Avaliação da linfangiogênese intratumoral em carcinoma precoce de colo de útero [tese]. São Paulo: Faculdade de Medicina, Universidade de São Paulo; 2010. 79p.

A incidência do câncer cervical permanece elevada em nosso país, provavelmente devido ao rastreamento ser realizado principalmente em áreas urbanas e haver áreas menos favorecidas onde os programas de rastreamento não são efetivos. É bem sabido que a mortalidade pelo câncer raramente é devida ao tumor primário, mas à disseminação metastática das células tumorais em órgãos distantes. A via linfática é considerada a preferencial para disseminação metastática nos tumores ginecológicos. E o estágio clínico e os linfonodos regionais são considerados os fatores prognósticos mais potentes no carcinoma de colo útero. A compreensão da linfangiogênese pode ser considerada uma importante chave na elucidação dos mecanismos usados pelas células tumorais na sua disseminação. Os objetivos do presente estudo são avaliar as características clínico-patológicas do câncer do colo do útero e sua associação com o comprometimento linfonodal e o desfecho; avaliar a linfangiogênese intratumoral pela análise quantitativa da microdensidade vascular linfática (MDVL), usando o método imunoistoquímico para marcação dos vasos linfáticos e três métodos morfométricos para a quantificação; determinar a associação entre a MDVL, características clínico-patológicas de apresentação, comprometimento linfonodal, desfecho e a expressão de podoplanina em células neoplásicas e a expressão da podoplanina em células fibroblásticas do estroma intratumoral. Os estudos sobre a MLVD em câncer de colo de útero são raros e controversos. Nossos resultados demonstraram que a MLVD foi mais acentuada nos tumores de menor tamanho $(<2 \mathrm{~cm})$, nos estádios iniciais (IB1), com menos infiltrações, sem comprometimento vascular e sem comprometimento linfonodal, provavelmente porque a indução da linfangiogênese pode ser um evento inicial na progressão do câncer, quando ainda nem todos os vasos neoformados estão funcionantes ou patentes. Isto explicaria a elevada MLVD nos tumores iniciais quando os linfonodos estavam frequentemente negativos. Observou-se que não não houve associação significativa entre expressão de podoplanina em células neoplásicas e comprometimento vascular, comprometimento dos linfonodos ou desfecho. A expressão de podoplanina em fibroblastos do estroma intratumoral no câncer precoce de colo de útero está associada a melhor prognóstico. Até o presente, acreditase que este seja o primeiro estudo a investigar o papel da expressão da podoplanina no estroma intratumoral de carcinoma precoce do colo do útero, relacionando-a com MLVD, comprometimento dos linfonodos e o desfecho.

Palavras-chave: 1.Carcinoma do colo de útero 2.Histerectomia radical 3.Linfangiogênese 4.Podoplanina 5.Metástase neoplásica 


\section{Summary}

Zaganelli FL. Evaluation of intratumoral lymphangiogenesis in early-stage carcinoma of the uterine cervix [Thesis]. São Paulo: "Faculdade de Medicina, Universidade de São Paulo"; 2010. 79p.

Cervix carcinoma incidence remains still high in our country, probably as the screening occurrence is carried out mainly in the urban areas and there are less favored areas where the screening programs are not effective. It is well known that the cancer mortality is rarely caused by the primary tumor, but it is caused by the metastatic spread of tumor cells in distant organs. The lymphatic route is considered the choice for the metastatic dissemination in the gynecological tumors. And the clinical stage and the regional lymphonodes are considered the most powerful prognostic factors in the uterine cervix cancer. The understanding of the lymphangiogenesis can be considered an important key for the elucidation of the mechanisms used in the tumor cells dissemination. The current study objectives are to evaluate the clinic-pathological characteristics of the uterine cervix carcinoma and its association with the lymphnodal involvement and outcome; to evaluate the intratumoral lymphangiogenesis by the quantitative analysis of the lymphatic vessel micro density (LVMD), using the immunoistochemical method for marking the lymphatic vessels and three morphometric methods for the quantification. To determine the association between the LVMD, the clinicpathological characteristics, the lymphonodal involvement and outcome and the podoplanin expression in neoplasic cells and in fibroblastic cells of the intratumoral stroma. Studies about the LVDM in uterine cervical cancer are rare and controversial. Our results demonstrated that the LVDM was more remarkable in the smaller tumors $(<2 \mathrm{~cm})$, in the initial stages $(\mathrm{IB} 1)$, with less infiltrations, with no vascular involvement and no lymphnodal involvement. Probably because the induction of lymphangiogenesis may be an early event in cancer progression, while still not all the newly formed vessels are functioning or patent. This would explain the high LVMD in the initial tumors while the lymphonodes were frequently negative. It was noted that there were no significant association between podoplanin expression in neoplasic cells and vessel involvement, lymphonodes involvement or outcome. Podoplanin expression in fibroblasts of the intratumoral stroma in early cervix carcinoma was associated to better prognosis. To date, it is believed that this is the first study to investigate the role of podoplanin expression in intratumoral stroma of cervix carcinoma, relating it to LVMD, lymph node involvement and outcome.

Keywords: 1.Uterine cervix cancer 2.Radical hysterectomy 3.Lymphangiogenesis 4.Podoplanin 5.Neoplasic metastasis 


\section{INTRODUÇÃO}

O câncer de colo de útero é o segundo tipo de câncer mais comum entre mulheres em todo o mundo. A estimativa em 1990 foi de 371.200 casos novos de câncer invasivo de colo uterino em todo o mundo, quase $80 \%$ deles em países em desenvolvimento'. No Brasil, o Instituto Nacional do Câncer (INCA), em 2005, estimou a incidência de 22 casos para cada 100.000 mulheres, com a ocorrência de 20.690 casos novos e 8.000 mortes. Para 2008, a estimativa foi de 19,18 casos por $100.000^{2,3}$ e

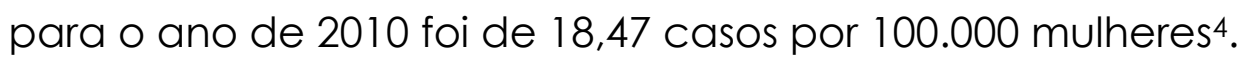

Apesar do câncer de colo uterino ser prevenível com rastreamento citológico, no Brasil a mortalidade por essa causa ainda é elevada, persistindo como problema de saúde pública ${ }^{5}$.

A metástase é considerada a principal causa de mortalidade em câncer, sendo o sistema linfático a principal via de disseminação para a maioria dos carcinomas, normalmente precedendo a via vascular. O acometimento dos linfonodos regionais em tumores sólidos é um marcador para disseminação, estágio avançado e pior prognóstico. A importância da metástase linfática é bem reconhecida no tratamento e estadiamento do câncer. O estado linfonodal determina a multimodalidade de tratamento em pacientes com tumores sólidos como câncer de mama, colorretal e de cabeça e pescoço. Nos carcinomas do colo uterino, o estado dos linfonodos pélvicos e para-aórticos é um dos fatores prognósticos mais importantes, ao lado do estadiamento clínico6-8.

O processo de metástase é bastante complexo e inclui modificações moleculares nas células neoplásicas que as capacitam para invasão do estroma local, entrada nos vasos linfáticos e implantação nos linfonodos regionais. Esse processo não é somente mecânico, mas envolve intrínsecas interações moleculares entre células neoplásicas, microambiente e sistema vascular linfático9,10. 
A invasão dos vasos linfáticos precede as metástases regionais, fazendo com que a identificação de comprometimento vascular em espécimes cirúrgicos seja de valor prognóstico e, em geral, associado a altas taxas de comprometimento linfonodal11,12. A formação de novos vasos linfáticos - a linfangiogênese - está provavelmente relacionada à disseminação metastática ${ }^{13-15}$. Entretanto, sua avaliação em carcinomas do colo uterino foi pouco estudada e os resultados têm sido controversos 16,17 .

Os mecanismos e o papel da linfangiogênese na disseminação regional ainda são pouco conhecidos, assim como a metodologia na sua avaliação, seja pela escolha do melhor marcador, seja pelo compartimento a ser avaliado (intra ou peritumoral)18-20. O estroma intratumoral encerra muitos dos segredos das interações entre as células neoplásicas e o hospedeiro. Nele ocorre o fenômeno da linfangiogênese, além do trânsito de várias moléculas implicadas na interação entre neoplasia e hospedeiro.

Entre essas moléculas destaca-se a podoplanina, inicialmente pesquisada nos tecidos por ser um marcador específico de vasos linfáticos, mas que pode ser expressa em células neoplásicas e em células do estroma intratumoral10,19,21-24. Já foi descrita sua presença em células neoplásicas, sobretudo escamosas, de várias localizações 19,22,24,25. Sua descrição no carcinoma escamoso cervical está limitada a raros trabalhos e com resultados controversos quanto ao seu significado 16,21.

Ainda mais controverso é o significado da expressão de podoplanina em células fibroblásticas do estroma intratumoral10,23. No câncer do colo de útero seu significado ainda não foi investigado. Portanto, trata-se de um cenário em que a compreensão das características moleculares do complexo microambiente neoplásico relacionadas à linfangiogênese poderá resultar no desenvolvimento de estratégias para o controle da progressão tumoral26-28. 


\section{REVISÃO DA IIIERATURA}

O estádio clínico e o estado dos linfonodos regionais são considerados os fatores prognósticos mais potentes no carcinoma de colo útero. Outras variáveis histológicas também podem contribuir, tais como: o tipo histológico, grau de diferenciação, embolização linfática, nível de infiltração da parede cervical e o padrão de infiltração29. O comprometimento vascular é a característica histológica com maior poder de previsão de linfonodos comprometidos ${ }^{27}$ e o comprometimento linfonodal é o principal fator relacionado à sobrevida30.

Compreender os mecanismos pelos quais as células neoplásicas atingem os linfonodos é de fundamental importância, pois nesses mecanismos pode estar a chave para intervenções terapêuticas 22,23. O conhecimento do sistema linfático nos tumores e da linfangiogênese é tema de muito interesse atual e motivou a realização do presente estudo.

A primeira descrição do sistema linfático foi feita em 1627, quando foram identificados os vasos linfáticos como sendo vaso leitoso (milk vein) no mesentério de um cachorro (well-fed dog). Na mesma época, foi descrita a circulação sanguínea ${ }^{31}$. Mesmo assim, passaram-se décadas para que se iniciasse a formulação de teorias sobre o desenvolvimento desses vasos.

O sistema linfático surge em torno da sexta ou sétima semana do desenvolvimento embrionário 32 , por volta de quatro semanas após o aparecimento dos primeiros componentes da circulação sanguínea.

A respeito da linfangiogênese, duas teorias foram propostas: centrífuga e centrípeta. A teoria mais aceita foi a descrita por Florence Sabin (1902), centrífuga, sugerindo que, precocemente, no desenvolvimento fetal, os sacos linfáticos primitivos seriam originados de 
brotamento de células endoteliais a partir de veias do embrião. Segundo essa teoria centrífuga, os vasos linfáticos se espalhariam perifericamente pelos tecidos e órgãos e a partir desses sacos linfáticos primitivos dariam origem aos capilares linfáticos 33 .

Já a teoria centrípeta, proposta por Huntington e McClure (1908), preconizava que os vasos linfáticos primitivos surgiam no mesênquima a partir de linfangioblastos, independentes das veias, crescendo centripetamente e estabelecendo conexões com as veias mais tardiamente 34 .

Os vasos linfáticos são muito similares aos vasos sanguíneos, inclusive histologicamente. Devido a isto, a maioria dos estudos no passado envolveu principalmente pesquisas relacionadas à angiogênese (formação dos vasos sanguíneos) e abordou menos sobre linfangiogênese (formação dos vasos linfáticos). Mas com a recente descoberta de marcadores específicos de endotélio de vasos linfáticos, os estudos sobre os linfáticos estão despertando acentuado interesse 35.

O conceito inicial de propagação linfática do tumor indicava que a metástase de células tumorais ocorria unicamente a partir da invasão de vasos linfáticos preexistentes em áreas marginais ao tumor, isto é, o tumor não seria linfangiogênico. Foram observados grupamentos de vasos linfáticos contendo células tumorais na periferia dos tumores, porém o mesmo não foi verificado no centro do tumor ${ }^{36}$.

É necessária a preexistência de vasos linfáticos peritumorais para que as células tumorais metastatizem para outros locais ${ }^{37}$. Estímulos moleculares específicos produzidos nos tumores induzem o sistema linfático preexistente a proliferar 38 .

Há alguns anos, pesquisadores no assunto falharam ao tentarem identificar vasos linfáticos funcionantes dentro do tumor, direcionando a 
suspeita de que a linfangiogênese poderia não ter importante papel na metástase tumora| ${ }^{39,40 .}$.

Essa ideia foi sustentada por outros autores que, promovendo a injeção de substâncias dentro dos linfáticos, não detectaram qualquer tipo de sinal intrínseco proveniente dos vasos linfáticos dentro do tumor ${ }^{41}$.

No entanto, essa ausência de sinal poderia ter sido apenas reflexo, pelo fato de os vasos linfáticos estarem colabados dentro do tumor, consequente ao aumento de pressão e estresse mecânico gerado pelas células tumorais em proliferação. Sugeriu-se, ainda, a necessidade de haver dilatação e proliferação dos vasos linfáticos no estroma de tecidos tumorais para que houvesse produção de fatores de crescimento pelas células tumorais ${ }^{38}$.

Entretanto, linfáticos preexistentes talvez precisassem ser estimulados pelas células tumorais a ponto de induzir a formação de novos vasos linfáticos pelo tumor. Esses estudos não conseguiram concluir se a passagem das células tumorais para os vasos linfáticos é um processo passivo ou ativo 38,42 .

O interesse pelo estudo dos vasos linfáticos dentro dos tumores é recente 36,38,39,43-46, pois para vários autores, até há pouco tempo, os vasos linfáticos não eram considerados parte ativa e funcionante do estroma tumoral36,38,43,46.

Avaliação de 97 pacientes com carcinoma escamoso de cabeça e pescoço salientou associação da densidade linfática intratumoral e pior prognóstico e recidiva. Enfatizou, também, que densidade linfática peritumoral estava associada à sobrevida favorável ${ }^{47}$.

Estudo com 52 pacientes com carcinoma escamoso de cabeça e pescoço ressaltou que áreas com aumento da densidade linfática 
peritumoral estavam associadas à metástase linfonodal, mas não houve correlação com sobrevida48.

A densidade linfática intratumoral e também peritumoral associouse à metástase de nódulo linfático. E alta densidade linfática intratumoral associou-se à baixa sobrevida total na pesquisa com 81 pacientes com carcinoma escamoso de cabeça e pescoço 49 .

Foram acompanhados 45 pacientes com câncer de mama correlacionado a mais densidade de vaso linfático com invasão linfovascular, mas não com a sobrevida50.

Apenas a minoria de 180 pacientes com câncer de mama apresentou linfáticos intratumorais, cuja densidade linfática peritumoral associou-se à metástase para nódulo linfático51.

Outros 113 pacientes também com câncer de mama apresentaram significativo aumento da densidade de vasos linfáticos associado a: metástase linfonodal, pior prognóstico e sobrevida livre de doença e presença do fator de crescimento endotelial vascular (VEGF-C) ${ }^{52}$.

Ao acompanhar 202 pacientes com melanoma de pele, registrou-se aumento da densidade linfática peritumoral associada à melhora da sobrevida total e intervalo livre de doença53.

Acentuada densidade linfática intratumoral foi constatada em 37 pacientes com melanomas. As metástases correlacionaram-se com curto intervalo livre de doença e menos sobrevida total ${ }^{54}$.

Foi apurado também, em 44 pacientes com melanoma, aumento da densidade linfática ao redor do melanoma maligno comparado com derme normal, carcinoma basocelular e carcinoma de célula de Merkel. A densidade linfática pode diferenciar o melanoma que metastatizou daquele que não55. 
Observou-se em 45 pacientes com melanoma que densidade linfática peritumoral associou-se à metástase para linfonodo sentinela e a menos sobrevida total. Maior rede de linfáticos intratumorais prediz o status do gânglio linfático56.

Representativa densidade de vasos linfáticos associou-se a significativo aumento da sobrevida em 85 pacientes com câncer cervical57.

Alta densidade linfática intratumoral associou-se a metástase linfonodal e pior sobrevida tota|58 em 111 pacientes com carcinoma precoce de colo de útero.

Estudo com 90 pacientes com câncer epitelial de ovário relatou que a densidade vascular linfática não se associou à sobrevida total ou sobrevida livre de progressão tumoral59. Outro trabalho com 108 pacientes obteve os mesmos resultados 60 .

Em 117 pacientes com câncer gástrico verificou-se que a densidade vascular linfática associou-se à metástase linfonodal e à pior sobrevida total61.

Há relato de que em carcinoma de células transicionais do trato urinário a densidade linfática intratumoral associou-se à sobrevida livre de doença e à sobrevida total62. Essa série abordou 125 indivíduos.

Alta densidade linfática peritumoral associou-se a metástase linfonodal e sobrevida total na casuística composta de 103 pacientes com câncer de pequenas células de pulmão63.

VEGF-C e VEGF-D agem através do seu receptor fator de crescimento endotelial vascular receptor (VEGFR-3) e promovem metástases. Para que isso ocorra, não só deve ser considerada linfangiogênese intratumoral ou peritumoral, mas também outras alterações sutis na célula tumoral e sua interação com células endoteliais 
linfáticas. O conhecimento dessas vias de sinalização poderá indicar terapias-alvo para inibição da metástase regional60. Com o desenvolvimento da biologia molecular e celular, novos marcadores específicos para vasos linfáticos têm sido identificados.

O primeiro progresso real nos estudos da linfangiogênese foi a identificação dos fatores de crescimento de vasos endoteliais (VEGFs). Entre os fatores dessa família estão VEGF-C e VEGF-D, os quais, agora se sabe, são apenas ligantes. Atuam na linfangiogênese através de receptores com atividade tirosina-quinase, ativando o VEGFR-3, o qual é um receptor altamente expresso no endotélio dos vasos linfáticos e é considerado um marcador de vaso linfático64-69.

Nos últimos anos tem-se presenciado a identificação de marcadores específicos para endotélio de vasos linfáticos incluindo a podoplanina, uma mucoproteína presente nas membranas do podócitos glomerulares 70,71 .

A avaliação da linfangiogênese se faz a partir da medida da microdensidade densidade vascular linfática (MDVL). Os primeiros estudos com determinação da MDVL usaram anticorpos diretamente contra os marcadores de células endoteliais 72 .

Secção imunoistoquímica em pequena magnificação em áreas de tecido com elevado número de vasos linfáticos fortemente marcados 52 determinou a densidade vascular linfática ao contar todos os vasos de áreas imunoistoquimicamente marcadas com magnificação x200.

Até pouco tempo atrás a MDVL era escassamente avaliada nas amostras de lâminas de tumor, devido a não ser considerada confiável como marcador de vasos linfáticos em secções de parafina. Com o advento dos anticorpos contra VEGFR-373-78, podoplanina50,57,59,79 e também o lymphatic vessel endothelial receptor-1 (LYVE-1)80, tornou-se possível avaliar a MDVL em tecidos embebidos em parafina. 
A podoplanina foi identificada pela primeira vez em 1990, em célula osteoblástica de murinos MC3Y3-E181. Mas sua identificação especificamente em células endoteliais linfáticas ocorreu em $1996^{82}$. Inicialmente foi designada com antígeno Ell e foi posteriormente chamada podoplanina devido à sua baixa expressão nos podócitos dos corpúsculos renais.

Podoplanina humana, também chamada Tla-2, aggrus ou gp36, é uma glicoproteína transmembrana tipo-1 de 38 KDa, com 162 aminoácidos, sendo nove destes pertencentes ao domínio intracelular22. Pode também ser chamada de aggrus devido à sua capacidade de induzir agregação plaquetária sem necessitar de componentes do plasma83. Foi demonstrado que o anticorpo monoclonal 8F11 é capaz de inibir a agregação plaquetária in vitro e também a metástase pulmonar em ratos proveniente do carcinoma de cólon in vivo ${ }^{84}$.

Reconhecida como uma sialoglicoproteína celular de superfície, pertence à família das glicoproteínas transmembrana tipo I sialomucinalike, com domínio extracelular rico em resíduos de serina e treonina, uma única porção transmembrana e pequena cauda citoplasmática, com sítios para proteína kinase $\mathrm{C}$ e fosforilação do AMP cíclico (CAMP)83.

A podoplanina possui também uma estrutura disialyl-core no domínio agregação plaquetária (PLAG), o qual é necessário para que ela consiga se ligar ao seu receptor específico ${ }^{85}$. O receptor-2 lecitina-like tipo C (CLEC-2) foi identificado como um receptor endógeno da podoplanina em plaquetas ${ }^{86}$. No entanto, já se encontrou que a partir da deleção do mutante CLEC-2-FC a inibição da podoplanina induzida pela agregação plaquetária indicaria que $\bigcirc$ CLEC-2 seria ligante fisiológico da podoplanina 85 .

A associação entre CLEC-2 e podoplanina foi confirmada por meio de citometria de fluxo e reportou-se ser dependente do ácido siálico no o- 
glycanos da podoplanina. O recombinante CLEC-2 é inibido pela agregação plaquetária, induzido pela expressão da podoplanina em células tumorais e células endoteliais linfáticas ${ }^{86}$. Esses achados sugerem que o CLEC-2 é uma proteína fisiológica alvo da podoplanina e a interação entre os dois poderia regular a capacidade de invasão tumoral e metástase, o que seria potencial alvo terapêutico para as metástases. A expressão da podoplanina na superfície de células tumorais induziria a agregação plaquetária por interagir com CLEC-2. Foi demonstrado que o CLEC-2 FC inibido induziria a podoplanina à agregação plaquetária85.

Nos tecidos normais, a podoplanina é expressa nos podócitos renais70, músculo-esquelético, placenta, pulmão e coração87, miofibroblastos da mama e glândula salivar, osteoblastos e células mesoteliais88. É também expressa na superfície apical de células alveolares tipo I de ratos ${ }^{89}$. Ocasionalmente, pode ser observada a expressão da podoplanina em áreas focais circunscritas da camada basal da epiderme humana90.

Em condições normais, a podoplanina é parte importante em prevenir adesão celular e está envolvida na regulação da forma dos pés dos podócitos e em manter a permeabilidade glomérul091-93.

Apesar da função fisiológica da podoplanina permanecer desconhecida, foi referido que a podoplanina está envolvida na formação dos vasos linfáticos, mas não influencia na formação dos vasos sanguíneos ${ }^{94}$. Pesquisa em ratos deficientes de podoplanina evidenciou que esses animais apresentavam defeitos em vasos linfáticos, associados a: diminuição do transporte linfático, linfedema congênito e vasos linfáticos dilatados 70 e normalmente morriam ao nascimento por falência respiratória ${ }^{94,95}$.

A expressão da podoplanina pode ser avaliada por imunoistoquímica. O anticorpo que reconhece a podoplanina é o D2-4096. 
A podoplanina é um marcador específico do endotélio de vasos linfáticos e não é expresso em vasos sanguíneos. Isto é observado tanto no desenvolvimento quanto na maturação das células endoteliais linfáticas e parece ser 0 marcador mais específico para endotélio de vasos linfáticos ${ }^{97}$.

A podoplanina marcada detecta pequenos vasos linfáticos a partir da coexpressão com VEGFR-3, assim como conglomerado de vasos linfáticos e sinusoides hepáticos, mas não detecta vasos linfáticos grandes nem vênulas endoteliais calibrosas dos nódulos linfáticos ${ }^{70}$.

Por microscopia eletrônica e microscopia imunoeletrônica, foi demonstrado que a podoplanina é principalmente expressa na superfície luminal da célula endotelial linfática e raramente fora da superfície do lúmen ou lateralmente à célula ou em organelas citoplasmáticas das células endoteliais 98 .

A podoplanina não é um marcador exclusivo de endotélio linfático. Em tecido humano normal, a podoplanina já foi demonstrada em podócitos, células osteoblásticas, osteócitos, queratinócitos basais, células epiteliais do plexo coroide, células epiteliais tipo I do timo, células mioepiteliais, células de reserva de glândula sebácea, miofibroblastos de próstata, células da granulosa do ovário, células dendríticas folicular e células alveolares82,90,99.

Os vasos linfáticos neoformados podem ser peritumorais e intratumorais. Os vasos linfáticos peritumorais apresentam-se mais largos e irregulares do que os intratumorais e têm MDVL mais baixa98. Os vasos linfáticos intratumorais são usualmente pequenos, aplainados e irregulares e ocasionalmente contêm células tumorais. Vários autores identificaram vasos que expressavam podoplanina em tumores malignos de estroma de ovário55, colo do útero57, pâncreas ${ }^{100,101}$ e mama50. 
No carcinoma de mama inflamatório, foi identificada a proliferação de células endoteliais tanto no tumor quanto em áreas peritumorais, com significativo aumento da positividade da podoplanina nos vasos linfáticos das áreas peritumorais ${ }^{18}$.

No colo do útero, em uma série de cones e histerectomias radicais, a podoplanina esteve expressa em $71 \%$ das amostras, focalmente, mas não intratumoral no tumor Bulk e esteve presente em $59 \%$ das amostras 21,102 .

O uso de podoplanina como marcador de endotélio linfático mostrou que o aumento da densidade vascular linfática não influencia a progressão do câncer epitelial de ovário e foi associado a prognóstico favorável no câncer de colo de útero' ${ }^{103}$.

Estudando a expressão da podoplanina em 151 pacientes, constatou-se que o adenocarcinoma exibiu menos expressão quando comparado com o carcinoma de células escamosas e adenoescamoso, sem correlação positiva com invasão de nódulo linfático e/ou metástase à distância nem com recorrência tumorall'b.

Os vasos linfáticos e/ou os fatores de crescimento linfangiogênicos são atraentes alvos terapêuticos quando se cogitam estratégias de tratamento para progressão tumoral e metástases. $O$ uso de antipodoplanina como estratégia terapêutica pode ser sugerido no tratamento das metástases tumorais, baseado em quatro considerações: a) a podoplanina é um marcador conhecido de células endoteliais linfáticas; b) ela é expressa em células tumorais de vários tipos de cânceres humanos; c) seu aumento parece estar associado a mau prognóstico e alto risco de metástase para nódulo linfático; d) está envolvida no processo de invasão tumoral ${ }^{16}$. 


\section{Objetivo Primánio}

- Avaliar a linfangiogênese intratumoral a partir da análise quantitativa da microdensidade vascular linfática (MDVL) em carcinomas precoce de colo do útero submetidos a tratamento cirúrgico.

\section{Objetivos Secundánios}

- Descrever as características clínico-patológicas de apresentação dos carcinomas de colo do útero (idade da paciente, estadiamento clínico, tamanho do tumor, tipo e grau histológico, atividade proliferativa, embolização vascular linfática, extensão parametrial, extensão vaginal) e sua associação com o comprometimento linfonodal e o desfecho.

- Determinar a associação entre a microdensidade vascular linfática (MDVL) e características clínico-patológicas de apresentação, comprometimento linfonodal, desfecho, expressão de podoplanina em células neoplásicas e em células fibroblásticas do estroma intratumoral. 


\section{MÉIOdOS}

\subsection{Casuística}

Este projeto foi submetido e aprovado pela Comissão de Ética em Pesquisa do Instituto Brasileiro de Controle do Câncer (IBCC) e pela Comissão de Ética para Análise de Projetos de Pesquisa do Hospital das Clínicas da Faculdade de Medicina da Universidade de São Paulo (CAPPesq) - protocolo no 0729/08 (APÊNDICE A).

Foram avaliados pacientes com diagnóstico de carcinoma de células escamosas e adenocarcinoma primário de colo de útero tratadas no IBCC no período de janeiro de 2000 a dezembro de 2008.

Foram incluídas somente as pacientes com diagnóstico histológico confirmado de carcinoma primário de colo do útero (carcinoma de células escamosas e adenocarcinoma) estádios I e II, submetidas ao tratamento cirúrgico com histerectomia radical e linfadenectomia pélvica, operadas sempre pela mesma equipe de cirurgiões dessa Instituição e que tivessem a totalidade do tumor excisada e linfonodos regionais, com blocos de parafina disponíveis. Foram excluídas as gestantes, as submetidas a qualquer forma de tratamento neoadjuvante radioterápico ou quimioterápico e as com carcinomatose.

\subsection{Métodos}

\subsubsection{Análise dos prontuánios}

Trata-se de estudo prognóstico tipo coorte histórica com análise dos prontuários dos quais foram coletadas as seguintes informações: idade da 
paciente no momento do diagnóstico, estadiamento clínico segundo a Federação Internacional de Ginecologia e Obstetrícia (FIGO)104, tipo de cirurgia realizada, tratamento adjuvante, tempo de seguimento e desfecho. Essas informações constam no ANEXO A.

Do laudo anatomopatológico foram recuperados os seguintes dados: tamanho do tumor, extensão para paramétrio, extensão para vagina e corpo do útero e número de linfonodos retirados e comprometidos.

Foram obtidos 144 casos que preencheram os critérios de inclusão e de exclusão propostos. Todos os dados obtidos do prontuário foram inseridos em planilha eletrônica (Excel Microsoft Office 2007).

\subsubsection{Método Anatomopatológico}

Todos os casos foram revisados inicialmente por uma patologista do Departamento de Patologia do Instituto Brasileiro de Controle do Câncer (IBCC), Dra. Eloá Muniz de Freitas Alves, que selecionou os cortes mais representativos dos tumores e avaliou:

- Tipo histológico segundo critérios da Organização Mundial de Saúde (OMS) 105: carcinoma de células escamosas ou adenocarcinoma;

- grau histológico baseado na diferenciação celular (escamosa ou glandular), pleomorfismo nuclear e atividade mitótica: 1 (bem diferenciado), 2 (moderadamente diferenciado) e 3 (pouco diferenciado);

- comprometimento vascular peritumoral: avaliado na parede cervical circunjacente ao tumor; 
- nível de infiltração da parede cervical em centímetros, medida desde o ponto de início da invasão estromal até o nível mais profundo de invasão.

Todos os casos foram revisados por um segundo patologista, Dr. Bernardo G. L. Almeida, e os episódios divergentes foram avaliados em conjunto com uma terceira patologista, Profa. Dra. Filomena M. Carvalho, do Departamento de Patologia da Faculdade de Medicina da Universidade de São Paulo. Os dados foram inclú́dos no banco de dados.

No Departamento de Patologia selecionou-se uma área representativa do tumor para construção de blocos de microarranjos de tecidos para os estudos imunoistoquímicos.

\subsubsection{Construção dos blocos de microananjos de tecidos (TMA)}

O procedimento foi realizado na Consultoria em Patologia, Botucatu (SP), sob orientação dos Professores Carlos E. Bacchi (diretor da Consultoria em Patologia) e Filomena M. Carvalho (Departamento de Patologia da Faculdade de Medicina da Universidade de São Paulo). Foi retirado um cilindro de $2,0 \mathrm{~mm}$ da área selecionada do tumor, em cada bloco de parafina, designado bloco doador. Esses cilindros foram enxertados em um bloco de parafina receptor em linhas e colunas com intervalo de 1,0 mm entre cada cilindro, obedecendo à orientação de um mapa de planejamento previamente desenhado. Foi utilizado um instrumento de precisão para construção de TMA, do fabricante Beecher Instruments, Silver Spring, MD, posicionado em bancada fixa para trabalho (Figuras 1 e 2). 
a

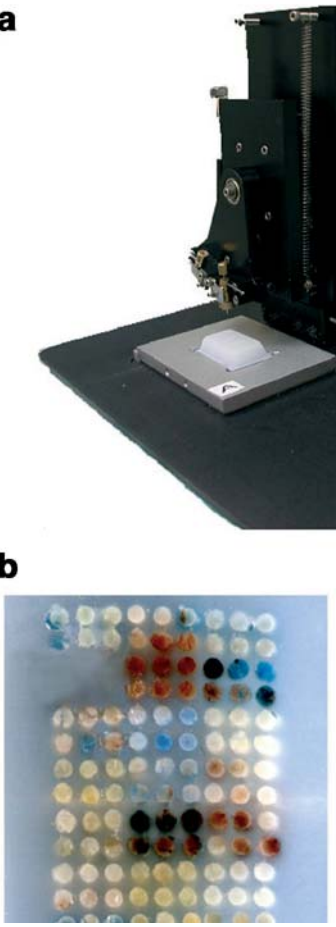

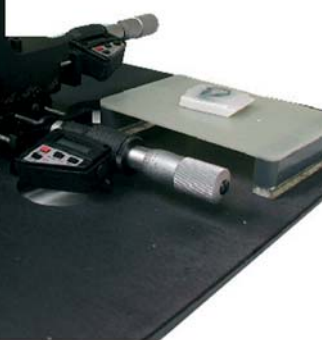

c

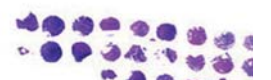

490904 - 10

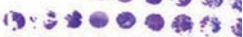
2 2 . -

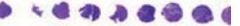
is 0 a - 9 04

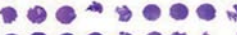

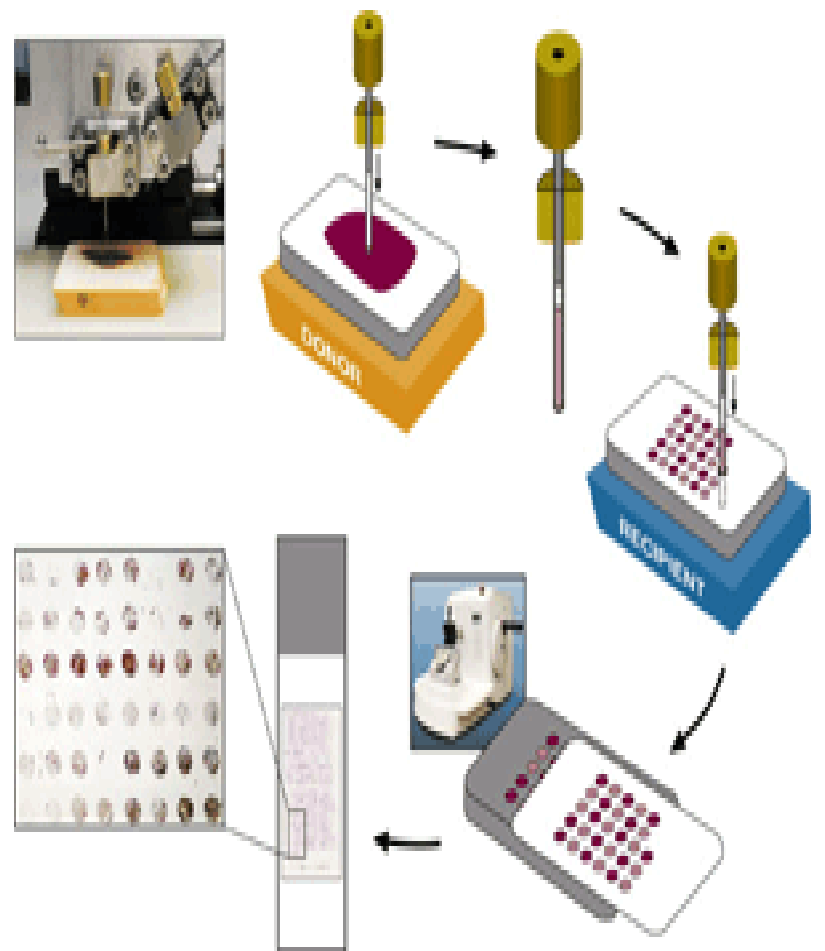

Figura 1 - Instrumento de precisão para construção de TMA, do fabricante Beecher Instruments, Silver Spring, MD
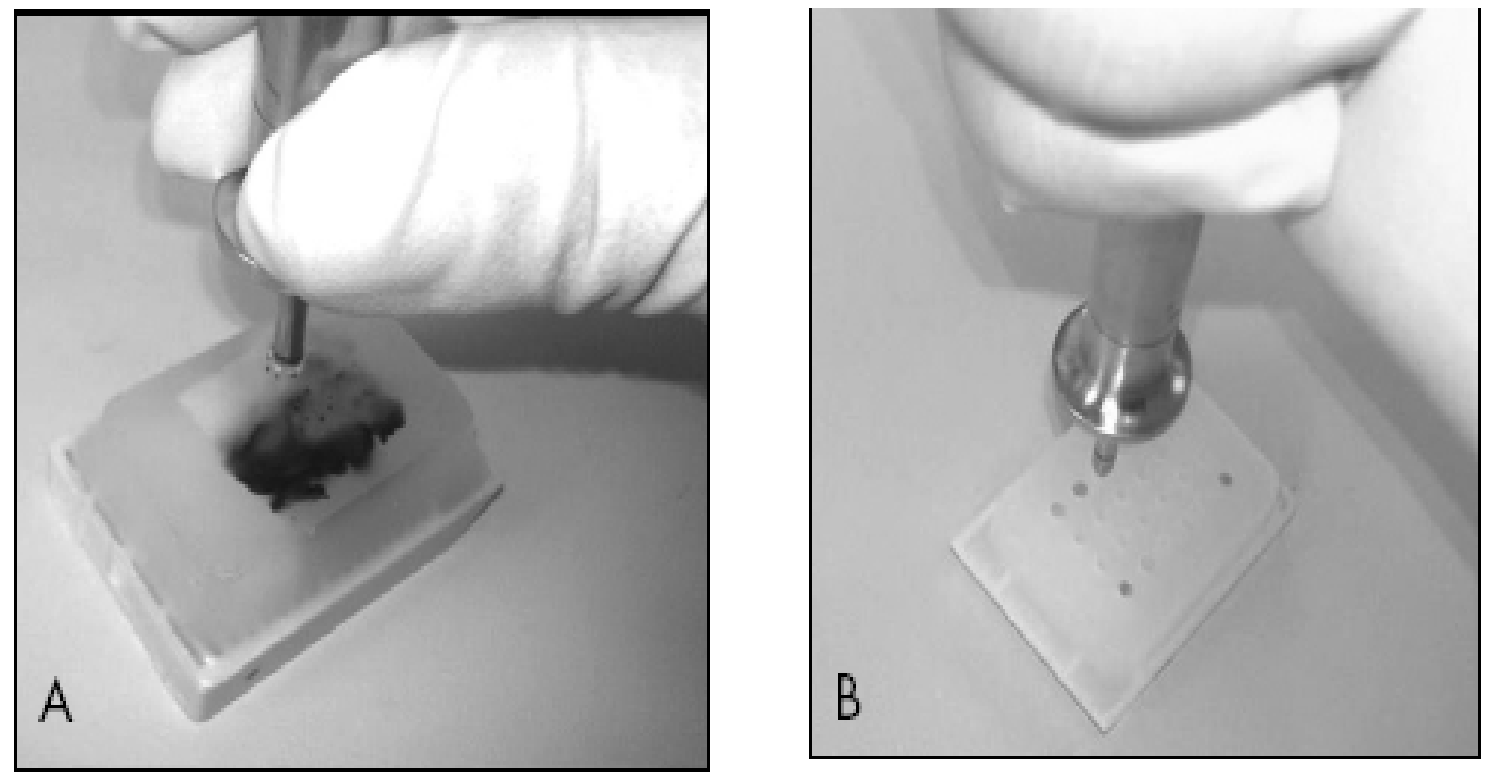

Figura 2 - (A) Transferência do bloco doador, (B) Bloco receptor 
Depois que os cilindros foram todos inseridos no bloco receptor, este foi aquecido por 10 minutos sob temperatura de $60^{\circ} \mathrm{C}$. Os 144 blocos originais geraram cinco blocos de TMA (Figura 3). A seguir, foram cortadas fitas de $5 \mu \mathrm{m}$ dos blocos em micrótomo convencional para confecção dos preparados histológicos, empregando-se lâminas apropriadas da marca Sta rfrost ${ }^{\circledR}$ slides, com técnica padronizada.
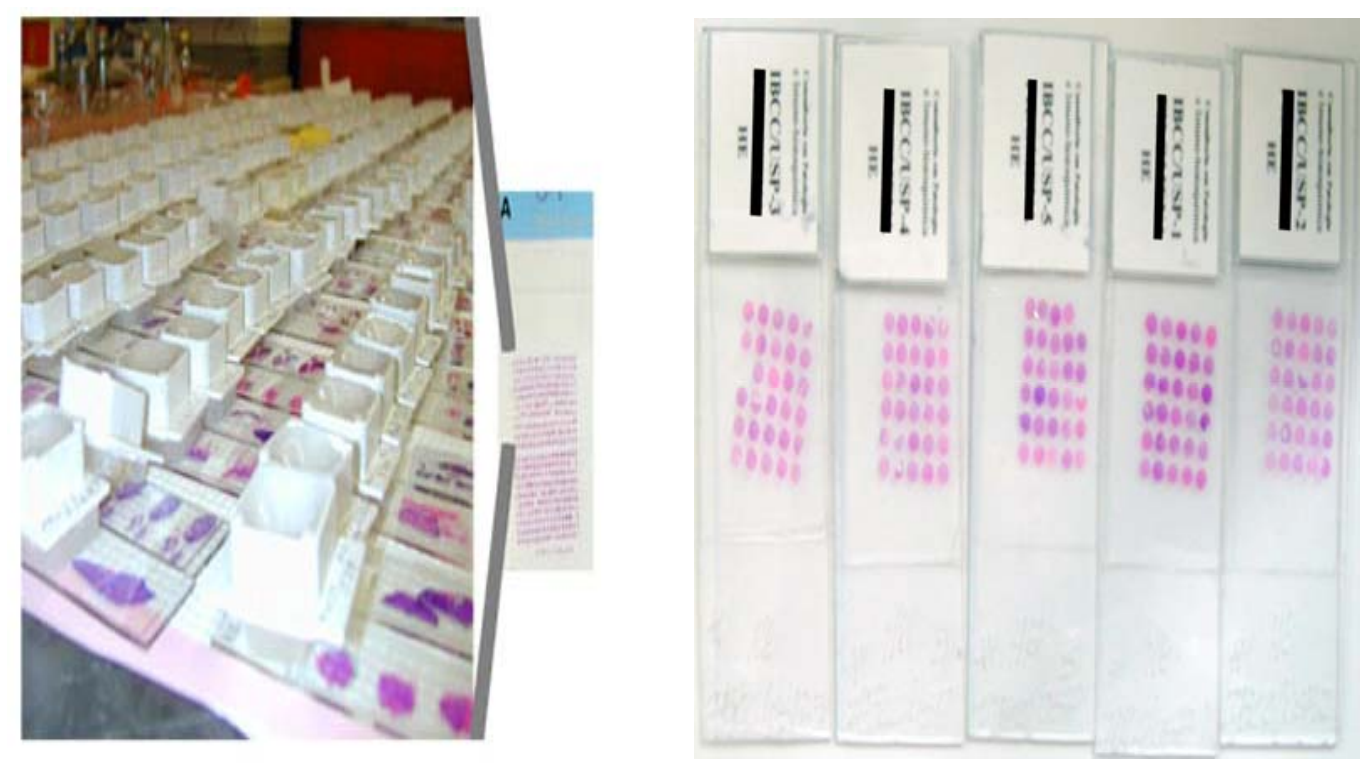

Figura 3 - 144 casos tornaram-se apenas cinco lâminas de TMA

Os primeiros cortes histológicos foram corados pela técnica da Hematoxilina-Eosina (Figuras $4 \mathrm{~B}$ e 5). A seguir, foram realizados os cortes histológicos para realização das reações imunoistoquímicas para podoplanina e proteína nuclear Ki-67 (Ki-67), sendo 15 casos convertidos para corte inteiro do bloco doador, devido à escassa representatividade do tumor no TMA. 

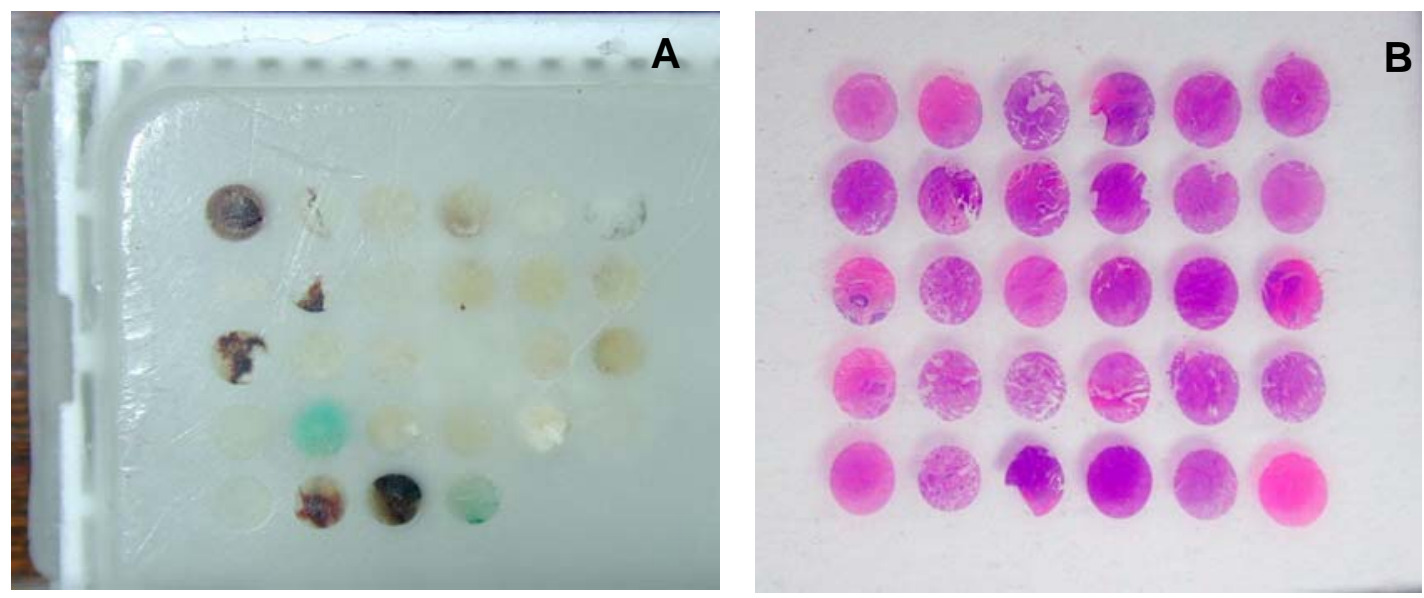

Figura 4 - Bloco de TMA (A), corte histológico de TMA corado com Hematoxilina-Eosina (B)
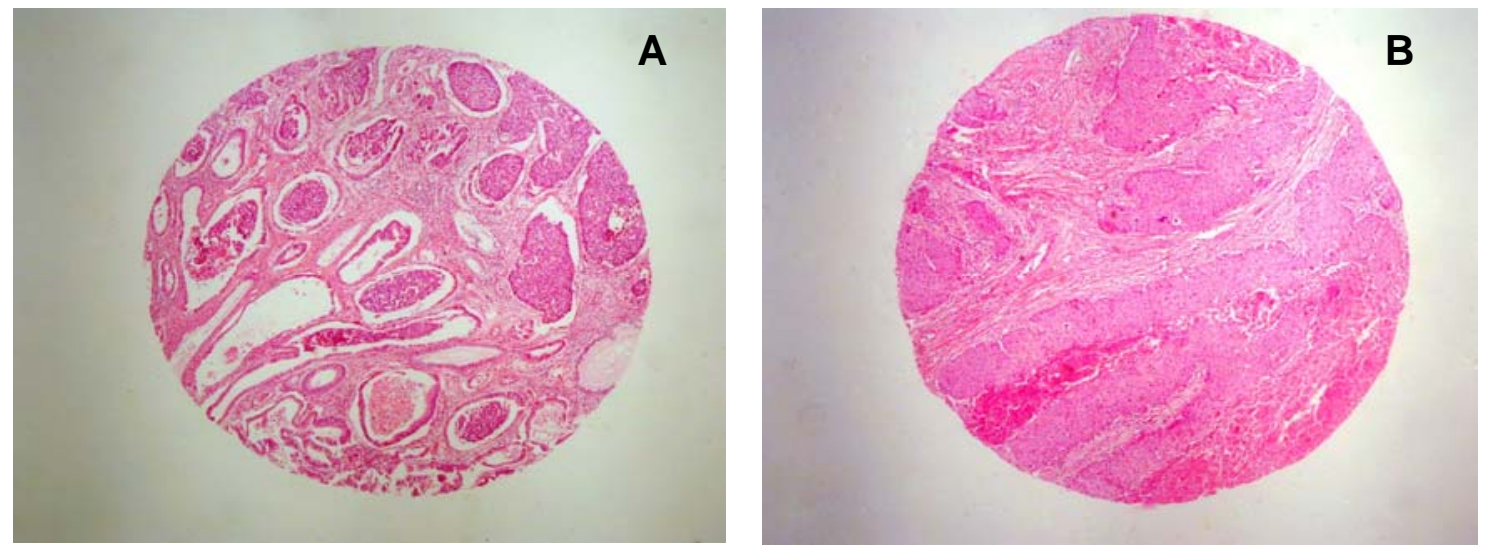

Figura 5 - Detalhe de um dos casos de (A) adenocarcinoma e (B) carcinoma de células escamosas, presentes em bloco de TMA

\subsubsection{Téc nica de imunoistoquímica}

Para a realização do exame imunoistoquímico, os cortes histológicos dos TMA, com espessura de $3 \mu \mathrm{m}$, foram estendidos em lâminas de vidro previamente tratadas pelo adesivo poli-D-lisina (Sigma Chemical Coonporation, EUA), para evitar o descolamento dos mesmos durante a imunocoloração.

Os cortes foram mantidos em estufa por quatro horas e, a seguir, submetidos à desparafinização com quatro banhos sucessivos de xilol seguidos de passagem em álcool etílico-absoluto (quatro banhos), 
lavagem com solução salina tamponada - tampão fosfato de sódio (PBS) e bloqueio da peroxidase endógena com solução de $\mathrm{H}_{2} \mathrm{O}_{2}$ a $3 \%$.

Os métodos de recuperação antigênica utilizados para os dois antígenos investigados foram:

a) Ki-67: pelo calor em panela de pressão por oito minutos, com lâminas incubadoras em solução de ácido cítrico $0,21 \%$, potencial de Hidrogênio (pH) 6,00.

b) Podoplanina: pelo calor em forno de micro-ondas por 15 minutos, com lâminas incubadas em solução de ácido cítrico 0,21\%, pH 6,00 .

A seguir, as lâminas foram incubadas com os anticorpos primários ovemight:

a) Ki-67: clone MIB-1 (Ref. M7240-DAKO), diluição 1:4800;

b) podoplanina: clone D2-40 (Ref. M3619-DAKO), diluição 1:400.

Após lavagem em PBS, as lâminas foram incubadas por 30 minutos com o anticorpo secundário, seguido pelo sistema de detecção com Novo Link polímero da Novocastra (Ref. 7161).

Posteriormente à nova lavagem com PBS, as lâminas foram tratadas com solução de 3,3 diaminobenzidina (DAB Sigma, St Louis, EUA, Ref.: 5637) diluída em TRIS-HCl-IM, pH 7,4 aquecida em $\mathrm{H}_{2} \mathrm{O}_{2}$ durante cinco minutos.

Nova lavagem em água corrente e água destilada foi feita e então os cortes foram contracorados pela Hematoxilina de Mayer e, a seguir, desidratados em cadeia crescente de etanóis, diafanizados em xilol, montados em resina para microscopia e examinados em microscópio de luz. 


\subsubsection{Interpretação imunoistoquímica}

Todas as reações foram interpretadas avaliando-se toda a superfície do tumor presente nos TMAs.

A reação imunoistoquímica positiva para o anticorpo D2-40 foi considerada avaliando-se a expressão no citoplasma das células endoteliais (Figura 6) para a quantificação da angiogênese. Foram também consideradas as colorações no citoplasma de células neoplásicas (Figura 7) e no citoplasma de células estromais tipo fibroblásticas (Figura 8) para avaliação desses compartimentos. A positividade de podoplanina em células neoplásicas e em células do estroma foi considerada positiva quando a intensidade foi moderada a forte em mais de $10 \%$ das células.

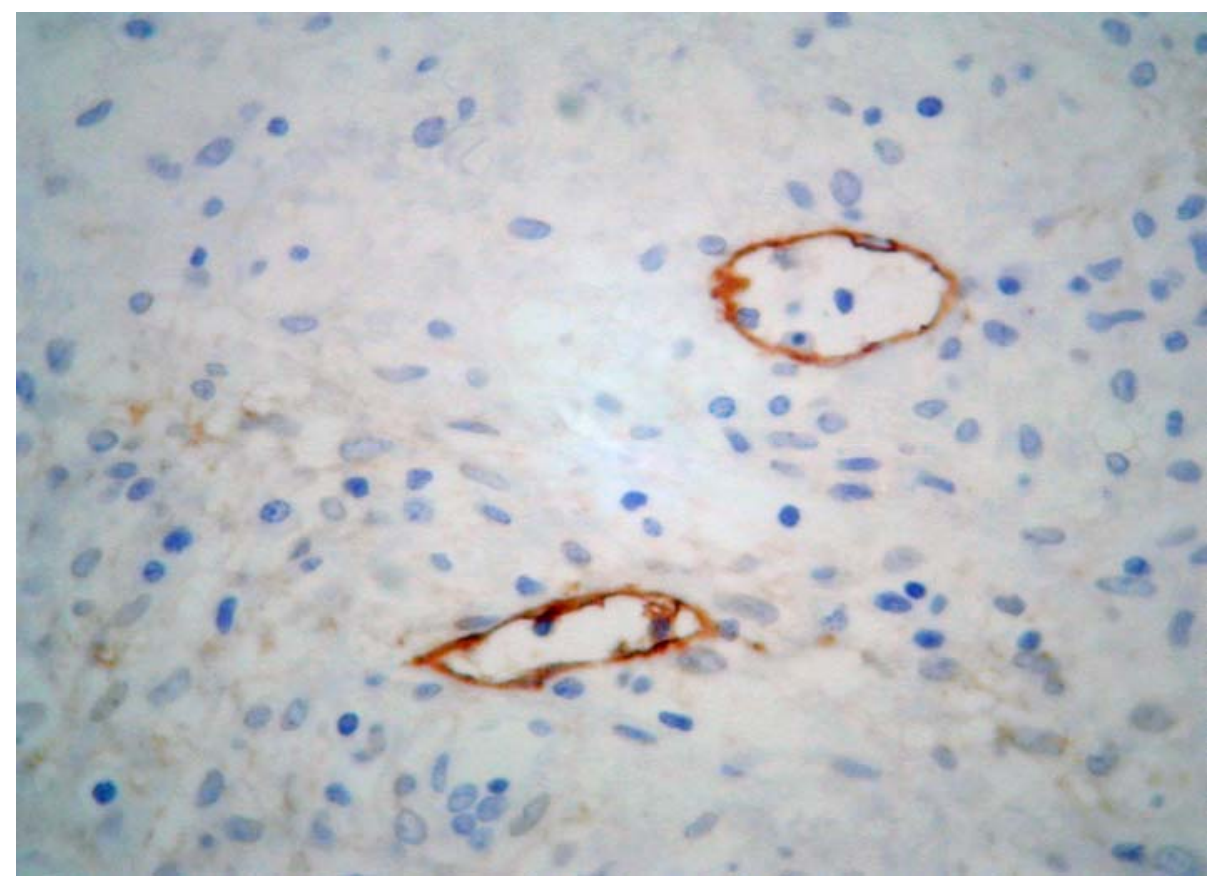

Figura 6 - Imunocoloração para podoplanina em vasos linfáticos intratumoral em caso de carcinoma de células escamosas 


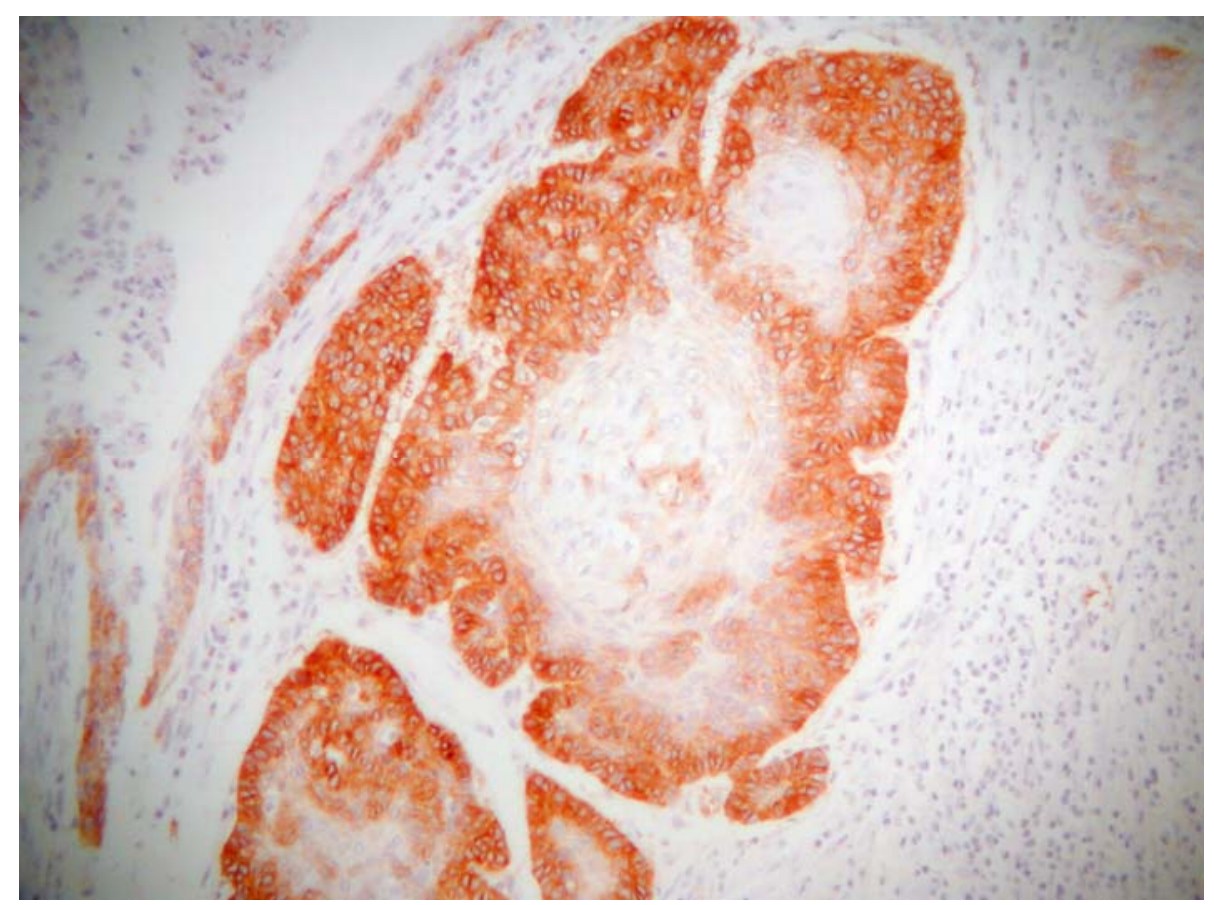

Figura 7 - Expressão de podoplanina em células neoplásicas com mais intensidade de coloração na interface com o estroma intratumoral circunjacente (exame imunoistoquímico, D2-40, aumento original 100X)



Figura 8 - Expressão forte de podoplanina em células fibroblásticas do estroma intratumoral (exame imunoistoquímico, D2-40, aumento original 400X) 
A expressão de Ki-67 foi considerada positiva em núcleos das células neoplásicas (Figura 9) e sua avaliação foi semiquantitativa, baseada na porcentagem de células neoplásicas positivas, assim determinadas:

- $\quad<50 \%$ de células positivas;

- $>50 \%$ de células positivas.

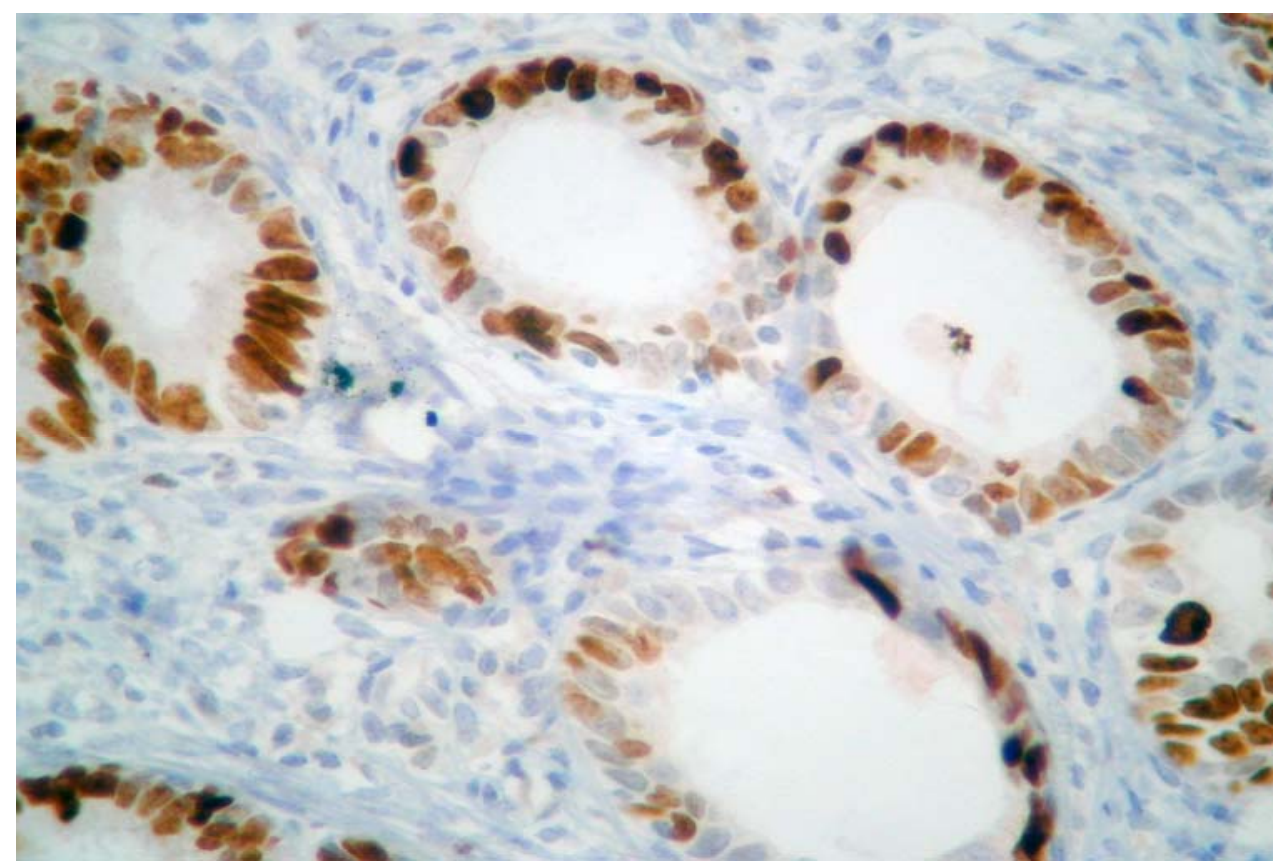

Figura 9 - Ki 67 positivo em > 50\% das células neoplásicas em casos de adenocarcinoma grau I

\subsubsection{Método de avaliação da mic rodensidade vascular}

A quantificação da MDVL foi baseada nos princípios de análise morfométrica descritos por Weibel106. Os preparados foram examinados em microscópio óptico marca Nikon modelo Alphaphot, utilizando-se, para contagem, objetiva de 40x e ocular de 10x contendo gratículo de 
integração de 10 linhas e 100 pontos com aumento total de 400x (Figura 10).

Foram consideradas vasos linfáticos as estruturas coradas em marrom e com morfologia consistente com vaso, com ou sem lúmen. Foram selecionados os 10 campos do tumor com mais densidade vascular para as contagens. Foram empregados os seguintes métodos de avaliação:

- Densidade vascular avaliada por pontos incidentes em vasos (DVP): foram contados o número de pontos do gratículo coincidentes com vasos nos 10 campos selecionados e calculada a média.

- Densidade vascular avaliada por intersecções de linhas do gratículo com os vasos marcados (DVT): o número de intersecções das linhas com os vasos foi contado nos 10 campos e obtida a média.

- Densidade vascular avaliada pelo número de espaços vasculares (DVV): foram contados o número de vasos em cada campo e calculada a média nos 10 campos.

Para fins de análise estatística, a mediana dos resultados foi considerada a linha de corte entre a baixa e a alta densidade vascular, conforme a literatura ${ }^{107}$. 

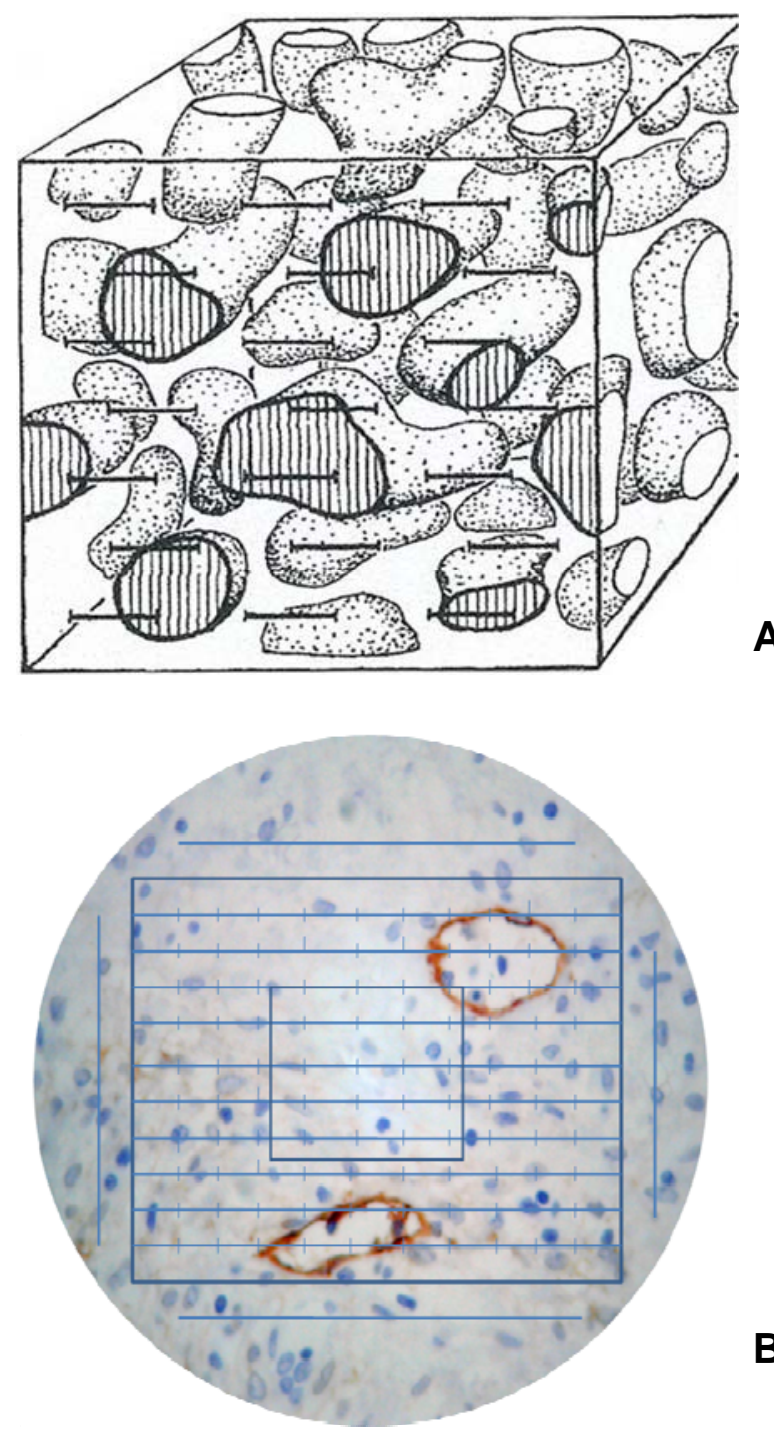

B

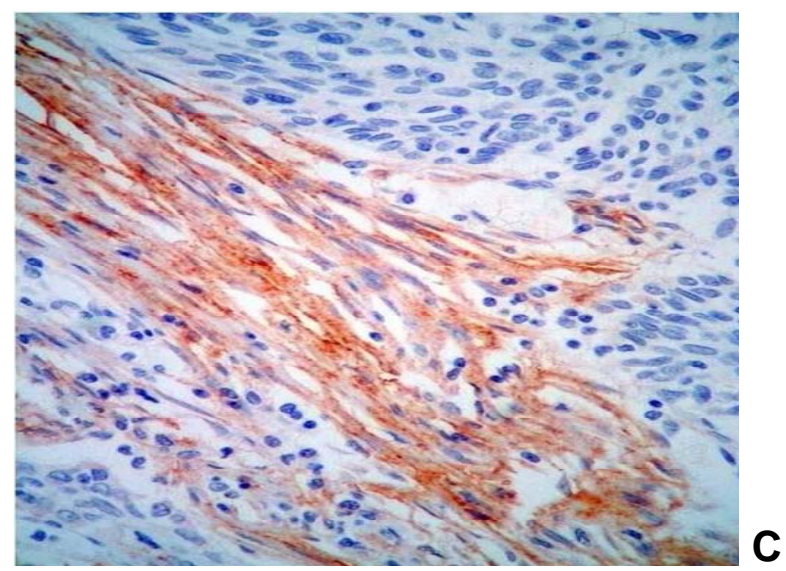

Figura 10 - (A) Quantificação da densidade vascular (DVL), (B) cálculo da DVL pelo método morfométrico de Weibel com gratículo 10 linhas e 10 pontos e (C) representação histológica da expressão da podoplanina em fibroblastos do estroma tumoral. 


\subsection{Análise estatística}

A estatística descritiva abrangeu todas as variáveis, com a distribuição das frequências para as categóricas e intervalos, média e desvio-padrão para as numéricas.

Para análise de efeito dos grupos definidos segundo o desfecho e comprometimento dos linfonodos, foram elaboradas tabelas de contingência para as discretas. Para teste de associação foi empregado o teste Qui-quadrado com estatística de Person.

As médias dos grupos foram comparadas de acordo com a técnica de análise de variância (ANOVA) com estatística de F-Fischer.

A técnica de Kaplan e Meier ajustada com base na tábua de vida das pacientes foi aplicada na análise do tempo total de sobrevida (TTS).

Foi empregada a estatística de Breslow para comparação das curvas de sobrevida dos dois grupos pesquisados.

Os três métodos de avaliação da densidade vascular foram comparados calculando-se os coeficientes de correlação de Pearson.

Na avaliação da linfangiogênese com base nas medidas DVV, DVT DVP, a mediana de cada uma delas foi determinada e a partir delas os resultados foram classificados em alto (acima da mediana) e baixo (abaixo da mediana). Tabelas de contingência foram então criadas para avaliação da associação entre as classificações obtidas com essas três medidas; e a estatística Qui-quadrado de Person foi adotada nessas análises.

Modelo de regressão logística multinomial foi ajustado na análise da MDVL e da expressão de podoplanina em células fibroblásticas do estroma, para verificar a associação com comprometimento linfonodal e desfecho. 
Em todos os testes o nível de significância adotado foi de 5\%. O nível descritivo associado a todas as estatísticas dos testes também foi calculado e apresentado. 
As características clínico-patológicas da população estudada estão sumarizadas na Tabela 1.

Tabela 1 - Caracteństicas clínico-patológicas de carcinomas de colo de útero submetidos a tratamento cinúrgic o primánio no peńodo de 2000 a 2008

\begin{tabular}{|c|c|c|c|}
\hline Variáveis & Valores & $\mathbf{N}$ & $\%$ \\
\hline Idade (anos) & $20-83(50,35 \pm 12,51)$ & 144 & \\
\hline \multirow{3}{*}{ Estadiamento clínico } & | B 1 & 84 & 58,33 \\
\hline & I B 2 & 44 & 30,56 \\
\hline & IIA & 16 & 11,1 \\
\hline \multirow[t]{4}{*}{ Tamanho (cm) } & $0,2-10,0 \mathrm{~cm}(3,12 \pm 1,7 \mathrm{~cm})$ & 144 & \\
\hline & Até $2 \mathrm{~cm}$ & 55 & 38,2 \\
\hline & 2 a $3,9 \mathrm{~cm}$ & 63 & 43,8 \\
\hline & $>4 \mathrm{~cm}$ & 26 & 18,1 \\
\hline \multirow[t]{2}{*}{ Tipo histológico } & Carcinoma céls escamosas & 101 & 70,14 \\
\hline & Adenocarcinoma & 43 & 29,86 \\
\hline \multirow[t]{3}{*}{ Grau histológico } & 1 & 26 & 18,6 \\
\hline & 2 & 84 & 60,0 \\
\hline & 3 & 30 & 21,4 \\
\hline \multirow[t]{3}{*}{ Profundidade de invasão $(\mathrm{cm})$} & $0,1-1,5 \mathrm{~cm}(0,81 \pm 0,38 \mathrm{~cm})$ & 144 & 78,5 \\
\hline & Atél, $0 \mathrm{~cm}$ & 113 & 78,5 \\
\hline & $>1,0 \mathrm{~cm}$ & 31 & 21,5 \\
\hline \multirow{2}{*}{ Paramétrio } & Não & 133 & 92,4 \\
\hline & $\operatorname{sim}$ & 11 & 7,6 \\
\hline \multirow[t]{2}{*}{ Vagina } & Não & 125 & 86,8 \\
\hline & Sim & 19 & 13,2 \\
\hline \multirow{2}{*}{ Invasão do corpo do útero } & Não & 143 & 99,3 \\
\hline & Sim & 1 & 0,7 \\
\hline \multirow[t]{2}{*}{ Comprometimento vascular } & Não & 76 & 52,8 \\
\hline & $\operatorname{sim}$ & 68 & 47,2 \\
\hline \multirow{2}{*}{$\mathrm{KI}-67$} & Até $50 \%$ & 41 & 29,3 \\
\hline & $>50 \%$ & 99 & 70,7 \\
\hline \multirow[t]{2}{*}{ Linfonodos pélvicos } & Comprometidos & 37 & 25,7 \\
\hline & Livres & 107 & 74,3 \\
\hline \multirow[t]{2}{*}{ Desfecho } & Vivo & 125 & \\
\hline & Morto & 19 & $13,2 \%$ \\
\hline Tempo de seguimento (anos) & $0,67-12,25$ (3,57 $\pm 2,06$ anos) & 144 & \\
\hline Tempo de sobrevida (anos) & $1-12$ anos $(3,52 \pm 2,03$ anos $)$ & 144 & \\
\hline
\end{tabular}


5.1 Análise comparativa dos grupos segundo o comprometimento dos linfonodos e desfec ho

$\mathrm{Na}$ Tabela 2 compara-se $\mathrm{O}$ estadiamento clínico com o comprometimento dos linfonodos.

Tabela 2 - Estadiamento clínico segundo o comprometimento dos linfonodos

\begin{tabular}{llcccc}
\hline \hline & & & \multicolumn{2}{c}{ Linfonodos regionais } & \multirow{2}{*}{ Total } \\
\cline { 3 - 5 } & & & Negativos & Positivos & \\
\hline & IB1 & $\mathbf{n}$ & 64 & 20 & 84 \\
Estádio clínico & & $\mathbf{\%}$ & $59,80 \%$ & $54,10 \%$ & $58,30 \%$ \\
& IB2 & $\mathbf{n}$ & 31 & 13 & 44 \\
& & $\mathbf{\%}$ & $29,00 \%$ & $35,10 \%$ & $30,6 \%$ \\
& II & $\mathbf{n}$ & 12 & 4 & 16 \\
& & $\mathbf{\%}$ & $11,20 \%$ & $10,80 \%$ & $11,10 \%$ \\
\hline & \multirow{2}{*}{ Total } & $\mathbf{n}$ & 107 & 37 & 144 \\
& & $\mathbf{\%}$ & $100,00 \%$ & $100,00 \%$ & $100,00 \%$ \\
\hline \hline
\end{tabular}

O teste de associação entre estadiamento clínico e comprometimento dos linfonodos teve estatística $\chi^{2}=0,502$, com $p=0,778$, indicando que as distribuições nos estádios foram equivalentes em ambos os grupos, independentemente do comprometimento dos linfonodos.

$\mathrm{Na}$ Tabela 3, a comparação do estadiamento clínico com o desfecho mostrou que no estádio IB2 houve mais óbitos $(57,9 \%)$ quando comparado ao estádio IB1 (26,3\%).

Tabela 3 - Estadiamento c línic o segundo desfec ho das pacientes

\begin{tabular}{cccccc}
\hline & & & \multicolumn{2}{c}{ Desfecho } & \multirow{2}{*}{ Total } \\
\cline { 3 - 5 } & & & Vivo & Morto & \\
\hline & IB1 & $\mathbf{n}$ & 79 & 5 & 84 \\
Estádio clínico & IB2 & $\mathbf{n}$ & $63,20 \%$ & $26,30 \%$ & $58,30 \%$ \\
& & $\%$ & $26,40 \%$ & $57,90 \%$ & $30,60 \%$ \\
& IA & $\mathbf{n}$ & 13 & 3 & 16 \\
& & $\%$ & $10,40 \%$ & $15,80 \%$ & $11,10 \%$ \\
\hline \hline
\end{tabular}


A estatística do teste de associação entre estadiamento clínico e desfecho foi $\chi^{2}=9,632$, com $p=0,008$, evidenciando significativa associação.

$\mathrm{Na}$ Tabela 4, comparando o tipo histológico com 0 comprometimento de linfonodos, observou-se que o comprometimento dos linfonodos foi independente do tipo histológico.

Tabela 4 - Tpo histológico segundo o comprometimento dos linfonodos

\begin{tabular}{|c|c|c|c|c|c|}
\hline & & & Linfonodo: & regionais & Tal \\
\hline & & & Negativos & Positivos & Iotit \\
\hline & Carcinoma de & $\mathbf{n}$ & 76 & 25 & 101 \\
\hline & células escamosas & $\%$ & $71,00 \%$ & $67,60 \%$ & $70,10 \%$ \\
\hline Tіро & Adenoc arcinoma & $\mathbf{n}$ & 31 & 12 & 43 \\
\hline histológico & & $\%$ & $29,00 \%$ & $32,40 \%$ & $29,90 \%$ \\
\hline & Tan & $\mathbf{n}$ & 107 & 37 & 144 \\
\hline & lotal & $\%$ & $100,00 \%$ & $100,00 \%$ & $100,00 \%$ \\
\hline
\end{tabular}

O teste de associação entre tipo histológico e comprometimento dos linfonodos teve estatística $\chi^{2}=0,305$, com $p=0,851$, ressaltando-se que as distribuições dos tipos histológicos foram equivalentes em relação à condição dos linfonodos.

$\mathrm{Na}$ Tabela 5, comparando o tipo histológico com o desfecho, verificou-se que, do total de óbitos, 52,6\% eram carcinomas de células escamosas e 47,40\% eram adenocarcinomas. O teste de associação entre o tipo histológico e o desfecho teve estatística $\chi^{2}=2,313, \operatorname{com} p=0,128$.

Tabela 5 - Tipo histológico segundo o desfec ho das pacientes

\begin{tabular}{|c|c|c|c|c|c|}
\hline & & & \multicolumn{2}{|c|}{ Desfecho } & \multirow[b]{2}{*}{ Total } \\
\hline & & & Vivo & Morto & \\
\hline \multirow{6}{*}{$\begin{array}{l}\text { Tpo } \\
\text { histológico }\end{array}$} & Carcinoma de & $\mathbf{n}$ & 91 & 10 & 101 \\
\hline & células esc amosas & $\%$ & $72,80 \%$ & $52,60 \%$ & $70,10 \%$ \\
\hline & Adenocarcinoma & $\mathbf{n}$ & 34 & 9 & 43 \\
\hline & & $\%$ & $27,20 \%$ & $47,40 \%$ & $29,90 \%$ \\
\hline & \multirow{2}{*}{ Total } & $n$ & 125 & 19 & 144 \\
\hline & & $\%$ & $100,0 \%$ & $100,0 \%$ & $100,0 \%$ \\
\hline
\end{tabular}


Ao relacionar o comprometimento de paramétrio com linfonodos comprometidos (Tabela 6), apurou-se que o acometimento de paramétrio foi mais frequente no grupo de pacientes com linfonodos comprometidos. O teste de associação entre acometimento de paramétrios e comprometimento dos linfonodos teve estatística $\chi^{2}=26,53$, com $p<0,001$.

Tabela 6 - Distribuição do acometimento de paramétrio nos gnupos

\begin{tabular}{lccccc}
\hline & & & \multicolumn{2}{c}{ linfonodos regionais } & \multirow{2}{*}{ Total } \\
\cline { 3 - 5 } & & & Negativos & Positivos & \\
\hline & Não & $\mathbf{n}$ & 106 & 27 & 133 \\
& & $\%$ & $99,10 \%$ & $73,00 \%$ & $92,40 \%$ \\
Comprometimento & $\mathbf{S i m}$ & $\mathbf{n}$ & 1 & 10 & 11 \\
dos paramétrios & & $\%$ & $0,90 \%$ & $27,00 \%$ & $7,60 \%$ \\
\cline { 2 - 5 } & Total & $\mathbf{n}$ & 107 & 37 & 144 \\
& & $\%$ & $100,00 \%$ & $100,00 \%$ & $100,00 \%$ \\
\hline \hline
\end{tabular}

Na Tabela 7 relacionou-se o acometimento do paramétrio com o desfecho das pacientes e foram registrados $21,1 \%$ de mortes no grupo com comprometimento de paramétrio e 5,6\% no grupo sem acometimento dos paramétrios. O teste de associação entre acometimento de paramétrio e o desfecho da paciente teve estatística $\chi^{2}=5,582$, com $p=0,018$.

Tabela 7 - Distribuição do acometimento de paramétrio segundo o desfec ho das pacientes

\begin{tabular}{lccccc}
\hline \hline & & & \multicolumn{2}{c}{ Desfecho } & Total \\
\cline { 3 - 5 } & & & Vivo & Morto & \\
\hline & & $\mathbf{n}$ & 118 & 15 & 133 \\
Acometimento & $\mathbf{S i m}$ & $\mathbf{n}$ & 7 & $78,90 \%$ & $92,40 \%$ \\
paramétrio & & $\mathbf{\%}$ & $5,60 \%$ & $21,10 \%$ & $7,60 \%$ \\
\cline { 2 - 5 } & Total & $\mathbf{n}$ & 125 & 19 & 144 \\
& & $\%$ & $100,0 \%$ & $100,0 \%$ & $100,0 \%$ \\
\hline \hline
\end{tabular}


Comparando o acometimento da vagina e o comprometimento dos linfonodos (Tabela 8), constataram-se 24,3 e 9,3\%, respectivamente, em vagina comprometida e não comprometida. O teste de associação entre acometimento da vagina e comprometimento dos linfonodos teve estatística $\chi^{2}=5,385$, com $p=0,020$.

Tábela 8 - Distribuição do acometimento da vagina segundo o comprometimento dos linfonodos

\begin{tabular}{|c|c|c|c|c|c|}
\hline & & & \multicolumn{2}{|c|}{ Linfonodos regionais } & \multirow{2}{*}{ Total } \\
\hline & & & Negativos & Positivos & \\
\hline \multirow{6}{*}{$\begin{array}{l}\text { Acometimento de } \\
\text { vagina }\end{array}$} & Não & $\mathbf{n}$ & 97 & 28 & 125 \\
\hline & & $\%$ & $90,70 \%$ & $75,70 \%$ & $86,60 \%$ \\
\hline & $\operatorname{sim}$ & $\mathbf{n}$ & 10 & 9 & 19 \\
\hline & & $\%$ & $9,30 \%$ & $24,30 \%$ & $13,20 \%$ \\
\hline & Total & $\mathbf{n}$ & 107 & 37 & 144 \\
\hline & & $\%$ & $100,00 \%$ & $100,00 \%$ & $100,00 \%$ \\
\hline
\end{tabular}

Na correlação do acometimento da vagina com o desfecho das pacientes (Tabela 9), o desfecho foi independente do acometimento da vagina. O teste da associação entre acometimento da vagina e desfecho das pacientes teve estatística $\chi^{2}=0,136$, com $p=0,712$.

Tabela 9 - Distribuição do acometimento de vagina segundo o desfecho das pacientes

\begin{tabular}{|c|c|c|c|c|c|}
\hline & & & \multicolumn{2}{|c|}{ Desfecho } & \multirow{2}{*}{ Total } \\
\hline & & & Vivo & Morto & \\
\hline \multirow{6}{*}{$\begin{array}{l}\text { Acometimento de } \\
\text { vagina }\end{array}$} & Não & $\mathbf{n}$ & 108 & 17 & 125 \\
\hline & & $\%$ & $86,40 \%$ & $89,50 \%$ & $86,80 \%$ \\
\hline & $\operatorname{sim}$ & $\mathbf{n}$ & 17 & 2 & 19 \\
\hline & & $\%$ & $13,60 \%$ & $10,50 \%$ & $13,20 \%$ \\
\hline & Total & $\mathbf{n}$ & 125 & 19 & 144 \\
\hline & & $\%$ & $100,0 \%$ & $100,0 \%$ & $100,0 \%$ \\
\hline
\end{tabular}


Não se verificou associação entre acometimento do corpo do útero com os linfonodos (Tabela 10). Não foi evidenciada diferença significativa nas distribuições do acometimento do corpo do útero nos grupos. A estatística do teste foi $\chi^{2}=0,312$, com $p=0,577$.

Tabela 10 - Distribuição do acometimento do útero segundo o comprometimento dos linfonodos



Da mesma maneira, o desfecho foi independente do acometimento do corpo do útero (Tabela 11).

Tabela 11 - Distribuição do acometimento do útero segundo o desfecho das pacientes

\begin{tabular}{lccccc}
\hline \hline & & & \multicolumn{2}{c}{ Desfec ho } & \multirow{2}{*}{ Total } \\
\cline { 3 - 5 } & & & Vivo & Morto & \\
\hline & Não & $\mathrm{n}$ & 124 & 19 & 143 \\
Comprometimento & & $\%$ & $99,20 \%$ & $100,0 \% \%$ & $99,30 \% \%$ \\
do como do útero & Sim & $\mathrm{n}$ & 1 & 0 & 1 \\
& & $\%$ & $0,80 \% \%$ & $0,00 \%$ & $0,70 \%$ \\
\hline & Total & $\mathrm{n}$ & 125 & 19 & 144 \\
& & $\%$ & $100,0 \%$ & $100,0 \%$ & $100,0 \%$ \\
\hline
\end{tabular}

Não foi realçada diferença significativa nas distribuições do acometimento do útero nos grupos. A estatística foi $\chi^{2}=0,312$, com $p=0,577$. 
Ao relacionar o grau histológico com os linfonodos (Tabela 12), percebeu-se que o comprometimento dos linfonodos foi independente do grau histológico. Não se destacou diferença significativa nas distribuições do grau histológico nos grupos. A estatística do teste foi $\chi^{2}=2,663$, com $p=0,264$.

Tabela 12 - Distribuição do grau histológico segundo o comprometimento dos linfonodos

\begin{tabular}{|c|c|c|c|c|c|}
\hline & & & \multicolumn{2}{|c|}{ Linfonodos regionais } & \multirow{2}{*}{ Total } \\
\hline & & & Negativos & Positivos & \\
\hline \multirow{8}{*}{ Grau histológico } & \multirow{3}{*}{1} & $\mathbf{n}$ & 22 & 4 & 26 \\
\hline & & $\%$ & $21,40 \%$ & $10,80 \%$ & $18,60 \%$ \\
\hline & & $\mathbf{n}$ & 58 & 26 & 84 \\
\hline & \multirow[t]{2}{*}{2} & $\%$ & $56,30 \%$ & $70,30 \%$ & $60,00 \%$ \\
\hline & & $\mathbf{n}$ & 23 & 7 & 30 \\
\hline & 3 & $\%$ & $22,30 \%$ & $18,90 \%$ & $21,40 \%$ \\
\hline & \multirow{2}{*}{ Total } & $\mathbf{n}$ & 103 & 37 & 140 \\
\hline & & $\%$ & $100,00 \%$ & $100,00 \%$ & $100,00 \%$ \\
\hline
\end{tabular}

Na Tabela 13 o grau histológico relaciona-se com o desfecho das pacientes, não se ressaltando associação. Não foi referida diferença significativa nas distribuições do grau histológico nos desfechos e a estatística do teste foi $\chi^{2}=3,738$, com $p=0,154$.

Tabela 13 - Distribuição do grau histológico nos gnupos segundo o desfec ho das pacientes

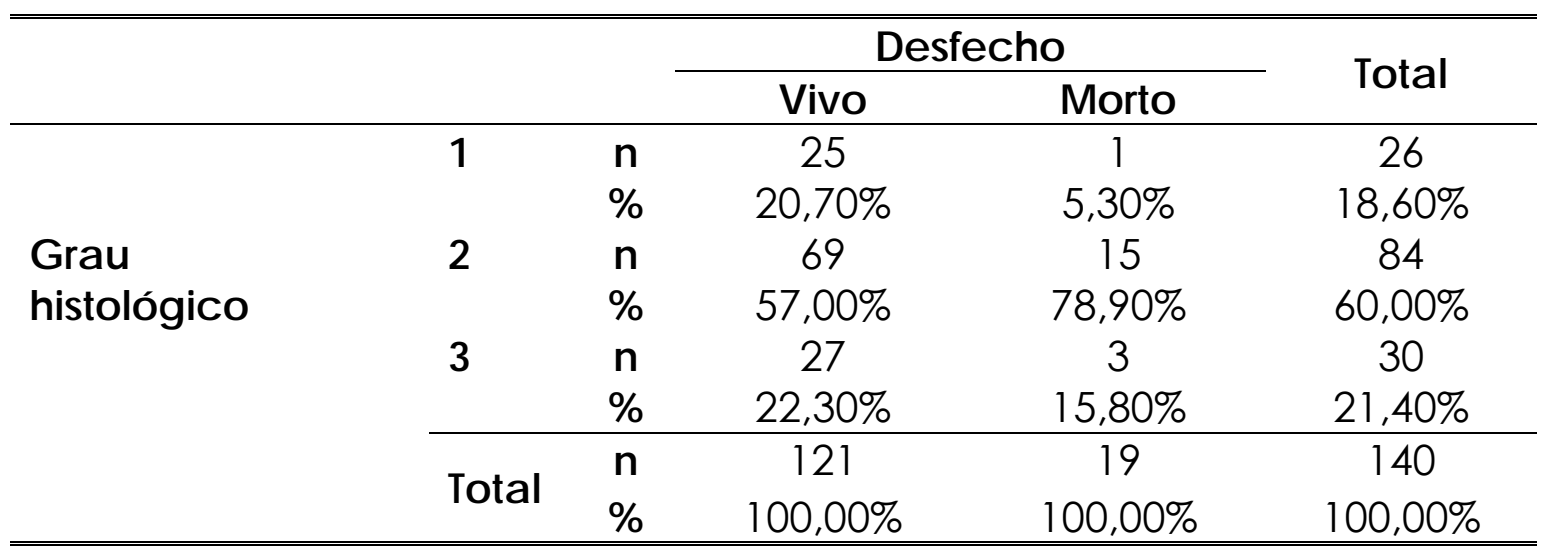


O comprometimento vascular associou-se fortemente ao comprometimento dos linfonodos (Tabela 14). O teste de associação entre o comprometimento vascular e o comprometimento dos linfonodos teve estatística $\chi^{2}=35,188$, com $p<0,001$.

Tábela 14 - Distribuição do comprometimento vascular segundo o comprometimento dos linfonodos

\begin{tabular}{|c|c|c|c|c|c|}
\hline & & & \multicolumn{2}{|c|}{ Linfonodos regionais } & \multirow{2}{*}{ Total } \\
\hline & & & Negativos & Positivos & \\
\hline \multirow{6}{*}{$\begin{array}{l}\text { Comprometimento } \\
\text { vascular }\end{array}$} & \multirow[t]{2}{*}{ Não } & $\mathbf{n}$ & 72 & 4 & 76 \\
\hline & & $\%$ & $67,30 \%$ & $10,80 \%$ & $52,80 \%$ \\
\hline & \multirow[t]{2}{*}{ Sim } & $\mathbf{n}$ & 35 & 33 & 68 \\
\hline & & $\%$ & $32,70 \%$ & $89,20 \%$ & $47,20 \%$ \\
\hline & \multirow{2}{*}{ Total } & $\mathbf{n}$ & 107 & 37 & 144 \\
\hline & & $\%$ & $100,00 \%$ & $100,00 \%$ & $100,00 \%$ \\
\hline
\end{tabular}

A distribuição para o desfecho segundo o comprometimento vascular está demonstrada na Tabela 15. O comprometimento vascular foi $73,70 \%$ mais frequente no grupo de pacientes que foram a óbito. O teste de associação entre comprometimento vascular e comprometimento dos linfonodos teve estatística $\chi^{2}=6,150$, com $p=0013$.

Tábela 15 - Distribuição do comprometimento vascular segundo o desfec ho das pacientes

\begin{tabular}{|c|c|c|c|c|c|}
\hline & & & \multicolumn{2}{|c|}{ Desfecho } & \multirow{2}{*}{ Total } \\
\hline & & & Vivo & Morto & \\
\hline \multirow{6}{*}{$\begin{array}{l}\text { Comprometimento } \\
\text { vascular }\end{array}$} & \multirow[t]{2}{*}{ Não } & $\mathbf{n}$ & 71 & 5 & 76 \\
\hline & & $\%$ & $56,80 \%$ & $26,30 \%$ & $52,80 \%$ \\
\hline & \multirow[t]{2}{*}{ Sim } & $\mathbf{n}$ & 54 & 14 & 68 \\
\hline & & $\%$ & $43,20 \%$ & $73,70 \%$ & $47,20 \%$ \\
\hline & \multirow{2}{*}{ Total } & $\mathbf{n}$ & 125 & 19 & 144 \\
\hline & & $\%$ & $100,00 \%$ & $100,00 \%$ & $100,00 \%$ \\
\hline
\end{tabular}


A alta atividade proliferativa do tumor determinada pela expressão de Ki-67 acima de 50\% não se relacionou com o comprometimento dos linfonodos (Tabela 16) nem com o desfecho (Tabela 17). A estatística do teste teve valor igual a $\chi^{2}=0,240$, com $p=0,624$. A distribuição do Ki-67 mostrou-se independente do comprometimento dos linfonodos. O teste de associação entre 0 marcador $\mathrm{Ki}-67$ e $\mathrm{O}$ desfecho das pacientes teve estatística $\chi^{2}=1,745$, com $\mathrm{p}=0,187$.

Tabela 16 - Distribuição da expressão do Ki-67 segundo o acometimento dos linfonodos

\begin{tabular}{cccccc}
\hline & & & \multicolumn{2}{c}{ Linfonodos } & \multirow{2}{*}{ Total } \\
\cline { 3 - 5 } & & & Negativo & Positivo & \\
\hline \multirow{4}{*}{ K 67 } & $\mathbf{5 0 \%}$ & $\mathbf{n}$ & 29 & 12 & 41 \\
& & $\mathbf{n}$ & $74,20 \%$ & $32,40 \%$ & $29,30 \%$ \\
& $>\mathbf{5 0} \%$ & $\mathbf{\%}$ & $71,80 \%$ & $67,60 \%$ & $70,70 \%$ \\
\cline { 3 - 5 } & Total & $\mathbf{n}$ & 103 & 37 & 140 \\
& & $\%$ & $100,00 \%$ & $100,00 \%$ & $100,00 \%$ \\
\hline \hline
\end{tabular}

Tabela 17 - Distribuição da expressão do Ki-67 segundo o desfecho das pacientes

\begin{tabular}{cccccc}
\hline & & & \multicolumn{2}{c}{ Desfec ho } & \multirow{2}{*}{ Total } \\
\cline { 3 - 5 } & & & Vivo & Morto & \\
\hline \multirow{4}{*}{ K 67 } & $\mathbf{5 0 \%}$ & $\mathbf{n}$ & 33 & 8 & 41 \\
& & $\mathbf{\%}$ & $27,30 \%$ & $42,10 \%$ & $29,30 \%$ \\
& $>\mathbf{5 0 \%}$ & $\mathbf{n}$ & 88 & 11 & 99 \\
& & $\mathbf{\%}$ & $72,70 \%$ & $57,90 \%$ & $70,70 \%$ \\
\cline { 3 - 5 } & Total & $\mathbf{n}$ & 121 & 19 & 140 \\
& & $\mathbf{\%}$ & $100,00 \%$ & $100,00 \%$ & $100,00 \%$ \\
\hline \hline
\end{tabular}


Ao comparar as médias de idade, tamanho do tumor e profundidade de infiltração com o comprometimento dos linfonodos, registrou-se que foram mais altas as médias de tamanho do tumor e nível de infiltração para o grupo com linfonodos comprometidos (Tabela 18).

Tábela 18 - Comparativo de médias segundo o comprometimento dos linfonodos

\begin{tabular}{|c|c|c|c|c|c|c|c|c|}
\hline & & $\mathbf{N}$ & Média & Desvio & $\begin{array}{r}\text { IC } \\
\text { Inferior }\end{array}$ & $\begin{array}{l}95 \% \\
\text { Superior }\end{array}$ & $\begin{array}{c}\text { F- } \\
\text { Fischer }\end{array}$ & $\mathbf{p}$ \\
\hline \multirow{3}{*}{$\begin{array}{l}\text { Tamanho } \\
\text { (cm) }\end{array}$} & Negativos & 107 & 2,84 & 1,6 & 2,53 & 3,15 & \multirow[t]{3}{*}{11,702} & 0,001 \\
\hline & Positivos & 37 & 3,91 & 1,74 & 3,33 & 4,49 & & \\
\hline & Total & 144 & 3,12 & 1,7 & 2,84 & 3,4 & & \\
\hline \multirow{3}{*}{$\begin{array}{l}\text { Infiltração } \\
\text { (cm) }\end{array}$} & Negativos & 107 & 0,73 & 0,39 & 0,65 & 0,8 & \multirow[t]{3}{*}{20,759} & \multirow[t]{3}{*}{$<0,001$} \\
\hline & Positivos & 37 & 1,04 & 0,26 & 0,95 & 1,12 & & \\
\hline & Total & 144 & 0,81 & 0,38 & 0,74 & 0,87 & & \\
\hline \multirow{3}{*}{$\begin{array}{l}\text { Idade } \\
\text { (anos) }\end{array}$} & Negativos & 107 & 50,28 & 11,41 & 48,09 & 52,47 & \multirow[t]{3}{*}{0,014} & \multirow[t]{3}{*}{0,905} \\
\hline & Positivos & 37 & 50,57 & 15,42 & 45,43 & 55,71 & & \\
\hline & Total & 144 & 50,35 & 12,51 & 48,29 & 52,41 & & \\
\hline
\end{tabular}

Na Tabela 19 apresentam-se as comparações das médias do tamanho do tumor, profundidade de invasão e idade das pacientes, segundo o desfecho. Observou-se que o tamanho do tumor foi maior no grupo de pacientes que foram a óbito. O nível de profundidade de infiltração da parede foi mais alto no grupo que foi a óbito, embora a diferença não tenha atingido nível de significância.

Tabela 19 - Comparações das médias segundo o desfec ho das pacientes

\begin{tabular}{|c|c|c|c|c|c|c|c|c|}
\hline & & $\mathbf{N}$ & Média & Desvio & $\begin{array}{r}\text { IC } \\
\text { Inferior }\end{array}$ & $\begin{array}{l}95 \% \\
\text { Superior }\end{array}$ & $\begin{array}{c}\text { F- } \\
\text { Fischer }\end{array}$ & p \\
\hline \multirow{3}{*}{$\begin{array}{l}\text { Tamanho } \\
\text { (cm) }\end{array}$} & Vivo & 125 & 2,93 & 1,55 & 2,66 & 3,21 & \multirow[t]{3}{*}{11,801} & \multirow[t]{3}{*}{0,001} \\
\hline & Morto & 19 & 4,32 & 2,12 & 3,3 & 5,34 & & \\
\hline & Total & 144 & 3,12 & 1,7 & 2,84 & 3,4 & & \\
\hline \multirow[t]{3}{*}{ Infiltração } & Vivo & 125 & 0,79 & 0,39 & 0,72 & 0,85 & \multirow[t]{3}{*}{3,007} & \multirow[t]{3}{*}{0,085} \\
\hline & Morto & 19 & 0,95 & 0,3 & 0,8 & 1,09 & & \\
\hline & Total & 144 & 0,81 & 0,38 & 0,74 & 0,87 & & \\
\hline \multirow[t]{3}{*}{ Idade } & Vivo & 125 & 50,22 & 11,99 & 48,09 & 52,34 & \multirow[t]{3}{*}{0,115} & \multirow[t]{3}{*}{0,705} \\
\hline & Morto & 19 & 51,26 & 15,85 & 43,62 & 58,9 & & \\
\hline & Total & 144 & 50,35 & 12,51 & 48,29 & 52,41 & & \\
\hline
\end{tabular}


No Gráfico 1 apresentam-se as curvas de sobrevida e o resultado do teste comparativo das mesmas segundo o comprometimento dos linfonodos. As pacientes que não tiveram linfonodos comprometidos tiveram maior sobrevida (10,76 anos).

Gráfico 1 - Curvas de sobrevida (Kaplan-Meyer) segundo o acometimento dos linfonodos, utilizando estatística de Breslow.

\section{Curvas de sobrevivência}

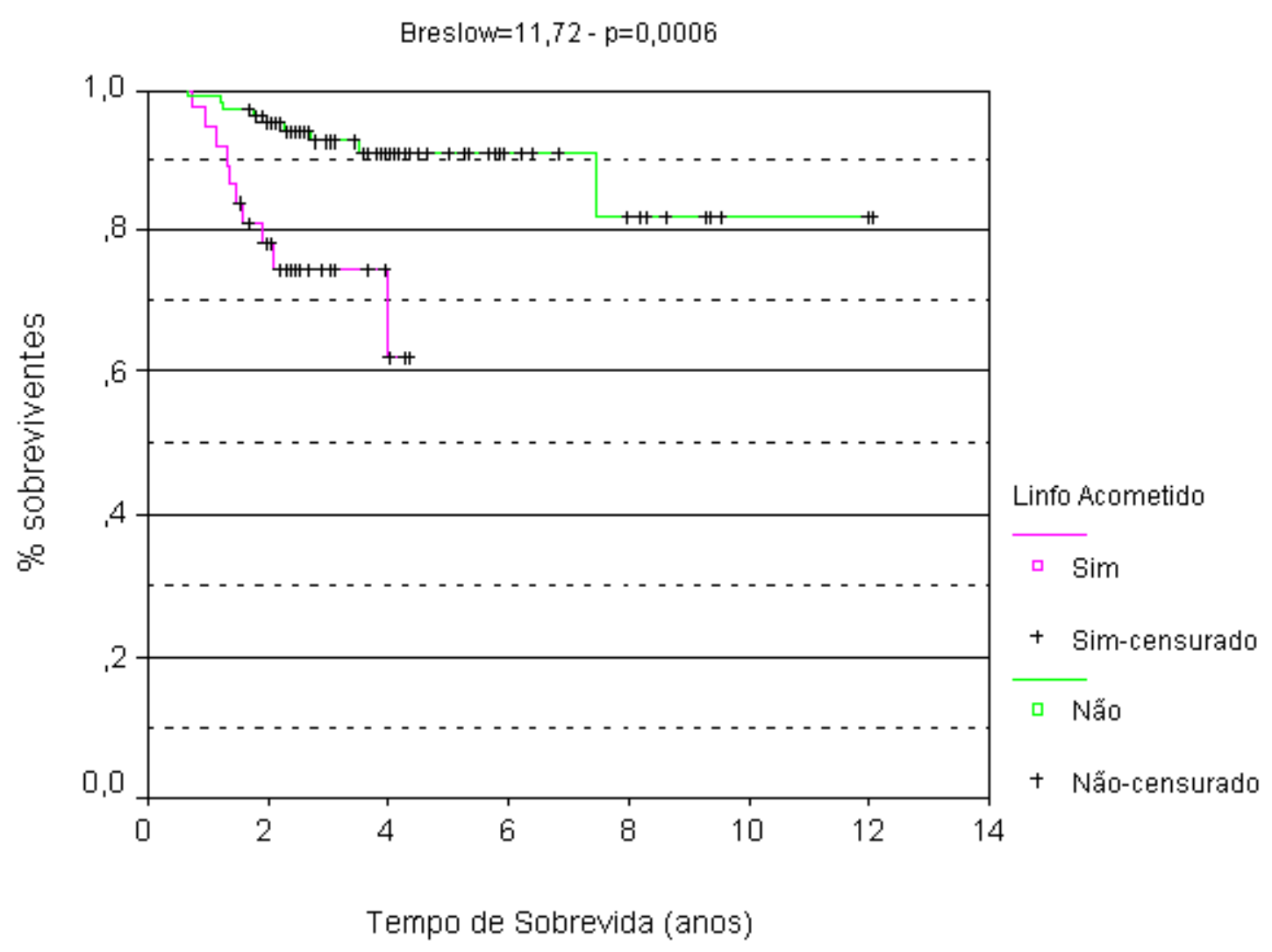

Com base nesse teste comparativo, pôde-se concluir que as curvas de sobrevivência dos dois grupos são distintas. A estatística de Breslow teve nível descritivo igual a $p=0,0006$, indicando que o comprometimento dos linfonodos se associou à redução da sobrevida. 
Nota-se que o tempo médio de sobrevida para o grupo com linfonodos comprometidos foi igual a 3,57 anos, com intervalo de confiança 95\% igual a [3,14 ---- 3,99 anos]; e para o grupo com linfonodos não comprometidos foi igual a 10,76 anos, com intervalo de confiança $95 \%$ igual a [9,79 ---- 11,72 anos].

Quando foram associados os grupos linfonodos positivos e negativos ao desfecho das pacientes, detectou-se taxa de óbito mais alta no grupo de linfonodos positivos (10/27) do que no grupo com linfonodos negativos (9/98). No grupo de pacientes que foram a óbito, 52,6\% tinham linfonodos positivos, enquanto no grupo de pacientes vivas a porcentagem foi de $21,60 \%$ (Tabela 20).

Tabela 20 - Associação entre comprometimento de linfonodos e desfecho das pacientes

\begin{tabular}{|c|c|c|c|c|c|}
\hline & & & \multicolumn{2}{|c|}{ Desfecho } & \multirow{2}{*}{ Total } \\
\hline & & & Vivo & Morto & \\
\hline & Não & $n$ & 98 & 9 & 107 \\
\hline & & $\%$ & $78,40 \%$ & $47,40 \%$ & $74,30 \%$ \\
\hline \multirow{4}{*}{$\begin{array}{l}\text { Linfonodos } \\
\text { positivos }\end{array}$} & Sim & $n$ & 27 & 10 & 37 \\
\hline & & $\%$ & $21,60 \%$ & $52,60 \%$ & $25,70 \%$ \\
\hline & Total & $n$ & 125 & 19 & 144 \\
\hline & & $\%$ & $100,0 \%$ & $100,0 \%$ & $100,0 \%$ \\
\hline
\end{tabular}

A associação foi significativa, a estatística do teste foi $\chi^{2}=6,773$, com $p=0,009$. 


\subsection{Comparação dos métodos de avaliação da linfangiogênese}

Foram comparados três métodos de avaliação da microdensidade vascular: DVV, DVT e DVP. Calcularam-se os coeficientes de correlação de Pearson, cujos resultados podem ser observados no Gráfico 2.

Gráfico 2 - Correlação entre os resultados dos métodos para avaliação da densidade vascular.



O método DVV apresentou correlações diretas, positivas, elevadas e significativas com os métodos DVT e DVP, caracterizando a equivalência entre os três métodos.

Na categorização da MDVL em alta e baixa, segundo o valor de corte na mediana, foram elaboradas as Tabelas 21 e 22 com as distribuições conjuntas dos métodos. 
Tabela 21 - Distribuição conjunta da classificação entre os métodos DVV e DVP

\begin{tabular}{|c|c|c|c|c|c|}
\hline & & & \multicolumn{2}{|c|}{ DV } & \multirow{2}{*}{ Total } \\
\hline & & & Baixo & Alto & \\
\hline & Baixo & $\begin{array}{l}n \\
\%\end{array}$ & $\begin{array}{c}69 \\
97.20 \%\end{array}$ & $\begin{array}{c}6 \\
8.30 \%\end{array}$ & $\begin{array}{c}75 \\
52.40 \%\end{array}$ \\
\hline \multirow[t]{3}{*}{ DVP } & Alto & $\begin{array}{l}n \\
\%\end{array}$ & $\begin{array}{c}2 \\
280 \%\end{array}$ & $\begin{array}{c}66 \\
9170 \%\end{array}$ & $\begin{array}{c}68 \\
4760 \%\end{array}$ \\
\hline & Total & $\%$ & $\begin{array}{c}2,80 \% \\
71\end{array}$ & $\begin{array}{c}91,10 \% \\
72\end{array}$ & $\begin{array}{c}4 /, 60 \% \\
143\end{array}$ \\
\hline & (6) & $\%$ & $100,0 \%$ & $100,0 \%$ & $100,0 \%$ \\
\hline
\end{tabular}

*DVP = Densidade vascular ponto dentro do vaso.

${ }^{* *} \mathrm{DVV}=$ Densidade vascular por contagem direta de número de vasos por campo.

A concordância dos resultados da classificação pelos métodos foi avaliada com base na estatística Kappa, que teve valor $k=0,888$, com $p<0,001$.

Tabela 22 - Distribuição conjunta da classificação entre os métodos DVV e DVT

\begin{tabular}{|c|c|c|c|c|c|}
\hline & & & & & \\
\hline & & & Baixo & Alto & Total \\
\hline & Baixo & $\mathbf{n}$ & 69 & 3 & 72 \\
\hline & & $\%$ & $97,20 \%$ & $4,20 \%$ & $50,30 \%$ \\
\hline DVT & Alto & $\mathbf{n}$ & 2 & 69 & 71 \\
\hline & & $\%$ & $2,80 \%$ & $95,80 \%$ & $49,70 \%$ \\
\hline & Total & $\mathbf{n}$ & 71 & 72 & 143 \\
\hline & & $\%$ & $100,0 \%$ & $100,0 \%$ & $100,0 \%$ \\
\hline
\end{tabular}

*DVT= Densidade vascular traço cortando vaso.

**DVV= Densidade vascular por contagem direta de número de vasos por campo.

A concordância dos resultados da classificação pelos métodos foi avaliada com base na estatística Kappa, que teve valor $k=0,930$, com $p<0,001$.

Assim, confirmou-se o alto nível de concordância entre os três métodos e optou-se pelo método DVV para avaliação da MDVL neste estudo, classificado em alto ou baixo (conforme acima ou abaixo da mediana). 
5.3 Associações entre MDVLe carac tenístic as clínic o-patológicas

Na Tabela 23 pode-se observar que a MDVL pode ser considerada independente da faixa etária. A estatística do teste foi $\chi^{2}=0,001$, com $p=0,975$.

Tabela 23 - MDVLsegundo a faixa etária das pacientes

\begin{tabular}{|c|c|c|c|c|c|}
\hline & & & \multicolumn{2}{|c|}{ MDVL } & \multirow{2}{*}{ Total } \\
\hline & & & Baixo & Alto & \\
\hline & & $\mathbf{n}$ & 9 & 8 & 17 \\
\hline & Até 35 anos & $\%$ & $12,70 \%$ & $11,10 \%$ & $11,90 \%$ \\
\hline \multirow[t]{4}{*}{ Faixa etária } & & $\mathbf{n}$ & 62 & 64 & 126 \\
\hline & $>35$ anos & $\%$ & $87,30 \%$ & $88,90 \%$ & $88,10 \%$ \\
\hline & Total & $\mathbf{n}$ & 71 & 72 & 143 \\
\hline & & $\%$ & $100,00 \%$ & $100,00 \%$ & $100,00 \%$ \\
\hline
\end{tabular}

A associação entre MDVL e estadiamento clínico das pacientes pode ser visualizada na Tabela 24. A MDVL foi mais alta no estádio clínico IB1. A estatística do teste foi $\chi^{2}=14,435$, com $p=0,001$.

Tabela 24 - MDVLsegundo o estadiamento c línico das pacientes

\begin{tabular}{|c|c|c|c|c|c|}
\hline & & & \multicolumn{2}{|c|}{ MDVL } & \multirow{2}{*}{ Total } \\
\hline & & & Baixo & Alto & \\
\hline & IB1 & $\mathbf{n}$ & 30 & 53 & 83 \\
\hline & & $\%$ & $42,30 \%$ & $73,60 \%$ & $58,00 \%$ \\
\hline \multirow[t]{6}{*}{ Estádio clínico } & IB2 & $\mathbf{n}$ & 30 & 14 & 44 \\
\hline & & $\%$ & $42,30 \%$ & $19,40 \%$ & $30,80 \%$ \\
\hline & IIA & $\mathbf{n}$ & 11 & 5 & 16 \\
\hline & & $\%$ & $15,50 \%$ & $6,90 \%$ & $11,20 \%$ \\
\hline & Total & $\mathbf{n}$ & 71 & 72 & 143 \\
\hline & & $\%$ & $100,00 \%$ & $100,00 \%$ & $100,00 \%$ \\
\hline
\end{tabular}


Não foi detectada associação significativa entre MDVL e o tipo histológico. A estatística do teste teve valor $\chi^{2}=0,615$, com $p=0,433$.

Tabela 25 - MDVLsegundo o tipo histológico

\begin{tabular}{cllcccc}
\hline & & & \multicolumn{2}{c}{ MDVL } & \multirow{2}{*}{ Total } \\
\cline { 3 - 5 } & & & Baixo & Alto & \\
\hline \multirow{3}{*}{ Tipo } & Carcinoma de & $\mathbf{n}$ & 47 & 53 & 100 \\
histológico & células escamosas & $\%$ & $66,20 \%$ & $73,60 \%$ & $69,90 \%$ \\
& Adenocarcinoma & $\mathbf{n}$ & 24 & 19 & 43 \\
& & $\mathbf{\%}$ & $33,80 \%$ & $26,40 \%$ & $30,10 \%$ \\
\cline { 3 - 5 } & Total & $\mathbf{n}$ & 71 & 72 & 143 \\
& & $\mathbf{\%}$ & $100,00 \%$ & $100,00 \%$ & $100,00 \%$ \\
\hline \hline
\end{tabular}

Verificou-se, pela Tabela 26, a associação entre tamanho do tumor e MDVL. A alta MDVL se associou aos menores tumores. A estatística do teste foi $\chi^{2}=18,116$, com $p<0,001$.

Tabela 26 - MDVLe tamanho do tumor

\begin{tabular}{|c|c|c|c|c|c|}
\hline & & & \multicolumn{2}{|c|}{ MDVL } & \multirow{2}{*}{ Total } \\
\hline & & & Baixo & Alto & \\
\hline & Até $2,0 \mathrm{~cm}$ & $\mathbf{n}$ & 17 & 38 & 55 \\
\hline & & $\%$ & $23,90 \%$ & $52,80 \%$ & $38,50 \%$ \\
\hline & 2 a $4 \mathrm{~cm}$ & $\mathbf{n}$ & 33 & 29 & 62 \\
\hline \multirow[t]{5}{*}{ Tamanho } & & $\%$ & $46,50 \%$ & $40,30 \%$ & $43,40 \%$ \\
\hline & $>4,0 \mathrm{~cm}$ & $\mathbf{n}$ & 21 & 5 & 26 \\
\hline & & $\%$ & $29.60 \%$ & $6,90 \%$ & $18,20 \%$ \\
\hline & Total & $\mathbf{n}$ & 71 & 72 & 143 \\
\hline & & $\%$ & $100,00 \%$ & $100,00 \%$ & $100,00 \%$ \\
\hline
\end{tabular}


A distribuição conjunta de MDVL e acometimento de paramétrio não apresentou associação entre eles. A estatística do teste foi $\chi^{2}=1,639$, com $p=0,201$.

Tabela 27 - MDVLe acometimento de paramétrio

\begin{tabular}{|c|c|c|c|c|c|}
\hline & & & \multicolumn{2}{|c|}{ MDVL } & \multirow{2}{*}{ Total } \\
\hline & & & Baixo & Alto & \\
\hline \multirow{6}{*}{$\begin{array}{l}\text { Acometimento } \\
\text { de paramétrio }\end{array}$} & Não & $\mathbf{n}$ & 63 & 69 & 132 \\
\hline & & $\%$ & $88,70 \%$ & $95,80 \%$ & $92,30 \%$ \\
\hline & Sim & $\mathbf{n}$ & 8 & 3 & 11 \\
\hline & & $\%$ & $11,30 \%$ & $4,20 \%$ & $7,70 \%$ \\
\hline & Total & $\mathbf{n}$ & 71 & 72 & 143 \\
\hline & & $\%$ & $100,00 \%$ & $100,00 \%$ & $100,00 \%$ \\
\hline
\end{tabular}

A MDVL pode ser considerada independente do acometimento da vagina. Isso pode ser percebido na Tabela 28, que exibe a distribuição conjunta de ambos. A estatística do teste foi $\chi^{2}=0,049$, com $p=0,826$.

Tabela 28 - MDVLe acometimento de vagina

\begin{tabular}{|c|c|c|c|c|c|}
\hline & & & \multicolumn{2}{|c|}{ MDVL } & \multirow{2}{*}{ Total } \\
\hline & & & Baixo & Alto & \\
\hline \multirow{6}{*}{$\begin{array}{l}\text { Acometimento } \\
\text { de vagina }\end{array}$} & Não & $n$ & 63 & 62 & 125 \\
\hline & \multirow{3}{*}{ Sim } & $\%$ & $88,70 \%$ & $86,10 \%$ & $87,40 \%$ \\
\hline & & $\mathbf{n}$ & 8 & 10 & 18 \\
\hline & & $\%$ & $11,30 \%$ & $13,90 \%$ & $12,60 \%$ \\
\hline & \multirow{2}{*}{ Total } & $n$ & 71 & 72 & 143 \\
\hline & & $\%$ & $100,00 \%$ & $100,00 \%$ & $100,00 \%$ \\
\hline
\end{tabular}


Na Tabela 29 demonstra-se a distribuição da MDVL segundo o acometimento dos linfonodos. A MDVL apresentou associação significativa com o acometimento dos linfonodos e a estatística do teste de associação foi $\chi^{2}=3,837$, com $p=0,050$. Alta $M D V L$ se associou $a$ linfonodos negativos.

Tabela 29 - MDVLe acometimento de linfonodos

\begin{tabular}{|c|c|c|c|c|c|}
\hline & & & \multicolumn{2}{|c|}{ MDVL } & \multirow{2}{*}{ Total } \\
\hline & & & Baixo & Alto & \\
\hline \multirow{6}{*}{$\begin{array}{l}\text { Linfonodos } \\
\text { acometidos }\end{array}$} & Não & $\mathbf{n}$ & 47 & 59 & 106 \\
\hline & \multirow{3}{*}{ Sim } & $\%$ & $66,20 \%$ & $81,90 \%$ & $74,10 \%$ \\
\hline & & $\mathbf{n}$ & 24 & 13 & 37 \\
\hline & & $\%$ & $33,80 \%$ & $18,10 \%$ & $25,90 \%$ \\
\hline & \multirow{2}{*}{ Total } & $\mathbf{n}$ & 71 & 72 & 143 \\
\hline & & $\%$ & $100,00 \%$ & $100,00 \%$ & $100,00 \%$ \\
\hline
\end{tabular}

A distribuição da MDVL segundo o grau histológico não ressaltou sua associação com o grau histológico (Tabela 30). A estatística do teste foi $\chi^{2}=1,599$, com $p=0,450$.

Tabela 30 - MDVLe grau histológico

\begin{tabular}{lccccc}
\hline & & & \multicolumn{2}{c}{ MDVL } & \multirow{2}{*}{ Total } \\
\cline { 3 - 5 } & & & Baixo & Alto & \\
\hline \multirow{3}{*}{ Grau } & $\mathbf{1}$ & $\mathbf{n}$ & 14 & 12 & 26 \\
histológico & & $\mathbf{\%}$ & $19,70 \%$ & $17,60 \%$ & $18,70 \%$ \\
& $\mathbf{2}$ & $\mathbf{n}$ & 39 & 44 & 83 \\
& & $\mathbf{\%}$ & $54,90 \%$ & $64,70 \%$ & $59,70 \%$ \\
& $\mathbf{3}$ & $\mathbf{n}$ & 18 & 12 & 30 \\
& & $\mathbf{\%}$ & $25,40 \%$ & $17,60 \%$ & $21,60 \%$ \\
\cline { 3 - 5 } & \multirow{2}{*}{ Total } & $\mathbf{n}$ & 71 & 68 & 139 \\
& & $\%$ & $100,00 \%$ & $100,00 \%$ & $100,00 \%$ \\
\hline \hline
\end{tabular}


Na Tabela 31 salienta-se a distribuição do comprometimento vascular segundo a MDVL. Esta apresentou associação inversa significativa com o comprometimento vascular. A estatística do teste foi $\chi^{2}=11,756$, com $\mathrm{p}<0,001$.

Tabela 31 - MDVLe comprometimento vasc ular

\begin{tabular}{|c|c|c|c|c|c|}
\hline & & & \multicolumn{2}{|c|}{ MDVL } & \multirow{2}{*}{ Total } \\
\hline & & & Baixo & Alto & \\
\hline \multirow{6}{*}{$\begin{array}{l}\text { Comprometimento } \\
\text { vasc ular }\end{array}$} & Não & $\mathbf{n}$ & 27 & 48 & 75 \\
\hline & & $\%$ & $38,00 \%$ & $66,70 \%$ & $52,40 \%$ \\
\hline & Sim & $\mathbf{n}$ & 44 & 24 & 68 \\
\hline & & $\%$ & $62,00 \%$ & $33,30 \%$ & $47,60 \%$ \\
\hline & & $\mathbf{n}$ & 71 & 72 & 143 \\
\hline & loral & $\%$ & $100,00 \%$ & $100,00 \%$ & $100,00 \%$ \\
\hline
\end{tabular}

Na distribuição da profundidade de invasão em função da MDVL (Tabela 32), a infiltração mais profunda se relacionou com menos densidade vascular linfática. A estatística do teste foi $\chi^{2}=6,147$, com $p=0,007$.

Tábela 32 - MDVLe profundidade de invasão

\begin{tabular}{|c|c|c|c|c|c|}
\hline & & & \multicolumn{2}{|c|}{ MDVL } & \multirow{2}{*}{ Total } \\
\hline & & & Baixo & Alto & \\
\hline \multirow{6}{*}{$\begin{array}{l}\text { Profundidade } \\
\text { de invasão }\end{array}$} & Até $1,0 \mathrm{~cm}$ & $\mathbf{n}$ & 49 & 63 & 112 \\
\hline & \multirow{3}{*}{$>1,0 \mathrm{~cm}$} & $\%$ & $69,00 \%$ & $87,50 \%$ & $78,30 \%$ \\
\hline & & $\mathbf{n}$ & 22 & 9 & 31 \\
\hline & & $\%$ & $31,00 \%$ & $12,50 \%$ & $21,70 \%$ \\
\hline & \multirow{2}{*}{ Total } & $\mathbf{n}$ & 71 & 72 & 143 \\
\hline & & $\%$ & $100,00 \%$ & $100,00 \%$ & $100,00 \%$ \\
\hline
\end{tabular}


Pôde-se constatar, a partir da Tabela 33, a distribuição da MDVL segundo o Ki-67. Não se enfatizou associação entre ambos. A estatística do teste foi $\chi^{2}=0,336$, com $p=0,562$.

Tabela 33 - MDVLe expressão do Ki-67

\begin{tabular}{|c|c|c|c|c|c|}
\hline & & & \multicolumn{2}{|c|}{ MDVL } & \multirow{2}{*}{ Total } \\
\hline & & & Baixo & Alto & \\
\hline & $<50 \%$ & $\mathbf{n}$ & 23 & 18 & 41 \\
\hline & & $\%$ & $32,40 \%$ & $26,50 \%$ & $29,50 \%$ \\
\hline \multirow[t]{4}{*}{ K 67} & $>50 \%$ & $\mathbf{n}$ & 48 & 50 & 98 \\
\hline & & $\%$ & $67,60 \%$ & $73,50 \%$ & $70,50 \%$ \\
\hline & Total & $\mathbf{n}$ & 71 & 68 & 139 \\
\hline & & $\%$ & $100,00 \%$ & $100,00 \%$ & $100,00 \%$ \\
\hline
\end{tabular}

Apresenta-se na Tabela 34 a distribuição da MDVL segundo o desfecho das pacientes. Houve forte indício de associação inversa entre MDVL e óbito. A estatística do teste foi $\chi^{2}=3,088$, com $p=0,079$.

Tabela 34 - MDVLe desfec ho das pacientes

\begin{tabular}{lccccc}
\hline \hline & & & \multicolumn{2}{c}{ MDVL } & \multirow{2}{*}{ Total } \\
\cline { 3 - 5 } & & & Baixo & Alto & \\
\hline \multirow{3}{*}{ Vesfecho } & $\mathbf{n}$ & 58 & 66 & 124 \\
& & $\%$ & $81,70 \%$ & $91,70 \%$ & $86,70 \%$ \\
& Morto & $\mathbf{n}$ & 13 & 6 & 19 \\
& & $\%$ & $18,30 \%$ & $8,30 \%$ & $13,30 \%$ \\
\cline { 3 - 6 } & Total & $\mathbf{n}$ & 71 & 72 & 143 \\
& & $\%$ & $100,00 \%$ & $100,00 \%$ & $100,00 \%$ \\
\hline \hline
\end{tabular}


5.4 Análise multivariada com inclusão da MDVL na previsão do desfecho das pacientes

O resultado do modelo ajustado para o desfecho das pacientes, incluindo múltiplas variáveis e a MDVL, está demonstrado na Tabela 35. O ajuste do modelo saturado revelou que a MDVL não apresentou contribuição significativa para o desfecho.

Tábela 35 - Resultados do modelo para o desfec ho, incluindo a MDVL

\begin{tabular}{lccc}
\hline \hline Variável & Qui-quadrado & g|** & $\mathbf{p}$ \\
\hline MDVL & 0,05 & 1 & 0,820 \\
Estadiamento clínico & 4,61 & 2 & 0,100 \\
Tipo histológico & 7,46 & 1 & 0,006 \\
Infiltração da parede cenical & 0,2 & 1 & 0,655 \\
Comprometimento vascular & 0,99 & 1 & 0,320 \\
Acometimento de linfonodos & 2,09 & 1 & 0,148 \\
Paramétrio comprometido & 0,01 & 1 & 0,936 \\
Vagina comprometida & 0,65 & 1 & 0,422 \\
Grau histológico & 7,36 & 2 & 0,025 \\
K-67 & 2,09 & 1 & 0,148 \\
Tamanho & 0,16 & 2 & 0,926 \\
\hline \hline
\end{tabular}

** gl = graus de liberdade da estatística (apresentados quando diferentes de 1).

* MDVL avaliada pelo método DVV (contagem de número de vasos linfáticos).

Na Tabela 36 encontram-se os resultados do modelo final ajustado para o desfecho. As variáveis associadas ao desfecho foram estádio clínico, tipo histológico, acometimento dos linfonodos e Ki-67. Houve indícios de que Ki 67 também tenha associação com o desfecho $(p=0,099$ no modelo ajustado, não apresentado na tabela).

Tabela 36 - Resultados do modelo para o desfecho das pacientes

\begin{tabular}{lccc}
\hline Variável & Qui-quadrado & g** $^{*}$ & p \\
\hline Estadiamento clínico & 8,19 & 2 & 0,017 \\
Tipo histológico & 6,72 & 1 & 0,010 \\
Acometimento de linfonodos & 4,64 & 1 & 0,031 \\
Grau histológico & 6,41 & 2 & 0,041 \\
\hline
\end{tabular}

* gl = graus de liberdade 
O acometimento dos linfonodos não contribuiu significativamente para o resultado da MDVL, no modelo saturado (Tabela 37).

Tabela 37 - Resultados do modelo para o acometimento dos linfonodos, incluindo a MDVL

\begin{tabular}{lccc}
\hline Variável & Qui-quadrado & gl & p \\
\hline MDVL & 0,11 & 1 & 0,742 \\
Estadiamento clínico & 1,69 & 2 & 0,430 \\
Tipo histológico & 1,56 & 1 & 0,211 \\
Infiltração da parede & 1,76 & 1 & 0,185 \\
Comprometimento vasc ular & 12,42 & 1 & 0,000 \\
Paramétrio comprometido & 8,85 & 1 & 0,003 \\
Vagina comprometida & 1,86 & 1 & 0,173 \\
Grau histológico & 1,41 & 2 & 0,493 \\
Ki-67 & 0,09 & 1 & 0,764 \\
Tamanho & 1,61 & 2 & 0,446 \\
\hline \hline
\end{tabular}

** $\mathrm{gl}=$ graus de liberdade.

* MDVL avaliada pelo método DVV (contagem de número de vasos linfáticos).

Os resultados do modelo final ajustado para o acometimento dos linfonodos evidenciaram que as variáveis associadas ao acometimento dos linfonodos foram: comprometimento vascular, comprometimento de paramétrio e profundidade de invasão (Tabela 38).

Tabela 38 - Resultados do modelo para o acometimento dos linfonodos

\begin{tabular}{lccc}
\hline \hline Variável & Qui-quadrado & g* $^{*}$ & $\mathbf{p}$ \\
\hline Comprometimento vascular & 19,51 & 1 & $<0,001$ \\
Comprometimento de paramétrio & 10,91 & 1 & 0,001 \\
Profundidade de invasão & 4,92 & 1 & 0,027 \\
\hline \hline
\end{tabular}

${ }^{*} \mathrm{gl}=$ graus de liberdade. 
5.5 Associação entre a MDVLe a expressão da podoplanina pelas células neoplásicas e células fibroblásticas do estroma intratumoral

Infere-se, pela Tabela 39, que a expressão de podoplanina em células neoplásicas associou-se à alta MDVL. A estatística do teste foi $\chi^{2}=7,825$, com $p=0,005$.

Tabela 39 - MDVLe expressão de podoplanina em células neoplásicas

\begin{tabular}{|c|c|c|c|c|c|}
\hline & & & \multicolumn{2}{|c|}{ MDVL } & \multirow{2}{*}{ Total } \\
\hline & & & Baixo & Alto & \\
\hline \multirow{6}{*}{$\begin{array}{l}\text { Podoplanina } \\
\text { em células } \\
\text { neoplásicas }\end{array}$} & Não & $\mathbf{n}$ & 63 & 49 & 112 \\
\hline & & $\%$ & $88,70 \%$ & $68,10 \%$ & $78,30 \%$ \\
\hline & Sim & $\mathbf{n}$ & 8 & 23 & 31 \\
\hline & & $\%$ & $11,30 \%$ & $31,90 \%$ & $21,70 \%$ \\
\hline & & $\mathbf{n}$ & 71 & 72 & 143 \\
\hline & Total & $\%$ & $100,00 \%$ & $100,00 \%$ & $100,00 \%$ \\
\hline
\end{tabular}

* MDVL avaliada pelo método DVV (contagem de número de vasos linfáticos).

${ }^{* *} \mathrm{Cel}+=$ expressão da podoplanina em células neoplásicas.

A Tabela 40 mostra a expressão da podoplanina em células fibroblásticas do estroma intratumoral segundo a MDVL. Esta pode ser considerada independente do estroma. A estatística do teste de associação foi $\chi^{2}=0,030$, com $p=0,862$.

Tabela 40 - MDVLe a expressão da podoplanina no estroma intratumoral

\begin{tabular}{|c|c|c|c|c|c|}
\hline & & & \multicolumn{2}{|c|}{ MDVL } & \multirow{2}{*}{ Total } \\
\hline & & & Baixo & Alto & \\
\hline \multirow{6}{*}{ Estroma } & \multirow{2}{*}{ Negativo } & $\mathbf{n}$ & 58 & 58 & 116 \\
\hline & & $\%$ & $81,70 \%$ & $80,60 \%$ & $81,10 \%$ \\
\hline & \multirow[t]{2}{*}{ Positivo } & $\mathbf{n}$ & 13 & 14 & 27 \\
\hline & & $\%$ & $18,30 \%$ & $19,40 \%$ & $18,90 \%$ \\
\hline & \multirow{2}{*}{ Total } & $\mathbf{n}$ & 71 & 72 & 143 \\
\hline & & $\%$ & $100,00 \%$ & $100,00 \%$ & $100,00 \%$ \\
\hline
\end{tabular}

* MDVL avaliada pelo método DVV (contagem de número de vasos linfáticos).

**Estroma = expressão da podoplanina no estroma intratumoral. 
5.6 Associação entre expressão de podoplanina em células neoplásicas com comprometimento vasc ular, acometimento de linfonodos e desfecho

Não houve associação significativa entre a expressão de podoplanina em células neoplásicas e comprometimento vascular, comprometimento dos linfonodos ou desfecho. Os resultados estão nas Tabelas 41 a 43.

Tabela 41 - Expressão da podoplanina em células neoplásicas e comprometimento vasc ular

\begin{tabular}{|c|c|c|c|c|c|}
\hline & & & Compron & to vascular & Tan \\
\hline & & & Não & Sim & Iotal \\
\hline & Não & $\mathbf{n}$ & 60 & 52 & 112 \\
\hline Podoplanina & & $\%$ & $74,10 \%$ & $82,50 \%$ & $77,80 \%$ \\
\hline $\begin{array}{l}\text { em celulas } \\
\text { neoplásicas }\end{array}$ & Sim & $\mathbf{n}$ & 21 & 11 & 32 \\
\hline & & $\%$ & $25,90 \%$ & $17,50 \%$ & $22,20 \%$ \\
\hline & Tatal & $\mathbf{n}$ & 81 & 63 & 144 \\
\hline & & $\%$ & $100,0 \%$ & $100,0 \%$ & $100,0 \%$ \\
\hline
\end{tabular}

O teste de associação entre a expressão de podoplanina em células neoplásicas e o comprometimento vascular teve estatística $\chi^{2}=1,469$, com $p=0,225$, indicando não ser significativa a associação.

Tabela 42 - Expressão da podoplanina em células neoplásicas e estado dos linfonodos

\begin{tabular}{|c|c|c|c|c|c|}
\hline & & & \multicolumn{2}{|c|}{ Linfonodos ac ometidos } & \multirow{2}{*}{ Total } \\
\hline & & & Não & Sim & \\
\hline \multirow{6}{*}{$\begin{array}{l}\text { Podoplanina } \\
\text { em células } \\
\text { neoplásicas }\end{array}$} & Não & $\mathbf{n}$ & 82 & 30 & 112 \\
\hline & & $\%$ & $76,60 \%$ & $81,10 \%$ & $77,80 \%$ \\
\hline & Sim & $\mathbf{n}$ & 25 & 7 & 32 \\
\hline & & $\%$ & $23,40 \%$ & $18,90 \%$ & $22,20 \%$ \\
\hline & & $\mathbf{n}$ & 107 & 37 & 144 \\
\hline & Total & $\%$ & $100,0 \%$ & $100,0 \%$ & $100,0 \%$ \\
\hline
\end{tabular}


A expressão de podoplanina em células neoplásicas associada ao acometimento dos linfonodos teve estatística $\chi^{2}=0,314$, com $p=0,575$, acentuando-se não ser significativa a associação.

Tabela 43 - Expressão da podoplanina em células neoplásicas e desfecho das pacientes

\begin{tabular}{|c|c|c|c|c|c|}
\hline & & & \multicolumn{2}{|c|}{ Desfecho } & \multirow{2}{*}{ Total } \\
\hline & & & Viva & Morta & \\
\hline \multirow{6}{*}{$\begin{array}{l}\text { Podoplanina } \\
\text { em células } \\
\text { neoplásicas }\end{array}$} & Não & $n$ & 95 & 17 & 112 \\
\hline & \multirow{3}{*}{ Sim } & $\%$ & $76,00 \%$ & $89,50 \%$ & $77,80 \%$ \\
\hline & & $n$ & 30 & 2 & 32 \\
\hline & & $\%$ & $24,0 \%$ & $10,50 \%$ & $22,20 \%$ \\
\hline & \multirow{2}{*}{ Total } & $\mathbf{n}$ & 125 & 19 & 144 \\
\hline & & $\%$ & $100,0 \%$ & $100,0 \%$ & $100,0 \%$ \\
\hline
\end{tabular}

O teste de associação entre a expressão de podoplanina em células neoplásicas e o desfecho para as pacientes teve estatística $\chi^{2}=1,732$, com $p=0,188$, sem significância.

5.7 Avaliação da expressão da podoplanina em células fibroblásticas do estroma intratumoral

Tabela 44 - Expressão da podoplanina em células neoplásicas e expressão da podoplanina no estroma intratumoral

\begin{tabular}{|c|c|c|c|c|c|}
\hline & & & \multicolumn{2}{|c|}{ Estroma } & \multirow{2}{*}{ Total } \\
\hline & & & Negativa & Positiva & \\
\hline \multirow{6}{*}{$\begin{array}{l}\text { Podoplanina } \\
\text { em células } \\
\text { neoplásicas }\end{array}$} & Não & $\mathbf{n}$ & 90 & 22 & 112 \\
\hline & & $\%$ & $76,60 \%$ & $81,50 \%$ & $78,30 \%$ \\
\hline & Sim & $\mathbf{n}$ & 26 & 5 & 31 \\
\hline & & $\%$ & $22,40 \%$ & $18,50 \%$ & $21,70 \%$ \\
\hline & D & $\mathbf{n}$ & 116 & 27 & 143 \\
\hline & local & $\%$ & $100,0 \%$ & $100,0 \%$ & $100,0 \%$ \\
\hline
\end{tabular}


O teste de associação entre a expressão de podoplanina em células neoplásicas e a expressão de podoplanina no estroma intratumoral teve estatística igual $\chi^{2}=0,196$, com $p=0,658$, reportando não ser significativa a associação.

No modelo de regressão logística ajustado para avaliação da associação entre a expressão de podoplanina no estroma e as demais variáveis potencialmente prognósticas, a expressão de podoplanina no estroma se associou a comprometimento linfonodal e desfecho (Tabelas 45 e 46).

Tabela 45 - Resultados do ajuste do modelo saturado para a expressão da podoplanina no estroma

\begin{tabular}{lcc}
\hline Variável & Qui-quadrado & p \\
\hline Estadiamento clínico & 1,21 & 0,546 \\
Tipo histológico & 1,78 & 0,182 \\
Idade & 2,06 & 0,151 \\
Infiltração & 0,76 & 0,384 \\
Acomet vasc ular & 0,11 & 0,744 \\
Acomet de linfonodos & 3,58 & 0,058 \\
Desfecho & 5,02 & 0,025 \\
Tamanho & 4,37 & 0,113 \\
\hline \hline
\end{tabular}

O modelo final, obtido após a retirada de todas as variáveis com contribuição não-significativa, teve os seguintes resultados, apresentados na Tabela 46.

Tabela 46 - Resultados do ajuste do modelo final para a expressão de podoplanina no estroma

\begin{tabular}{lcc}
\hline \hline Variável & Qui-quadrado & p \\
\hline Comprometimento de linfonodos & 8,19 & 0,004 \\
Desfecho & 6,05 & 0,014 \\
\hline \hline
\end{tabular}


Na Tabela 47 o teste de associação entre a expressão de podoplanina em células fibroblásticas do estroma intratumoral e o comprometimento linfonodos teve estatística $\chi^{2}=5,985$, com $p=0,014$, indicando ser significativa a associação.

Tabela 47 - Expressão da podoplanina em células fibroblásticas do estroma intratumoral e comprometimento de linfonodos

\begin{tabular}{lllccc}
\hline \hline & & & \multicolumn{2}{c}{ Linfonodo acometido } & Total \\
\cline { 3 - 5 } & & & Não & Sim & \\
\hline \multirow{3}{*}{ Estroma } & Negativo & $\mathbf{n}$ & 91 & 25 & 116 \\
& & $\%$ & $85,80 \%$ & $67,60 \%$ & $81,10 \%$ \\
& Positivo & $\mathbf{n}$ & 15 & 12 & 27 \\
& & $\%$ & $14,20 \%$ & $32,40 \%$ & $18,90 \%$ \\
\cline { 3 - 5 } & & $\mathbf{n}$ & 106 & 37 & 143 \\
& Total & $\%$ & $100,00 \%$ & $100,00 \%$ & $100,00 \%$ \\
\hline \hline
\end{tabular}

Pearson Chi-Square $X^{2}=5,985 \mathbf{P}=\mathbf{0 , 0 1 4}$.

A estatística do teste salientou significativa associação entre a expressão de podoplanina em células fibroblásticas do estroma intratumoral e o comprometimento de linfonodos foi $\chi^{2}=5,985$, com $p=0,014$.

Tabela 48 - Expressão da podoplanina em células fibroblásticas do estroma intratumoral e desfec ho das pacientes

\begin{tabular}{cccccc}
\hline \hline & & & \multicolumn{2}{c}{ Desfecho } & Total \\
\cline { 3 - 5 } & & & Vivo & Morto & \\
\hline \multirow{3}{*}{ Estroma } & \multirow{2}{*}{ Negativo } & $\mathbf{n}$ & 98 & 18 & 116 \\
& & $\%$ & $79,00 \%$ & $94,70 \%$ & $81,10 \%$ \\
& \multirow{2}{*}{ Positivo } & $\mathbf{n}$ & 26 & 1 & 27 \\
& & $\%$ & $21,00 \%$ & $5,30 \%$ & $18,90 \%$ \\
\hline \hline & \multirow{2}{*}{ Total } & $\mathbf{n}$ & 124 & 19 & 143 \\
& & $\%$ & $100,00 \%$ & $100,00 \%$ & $100,00 \%$ \\
\hline
\end{tabular}


5.8 Análise multivariada incluindo a MDVL, expressão de podoplanina pelas células neoplásicas e em células fibroblásticas do estroma para previsão do acometimento dos linfonodos e no desfecho das pacientes

Tabela 49 - Modelo inicial para acometimento de linfonodos incluindo expressão da podoplanina nas células neoplásicas

\begin{tabular}{lccc}
\hline Variável & Qui-quadrado & gl & p \\
\hline Podoplanina em células neoplásicas & 2,00 & 1 & 0,157 \\
Faixa etána & 12,37 & 1 & 0,000 \\
Estádio & 5,71 & 2 & 0,058 \\
Tipo histológico & 5,72 & 1 & 0,017 \\
MDVL & 1,86 & 1 & 0,173 \\
Tamanho & 1,74 & 2 & 0,419 \\
Paramétrio comprometido & 10,64 & 1 & 0,001 \\
Vagina comprometida & 3,98 & 1 & 0,046 \\
Grau histológico & 4,56 & 2 & 0,102 \\
Comprometimento vasc ular & 17,57 & 1 & 0,000 \\
Infiltração da parede & 1,87 & 1 & 0,171 \\
K 67 alto & 0,23 & 1 & 0,629 \\
\hline \hline
\end{tabular}

Após a retirada das variáveis com menos contribuição, chegou-se ao modelo final (Tabela 50).

Tabela 50 - Modelo final para previsão de acometimento de linfonodos

\begin{tabular}{lccc}
\hline Variável & Qui-quadrado & gl & p \\
\hline Faixa etánia & 4,96 & 1 & 0,026 \\
Paramétrio comprometido & 10,54 & 1 & 0,001 \\
Comprometimento vasc ular & 21,87 & 1 & 0,000 \\
Profundidade de invasão & 4,37 & 1 & 0,037 \\
\hline \hline
\end{tabular}

As variáveis preditivas para o acometimento dos linfonodos foram: faixa etária, comprometimento de paramétrio, comprometimento vascular e profundidade de invasão. A expressão de podoplanina nas células neoplásicas não apresentou contribuição significativa para 
explicar o acometimento dos linfonodos quando em conjunto com as demais variáveis do modelo.

O resultado do ajuste do modelo saturado para previsão do acometimento dos linfonodos, incluindo também a expressão da podoplanina no estroma intratumoral, encontra-se na Tabela 51.

Tabela 51 - Modelo inicial para acometimento dos linfonodos incluindo expressão da podoplanina no estroma intratumoral

\begin{tabular}{lccc}
\hline Variável & Qui-quadrado & gl & p \\
\hline Podoplanina (+) em células neoplásicas & 2,63 & 1 & 0,105 \\
Podoplanina (+) em células fibroblásticas & & & \\
Faixa etána & 13,84 & 1 & 0,000 \\
Estádio & 4,74 & 2 & 0,093 \\
Tipo histológico & 5,21 & 1 & 0,022 \\
MDVL & 1,20 & 1 & 0,274 \\
Tamanho & 1,48 & 2 & 0,476 \\
Paramétrio comprometido & 7,72 & 1 & 0,005 \\
Vagina comprometida & 2,99 & 1 & 0,084 \\
Grau histológico & 4,63 & 2 & 0,099 \\
Comprometimento vascular & 16,43 & 1 & 0,000 \\
Infiltração da parede & 1,94 & 1 & 0,163 \\
K 67 & 0,51 & 1 & 0,477 \\
\hline \hline
\end{tabular}

Após a remoção das variáveis menos significativas, chegou-se ao modelo final (Tabela 52).

Tabela 52 - Modelo quase final para o acometimento dos linfonodos inc luindo expressão da podoplanina no estroma intratumoral

\begin{tabular}{lccc}
\hline \hline Variável & Qui-quadrado & gl & p \\
\hline Faixa etánia & 5,85 & 1 & 0,016 \\
Paramétrio comprometido & 9,22 & 1 & 0,002 \\
Comprometimento vasc ular & 20,60 & 1 & 0,000 \\
Profundidade de invasão & 3,83 & 1 & 0,050 \\
Expressão de podoplanina no estroma & 2,50 & 1 & 0,114 \\
\hline \hline
\end{tabular}


A Tabela 53 apresenta o resultado do ajuste do modelo saturado (com todas as variáveis preditivas) para previsão do desfecho das pacientes, usando a expressão da podoplanina nas células neoplásicas. As variáveis com contribuição não-significativa $(p>0,05)$ devem então ser removidas uma a uma (a partir da menos significante - maior $p$ ), até que somente variáveis com contribuição significativa permaneçam no modelo.

Tabela 53 - Modelo inicial para previsão do desfecho incluindo a expressão da podoplanina nas células neoplásicas

\begin{tabular}{lccc}
\hline Variável & $\begin{array}{c}\text { Qui- } \\
\text { quadrado }\end{array}$ & gl & p \\
\hline Expressão da podoplanina em células neoplásicas & 0,66 & 1 & 0,416 \\
Faixa etánia & 2,49 & 1 & 0,114 \\
Estádio & 3,01 & 2 & 0,222 \\
Tipo histológico & 8,51 & 1 & 0,004 \\
MDVL & 0,10 & 1 & 0,747 \\
Tamanho & 0,29 & 2 & 0,865 \\
Paramétrio comprometido & 0,17 & 1 & 0,679 \\
Vagina comprometida & 0,21 & 1 & 0,648 \\
Grau histológico & 10,21 & 2 & 0,006 \\
Comprometimento vasc ular & 1,77 & 1 & 0,183 \\
Infiltração & 0,06 & 1 & 0,805 \\
Ki 67 & 2,40 & 1 & 0,121 \\
\hline \hline
\end{tabular}

Tamanho do tumor foi a menos significativa e precisou ser removida, assim como as demais, uma a uma, até o modelo final com todas significativas para explicar o desfecho.

Tabela 54 - Modelo final para o desfecho incluindo a expressão da podoplanina nas células neoplásicas

\begin{tabular}{lccc}
\hline \hline Variável & Qui-quadrado & gl & $\mathbf{p}$ \\
\hline Estádio & 7,82 & 2 & 0,020 \\
Tipo histológico & 6,84 & 1 & 0,009 \\
Grau histológico & 7,86 & 2 & 0,020 \\
Comprometimento vascular & 4,12 & 1 & 0,042 \\
\hline \hline
\end{tabular}


As variáveis preditivas para o desfecho foram: estádio, tipo histológico, grau histológico e comprometimento vascular. A expressão da podoplanina nas células neoplásicas não apresentou contribuição significativa com essas variáveis presentes no modelo.

O resultado do ajuste do modelo saturado (com todas as variáveis preditivas) para previsão do desfecho das pacientes, usando a expressão da podoplanina no estroma intratumoral, pode ser visto na Tabela 55.

As variáveis com contribuição não-significativa $(p>0,05)$ foram então ser removidas uma a uma (a partir da menos significante - maior p) até que somente aquelas com contribuição significativas permanecessem no modelo.

Tabela 55 - Modelo inicial para previsão do desfecho incluindo a expressão da podoplanina no estroma intratumoral

\begin{tabular}{lccc}
\hline Variável & Qui-quadrado & gl & p \\
\hline Expressão de podoplanina no estroma & 3,03 & 1 & 0,082 \\
Faixa etánia & 1,33 & 1 & 0,248 \\
Estádio & 2,29 & 2 & 0,318 \\
Tipo histológico & 7,66 & 1 & 0,006 \\
MDVL & 0,02 & 1 & 0,902 \\
Tamanho & 0,45 & 2 & 0,800 \\
Paramétrio comprometido & 0,38 & 1 & 0,539 \\
Vagina comprometida & 0,01 & 1 & 0,918 \\
Grau histológico & 9,68 & 2 & 0,008 \\
Comprometimento vascular & 2,65 & 1 & 0,103 \\
Infiltração & 0,15 & 1 & 0,696 \\
K 67 & 2,15 & 1 & 0,142 \\
\hline \hline
\end{tabular}


Acometimento da vagina foi a menos significativa, seguida da MDVL. Elas foram retiradas, uma a uma, até que no modelo final constassem somente variáveis com contribuição significativa para explicar o desfecho (Tabela 56).

Tabela 56 - Modelo final para previsão de desfecho incluindo a expressão da podoplanina no estroma

\begin{tabular}{lccc}
\hline \hline Variável & Qui-quadrado & gl & p \\
\hline Expressão de podoplanina no estroma & 4,40 & 1 & 0,036 \\
Estádio & 7,39 & 2 & 0,025 \\
Tipo histológico & 6,09 & 1 & 0,014 \\
Grau histológico & 9,17 & 2 & 0,010 \\
Comprometimento vascular & 5,15 & 1 & 0,023 \\
\hline \hline
\end{tabular}

As variáveis preditivas para o desfecho foram: a expressão da podoplanina no estroma intratumoral, estádio clínico, tipo histológico, grau histológico e comprometimento vascular. A expressão da podoplanina no estroma intratumoral agrega valor na previsão, mesmo com as demais variáveis já presentes no modelo. 


\section{Discussão}

O estudo dos vasos linfáticos dentro do tumor vem ganhando crescente interesse $36,38,39,43-46$. Sabe-se que a mortalidade pelo câncer raramente é causada pelo tumor primário, sendo mais atribuída à disseminação metastática causada pelas células tumorais a órgãos distantes.

A compreensão da linfangiogênese pode ser considerada chave importante na elucidação de mecanismos usados pelas células tumorais ao se disseminarem ${ }^{108}$.

Neste presente estudo, das 144 pacientes tratadas com histerectomia radical, $37(25,7 \%)$ apresentavam linfonodos positivos. E quando os linfonodos estavam comprometidos, ocorreu a morte em 10 $(52,60 \%)$.

Os linfonodos acometidos estavam associados a tamanho do tumor, profundidade de invasão, envolvimento de paramétrio ou vagina e embolização vascular-linfática(EVL). Mas não houve associação com tipo histológico, idade, grau histológico, expressão do Ki-67, acometimento de corpo de útero ou estadiamento clínico.

É sabido que o tumor induz linfangiogênese. Esse processo provoca a formação de novos vasos linfáticos a partir de vasos preexistentes e da circulação de células progenitoras endoteliais linfáticas ${ }^{109}$. A célula tumoral promove a remodelação de vasos linfáticos locais, o desenvolvimento de rede linfática regional no nódulo linfático e também - aumento do número e diâmetro dos vasos linfáticos. Consequentemente, o escoamento de linfa do tumor aumenta, podendo produzir significativo aumento de metástase de células tumorais para nódulos linfáticos.

Em nosso estudo foi avaliada a microdensidade vascular linfática em carcinomas de colo do útero iniciais e relacionados esses achados 
com as características clínico-patológicas clássicas do câncer precoce de colo de útero.

A linfangiogênese foi estimada pela quantificação das estruturas vasculares que expressam podoplanina, que é expressa especificamente em endotélio de vasos linfáticos, mas não em vasos sanguíneos ${ }^{14}$.

Pesquisas sobre a MLVD em câncer de colo de útero são raros e controversos 110,111. Em câncer invasivo já foram descritos 0-12,3 microvasos linfáticos (média de 6,15 vasos/×200hpf) e carcinoma microinvasor com aumento de 10,3-19,3 (média de 14,8 vasos/x200hpf) 17.

Em 2007 detectou-se aumentada densidade vascular linfática (DVL) em lesões invasivas na comparação com as pré-invasivas, sem associação com lesões invasivas com linfonodos comprometidos ou metástases ${ }^{16}$. Quando associada displasia de alto grau a carcinoma in situ, constatou-se elevação na densidade dos vasos linfáticos, sugerindo o importante papel desse aumento para a progressão para tumor invasivo na carcinogênese cervical58.

Em nosso estudo a MLVD foi maior nos tumores de menor tamanho (<2 cm) e estádios iniciais (IB 1), provavelmente demonstrando que a indução da linfangiogênese pode ser evento inicial na progressão do câncer, quando ainda nem todos os novos vasos neoformados estão funcionantes ou patentes. Isto explicaria o achado da MLVD estar elevada nos tumores iniciais, entretanto, os linfonodos estavam frequentemente negativos.

Outro ponto importante que merece ser estudado é a interação das células neoplásicas com o estroma adjacente. No estroma existem outras células (fibroblastos), proteínas da matriz extracelular e moléculas de adesão célula-célula como as caderinas.

As caderinas são moléculas de adesão dependentes de $\mathrm{Ca}^{2+}$ que medeiam a interação homotípica célula-célula, inicialmente identificadas nas junções aderentes (adherens junctions). As caderinas são uma superfamília de pelo menos 30 diferentes moléculas, cuja expressão é controlada têmporo-espacialmente. 
A molécula de e-caderina, que é expressa por células epiteliais, é a que se encontra mais frequentemente alterada em tumores. Diferentes estudos revelam que a e-caderina é frequentemente inativada durante o desenvolvimento de carcinomas humanos, como mama, cólon, próstata, estômago, fígado, esôfago, pele, rim e pulmão, e está associada à invasão e à formação de metástase em linfonodos e à distância.

A inibição da expressão da e-caderina em células de carcinoma facilita a invasão tumoral, enquanto o restabelecimento da expressão de e-caderina resulta em diminuição de proliferação e inibição de invasão e metástase.

A e-caderina é, em parte, responsável pelo fenômeno de inibição por contato, uma característica de células epiteliais normais, associado ao bloqueio de proliferação quando células entram em contato umas com as outras. Essa característica é fundamental para a manutenção de arquitetura dos epitélios. Essa mudança no padrão da expressão de caderinas ocorre durante a progressão tumoral e já foi documentada in vitro e in vivo.

Ao mesmo tempo em que as células tumorais se soltam do tumor primário por diminuição da interação célula-célula, elas devem ter a capacidade de migrar e invadir o estroma adjacente. Células de carcinomas passam por um processo denominado transição epitéliomesenquimal (EMT): a célula tumoral, de origem epitelial, passa a expressar um conjunto de genes tipicamente expressos em células do tecido conjuntivo. Do ponto de vista celular, a transição se dá entre um morfotipo epitelioide (menos migratório) para um morfotipo fibroblastoide (mais migratório) ${ }^{112}$.

Baseados nestes dados, estão surgindo evidências na literatura de que mudanças no fenótipo molecular que ocorrem no microambiente do estroma tumoral, conhecido como EMT, poderiam estar envolvidas no mecanismo de metástase dos tumores ${ }^{113}$. Embora as bases moleculares do EMT ainda não tenham sido elucidadas, algumas sinalizações moleculares têm sido identificadas e todas elas, de alguma forma, estão relacionadas 
à perda da função da adesão da proteína transmembrana e-caderina113. A EMT é importante, particularmente, em cânceres com migração celular única e na disseminação inicial das células tumorais ${ }^{114}$.

A podoplanina poderia utilizar mecanismos de sinalização da ecaderina para estimular a migração, de forma coletiva, das células tumorais e, assim, promover invasão; e por esta razão estar envolvida no processo de metástase das células tumorais22,115.

Neste trabalho observou-se a expressão da podoplanina em fibroblastos do estroma intratumoral (ITS) em 27 (18,88\%) dos 144 casos, associada à metástase para nódulo linfático e ao desfecho.

Por outro lado, não houve associação entre expressão da podoplanina e idade, estádio clínico, tamanho do tumor, tipo histológico, profundidade de infiltração ou envolvimento vascular.

Estudo de 138 casos de carcinoma invasivo de células escamosas no colo de útero evidenciou imunorreatividade à podoplanina de forma difusa em 17 (12\%) e focal em 81 (59\%), enquanto 40 (29\%) não apresentaram imunorreatividade ${ }^{21}$.

Este trabalho registrou, ainda, que a invasão linfática e metástase para linfonodos foram significativamente mais comuns em tumores que expressaram baixa imunorreatividade à podoplanina $(p<0,0001$ e 0,002, respectivamente). Das características clínico-patológicas, a podoplanina não se correlacionou com estádio clínico, tamanho tumor e grau histológico. Já a baixa imunorreatividade esteve associada a curto período livre de doença, mas não à sobrevida.

De acordo com levantamento bibliográfico realizado até o momento, este é o primeiro estudo a investigar a importância da expressão da podoplanina no estroma intratumoral de carcinoma do colo do útero, relacionando-a com MLVD, comprometimento dos linfonodos e desfecho. 


\section{CONCLUSÕES}

- Avaliação da linfangiogênese intratumoral a partir da análise quantitativa da microdensidade vascular linfática (MDVL) em carcinomas do colo do útero submetidos a tratamento cirúrgico revelou resultados equivalentes para os três métodos morfométricos de quantificação (DVV, DVT DVP).

- O estadiamento clínico e o estado dos linfonodos foram variáveis independentes associadas a óbito.

- As variáveis associadas a comprometimento linfonodal foram tamanho do tumor, profundidade de infiltração cervical, embolização vascular linfática, infiltração parametrial e extensão para a vagina. A idade da paciente, estadiamento clínico, tipo e grau histológico, extensão para o corpo uterino e atividade proliferativa determinada pela expressão do Ki-67 não se associaram significantemente ao comprometimento dos linfonodos.

- As variáveis associadas a óbito pela doença foram estadiamento clínico, tamanho do tumor, profundidade de invasão, embolização vascular linfática, extensão para os paramétrios e estado dos linfonodos. As demais variáveis (idade, tipo e grau histológico, extensão para vagina e atividade proliferativa) não mostraram associação significativa.

- A alta MDVL se associou a tumores de menor tamanho, com menos profundidade de infiltração, estádio clínico inicial, ausência de invasão linfovascular e linfonodos negativos. A MDVL não se associou a idade, tipo histológico, grau histológico, invasão de paramétrio ou vagina ou expressão de Ki-67. 
- Na análise multivariada, a MDVL não foi variável preditiva de comprometimento linfonodal ou óbito. Não houve associação entre a expressão de podoplanina pelas células neoplásicas e características clínico-patológicas, acometimento de linfonodos ou óbito. A expressão de podoplanina em células fibroblásticas do estroma intratumoral foi associada a bom prognóstico.

- Não houve associação da MDVL com idade, estádio clínico, tamanho do tumor, tipo histológico, profundidade de invasão ou embolização vascular linfática. 


\section{ANEXOS}

\section{ANEXO A - BANCO DE DADOS}

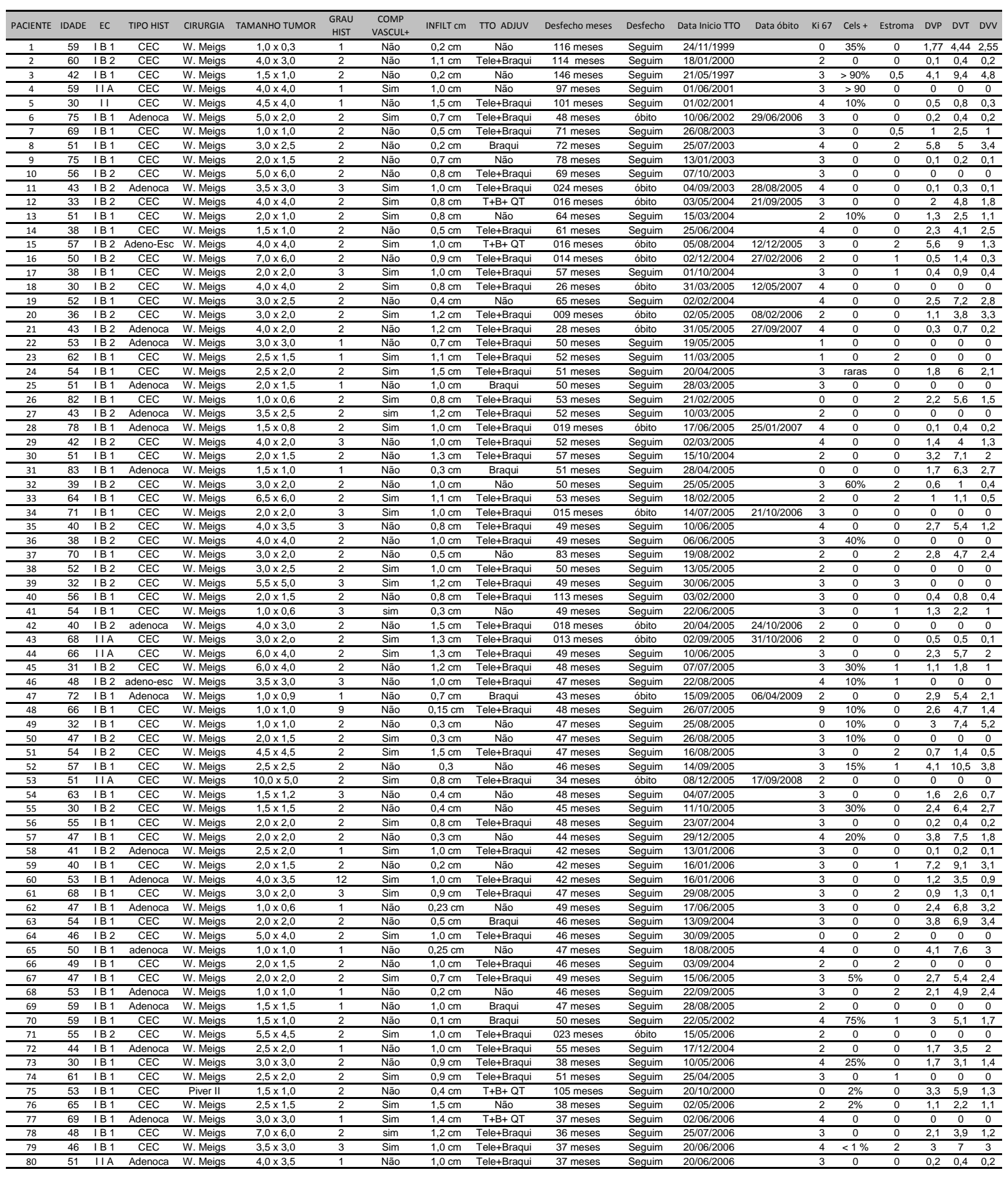

Continua... 
Conclusão Anexo A






\section{ANEXO B - PROTOCOLO DE PESQUISA CARCINOMA DE COLO DE ÚTERO}

1- Nome da paciente

2- Idade

3- Número Prontuário
4- Estádio clínico
口।
口II

5- Tipo Histológico Bx colo acélulas escamosas aadenocarcinoma r adeno- escamoso

6- Tipo de cirurgia

7- Tamanho tumor _

8- Extensão paramétrio घsim anão

9- Extensão vagina asim anão

10- Corpo útero asim anão

11- Número linfonodos retirados e acometidos (___ _ )

12- Grau histológico $\quad$ a $1 \quad \square 2 \quad \square 3$

13- Comprometimento vascular peritumoral $\square \operatorname{sim} \quad \square$ não

14- Nível de infiltração parede cervical $\mathrm{mm}$ 


\section{RETERÊnCIAS}

1. Parkin DM, Pisani P, Ferlay J. Estimates of the worldwide incidence of 25 major cancers in 1990. Int J Cancer 1999; 80(6):827-41.

2. Instituto Nacional do Câncer - INCA. Incidência de câncer no Brasil. In: CdPeVE, editor. Rio de Janeiro: INCA; 2005.

3. INCA. Estimativa 2008. In: INCA, editor. [citado 22 dez 2009]. Disponível em:

http://www.inca.gov.br/estimativa/2008/tabelasestados.asp? UF=BR; 2008.

4. INCA INdC. Estimativa 2010 - Incidência de Câncer no Brasil - INCA. [citado 22 dez. 2009]. Disponível em: http://www.inca.gov.br/estimativa/2010/tabelaestados.asp? UF=BR; 2010.

5. Derossi SA, Aquino E, Silva LM. Evolução da mortalidade e anos pontenciais de vida perdidos por câncer cérvico-uterino em Salvador. Rev Bras Cancerol 2001; 47(2):163-70.

6. Trimble EL. Cervical cancer state-of-the-clinical-science meeting on pretreatment evaluation and prognostic factors, September 27-28, 2007: proceedings and recommendations. Gynecol Oncol 2009; 114(2):14550.

7. Lanciano RM, Martz K, Coia LR, Hanks GE. Tumor and treatment factors improving outcome in stage III-B cervix cancer. Int J Radiat Oncol Biol Phys 1991; 20(1):95-100.

8. Tavares MB, Sousa RB, Oliveira e Silva T, Moreira LA, Silva LT, Tavares CB, et al. Prevalence of prognostic factors for cancer of the uterine cervix after radical hysterectomy. Sao Paulo Med J 2009; 127(3):145-9.

9. Achen MG, Stacker SA. Molecular control of lymphatic metastasis. Ann N Y Acad Sci 2008; $1131: 225-34$.

10. Yamanashi T, Nakanishi Y, Fujii G, Akishima-Fukasawa Y, Moriya Y, Kanai $Y$, et al. Podoplanin expression identified in stromal fibroblasts as a favorable prognostic marker in patients with colorectal carcinoma. Oncology 2009; 77(1):53-62. 
11. Lim CS, Alexander-Sefre F, Allam M, Singh N, Aleong JC, Al-Rawi H, et al. Clinical value of immunohistochemically detected lymphovascular space invasion in early stage cervical carcinoma. Ann Surg Oncol 2008; 15(9):2581-8.

12. Herr D, Konig J, Heilmann V, Koretz K, Kreienberg R, Kurzeder C. Prognostic impact of satellite-lymphovascular space involvement in early-stage cervical cancer. Ann Surg Oncol 2009; 16(1):128-32.

13. Das S, Skobe M. Lymphatic vessel activation in cancer. Ann N Y Acad Sci 2008; 1131:235-41.

14. Stacker SA, Achen MG, Jussila L, Baldwin ME, Alitalo K. Lymphangiogenesis and cancer metastasis. Nat Rev Cancer 2002; 2(8):573-83.

15. Saharinen P, Petrova TV. Molecular regulation of lymphangiogenesis. Ann N Y Acad Sci 2004; 1014:76-87.

16. Longatto-Filho A, Pinheiro C, Pereira SM, Etlinger D, Moreira MA, Jubé LF, et al. Lymphatic vessel density and epithelial D2-40 immunoreactivity in pre-invasive and invasive lesions of the uterine cervix. Gynecol Oncol 2007; 107(1):45-51.

17. Saptefrati L, Cimpean AM, Ciornii A, Ceausu R, Esanu N, Raica M. Identification of lymphatic vessels and prognostic value of lymphatic microvessel density in lesions of the uterine cervix. Rom J Morphol Embryol 2009; 50(4):589-94.

18. Van der Auwera I, Cao Y, Tille JC, Pepper MS, Jackson DG, Fox SB, et al. First international consensus on the methodology of lymphangiogenesis quantification in solid human tumours. Br J Cancer 2006; 95(12):161 1-25.

19. Raica M, Cimpean AM, Ribatti D. The role of podoplanin in tumor progression and metastasis. Anticancer Res 2008; 28(5B):2997-3006.

20. Baluk P, McDonald DM. Markers for microscopic imaging of lymphangiogenesis and angiogenesis. Ann N Y Acad Sci 2008; 1131:1-12.

21.Dumoff KL, Chu C, XU X, Pasha T, Zhang PJ, Acs G. Low D2-40 immunoreactivity correlates with lymphatic invasion and nodal metastasis in early-stage squamous cell carcinoma of the uterine cervix. Mod Pathol 2005; 18(1):97-104.

22. Wicki A, Christofori $G$. The potential role of podoplanin in tumour invasion. Br J Cancer 2007; 96(1):1-5. 
23. Kawase A, Ishii G, Nagai K, Ito T, Nagano T, Murata Y, et al. Podoplanin expression by cancer associated fibroblasts predicts poor prognosis of lung adenocarcinoma. Int J Cancer 2008; 123(5):1053-9.

24. Yuan P, Temam S, El-Naggar A, Zhou X, Liu DD, Lee JJ, et al. Overexpression of podoplanin in oral cancer and its association with poor clinical outcome. Cancer 2006; 107(3):563-9.

25. Chuang WY, Yeh CJ, Wu YC, Chao YK, Liu YH, Tseng CK, et al. Tumor cell expression of podoplanin correlates with nodal metastasis in esophageal squamous cell carcinoma. Histol Histopathol 2009; 24(8):1021-7.

26. Michel G MP, Castaigne D, Leblanc M, Rey A, Duvillard P. Lymphatic spread in stage IB and II cervical carcinoma. Obstet Gynecol 1998; 91(3):360-3.

27. Piura B, Rabinovich A, Friger M. Number and distribution of pelvic lymph nodes and effect of surgical pathologic factors on pelvic lymph node status in patients with early-stage cervical carcinoma treated with radical hysterectomy and pelvic lymph node dissection. Eur J Gynaecol Oncol 2006; 27(5):463-6.

28. Achen MG, Mann GB, Stacker SA. Targeting lymphangiogenesis to prevent tumour metastasis. Br J Cancer 2006; 94(10):1355-60.

29. Singh N, Arif S. Histopathologic parameters of prognosis in cervical cancer- a review. Int J Gynecol Cancer 2004; 14(5):741-50.

30. Piura B, Rabinovich A, Friger M. Surgical pathologic factors in patients with early-stage cervical carcinoma treated with radical hysterectomy and pelvic lymph node dissection: association with administration of adjuvant radiotherapy and effect on survival. Eur J Gynaecol Oncol 2006; 27(6):573-8.

31. Witte $\mathrm{MH}$, Bernas MJ, Martin CP, Witte CL. Lymphangiogenesis and lymphangiodysplasia: from molecular to clinical lymphology. Microsc Res Tech 2001; 55(2):122-45.

32. Tille JC, Pepper MS. Hereditary vascular anomalies: new insights into their pathogenesis. Arterioscler Thromb Vasc Biol 2004; 24(9):1578-90.

33. Sabin FR. On the origin of the lymphatic system from the veins and the development of lymph hearts and thoracic duct in the pig. Am J Anat 1902; 1:367-91. 
34. Huntington GS, MCClure CFW. The anatomy and development of the jugular lymph sac in the dome( Felis domestica). Am J Anat 1910; 10:177-311.

35. Al-Rawi MA, Mansel RE, Jiang WG. Lymphangiogenesis and its role in cancer. Histol Histopathol Jan 2005; 20(1):283-98.

36. Folkman J. Tumor angiogenesis and tissue factor. Nat Med 1996; 2(2):167-8.

37. Fisher B, Fisher ER. Role of the lymphatic system in dissemination of tumour. Lymph 1966:324.

38. Leu AJ, Berk DA, Lymboussaki A, Alitalo K, Jain RK. Absence of functional lymphatics within a murine sarcoma: a molecular and functional evaluation. Cancer Res 2000; 60(16):4324-7.

39. Carmeliet $P$, Jain RK. Angiogenesis in cancer and other diseases. Nature 2000; 407(6801):249-57.

40. Jain RK. Transport of molecules in the tumor interstitium: a review. Cancer Res 1987; 47(12):3039-51.

41. Tanigawa N, Kanazawa T, Satomura K, Hikasa Y, Hashida M, Muranishi S, et al. Experimental study on lymphatic vascular changes in the development of cancer. Lymphology 1981; 14(4):149-54.

42. Hartveit E. Attenuated cells in breast stroma: the missing lymphatic system of the breast. Histopathology 1990; 16(6):533-43.

43. Baxter LT, Jain RK. Transport of fluid and macromolecules in tumors. II. Role of heterogeneous perfusion and lymphatics. Microvasc Res 1990; 40(2):246-63.

44. Jackson DG, Prevo R, Clasper S, Banerji S. LYVE-1, the lymphatic system and tumor lymphangiogenesis. Trends Immunol 2001; 22(6):317-21.

45. Pepper MS. Lymphangiogenesis and tumor metastasis: myth or reality? Clin Cancer Res 2001; 7(3):462-8.

46. Karkkainen MJ, Alitalo K. Lymphatic endothelial regulation, lymphoedema, and lymph node metastasis. Semin Cell Dev Biol 2002; 13(1):9-18.

47. Maula SM, Luukkaa M, Grenman R, Jackson D, Jalkanen S, Ristamaki R. Intratumoral lymphatics are essential for the metastatic spread and prognosis in squamous cell carcinomas of the head and neck region. Cancer Res 2003; 63(8):1920-6. 
48. Franchi A, Gallo O, Massi D, Baroni G, Santucci M. Tumor lymphangiogenesis in head and neck squamous cell carcinoma: a morphometric study with clinical correlations. Cancer 2004; 101 (5):973-8.

49. Kyzas PA, Geleff S, Batistatou A, Agnantis NJ, Stefanou D. Evidence for lymphangiogenesis and its prognostic implications in head and neck squamous cell carcinoma. J Pathol 2005; 206(2):170-7.

50. Schoppmann SF, Birner P, Studer P, Breiteneder-Geleff S. Lymphatic microvessel density and lymphovascular invasion assessed by antipodoplanin immunostaining in human breast cancer. Anticancer Res $2001 ; 21(4 \mathrm{~A}): 2351-5$.

51. Bono P, Wasenius VM, Heikkila P, Lundin J, Jackson DG, JoensuU H. High LYVE-1-positive lymphatic vessel numbers are associated with poor outcome in breast cancer. Clin Cancer Res 2004; 10(21):7144-9.

52. Nakamura Y, Yasuoka H, Tsujimoto M, Imabun S, Nakahara M, Nakao K, et al. Lymph vessel density correlates with nodal status, VEGF-C expression, and prognosis in breast cancer. Breast Cancer Res Treat 2005; $91(2): 125-32$.

53. Straume O, Jackson DG, Akslen LA. Independent prognostic impact of lymphatic vessel density and presence of low-grade lymphangiogenesis in cutaneous melanoma. Clin Cancer Res 2003; 9(1):250-6.

54. Dadras SS, Paul T, Bertoncini J, Brown LF, Muzikansky A, Jackson DG, et al. Tumor lymphangiogenesis: a novel prognostic indicator for cutaneous melanoma metastasis and survival. Am J Pathol 2003; 162(6):1951-60.

55. Shields JD, Borsetti M, Rigby H, Harper SJ, Mortimer PS, Levick JR, et al. Lymphatic density and metastatic spread in human malignant melanoma. Br J Cancer 2004; 90(3):693-700.

56. Massi D, Puig S, Franchi A, Malvehy J, Vidal-Sicart S, González-Cao M, et al. Tumour lymphangiogenesis is a possible predictor of sentinel lymph node status in cutaneous melanoma: a case-control study. J Clin Pathol 2006; 59(2):166-73.

57. Birner P, Schindl M, Obermair A, Breitenecker G, Kowalski H, Oberhuber G. Lymphatic microvessel density as a novel prognostic factor in earlystage invasive cervical cancer. Int J Cancer 2001; 95(1):29-33.

58. Gombos Z, Xu X, Chu CS, Zhang PJ, Acs G. Peritumoral lymphatic vessel density and vascular endothelial growth factor $C$ expression in earlystage squamous cell carcinoma of the uterine cervix. Clin Cancer Res 2005; $11(23): 8364-71$. 
59. Birner P, Schindl M, Obermair A, Plank C, Breitenecker G, Kowalski $H$, et al. Lymphatic microvessel density in epithelial ovarian cancer: its impact on prognosis. Anticancer Res 2000; 20(5A):2981-5.

60. Sundar SS, Zhang H, Brown P, Manek S, Han C, Kaur K, et al. Role of lymphangiogenesis in epithelial ovarian cancer. $\mathrm{Br} J$ Cancer 2006; 94(11):1650-7.

61. Nakamura Y, Yasuoka H, Tsujimoto M, Kurozumi K, Nakahara M, Nakao $K$, et al. Importance of lymph vessels in gastric cancer: a prognostic indicator in general and a predictor for lymph node metastasis in early stage cancer. J Clin Pathol 2006; 59(1):77-82.

62. Miyata Y, Kanda S, Ohba K, Nomata K, Eguchi J, Hayashida Y, et al. Tumor lymphangiogenesis in transitional cell carcinoma of the upper urinary tract: association with clinicopathological features and prognosis. J Urol 2006; 176(1):348-53.

63. Renyi-Vamos F, Tovari J, Fillinger J, Timar J, Paku S, Kenessey I, et al. Lymphangiogenesis correlates with lymph node metastasis, prognosis, and angiogenic phenotype in human non-small cell lung cancer. Clin Cancer Res 2005; 11 (20):7344-53.

64. Kaipainen A, Korhonen J, Mustonen T, van Hinsbergh VW, Fang GH, Dumont $D$, et al. Expression of the fms-like tyrosine kinase 4 gene becomes restricted to lymphatic endothelium during development. Proc Natl Acad Sci USA 1995; 92(8):3566-70.

65. Alitalo K. Vascular endothelial growth factors and receptors involved in angiogenesis and lymphangiogenesis. Eur J Cancer 1997; 33:1017-.

66. Karkkainen MJ, Petrova TV. Vascular endothelial growth factor receptors in the regulation of angiogenesis and lymphangiogenesis. Oncogene 2000; 19(49):5598-605.

67. Karkkainen MJ, Jussila L, Ferrell RE, Finegold DN, Alitalo K. Molecular regulation of lymphangiogenesis and targets for tissue oedema. Trends Mol Med 2001; 7(1):18-22.

68. Karkkainen MJ, Ferrell RE, Lawrence EC, Kimak MA, Levinson KL, McTigue $M A$, et al. Missense mutations interfere with VEGFR-3 signalling in primary lymphoedema. Nat Genet 2000; 25(2):153-9.

69. Jussila L, Alitalo K. Vascular growth factors and lymphangiogenesis. Physiol Rev 2002; 82(3):673-700. 
70. Breiteneder-Geleff S, Soleiman A, Kowalski H, Horvat R, Amann G, Kriehuber $E$, et al. Angiosarcomas express mixed endothelial phenotypes of blood and lymphatic capillaries: podoplanin as a specific marker for lymphatic endothelium. Am J Pathol 1999; 154(2):385-94.

71. Weninger W, Partanen TA, Breiteneder-Geleff S, Mayer C, Kowalski H, Mildner $M$, et al. Expression of vascular endothelial growth factor receptor-3 and podoplanin suggests a lymphatic endothelial cell origin of Kaposi's sarcoma tumor cells. Lab Invest 1999; 79(2):243-51.

72. Weidner N, Semple JP, Welch WR, Folkman J. Tumor angiogenesis and metastasis--correlation in invasive breast carcinoma. N Engl J Med 1991; 324(1):1-8.

73. Sleeman JP, Krishnan J, Kirkin V, Baumann P. Markers for the lymphatic endothelium: in search of the holy grail? Microsc Res Tech 2001; 55(2):61-9.

74. Kitadai Y, Amioka T, Haruma K, Tanaka S, Yoshihara M, Sumii K, et al. Clinicopathological significance of vascular endothelial growth factor (VEGF)-C in human esophageal squamous cell carcinomas. Int J Cancer 2001; 93(5):662-6.

75. Kajita T, Ohta Y, Kimura K, Tamura M, Tanaka Y, Tsunezuka Y, et al. The expression of vascular endothelial growth factor $C$ and its receptors in non-small cell lung cancer. Br J Cancer 2001; 85(2):255-60.

76. Clarijs R, Schalkwijk L, Ruiter DJ, de Waal RM. Lack of lymphangiogenesis despite coexpression of VEGF-C and its receptor Flt-4 in uveal melanoma. Invest Ophthalmol Vis Sci 2001; 42(7):1422-8.

77. Nathanson SD, Zarbo RJ, Wachna DL, Spence CA, Andrzejewski TA, Abrams J. Microvessels that predict axillary lymph node metastases in patients with breast cancer. Arch Surg 2000; 135(5):586-93; discussion 93-4.

78. Partanen TA, Paavonen K. Lymphatic versus blood vascular endothelial growth factors and receptors in humans. Microsc Res Tech 2001; 55(2):108-21.

79. Birner P, Obermair A, Schindl M, Kowalski H, Breitenecker G, Oberhuber $G$. Selective immunohistochemical staining of blood and lymphatic vessels reveals independent prognostic influence of blood and lymphatic vessel invasion in early-stage cervical cancer. Clin Cancer Res 2001; 7(1):93-7. 
80. Mouta Carreira C, Nasser SM, di Tomaso E, Padera TP, Boucher Y, Tomarev SI, et al. LYVE-1 is not restricted to the lymph vessels: expression in normal liver blood sinusoids and down-regulation in human liver cancer and cirrhosis. Cancer Res 2001; 61 (22):8079-84.

81. Nose K, Saito H, Kuroki T. Isolation of a gene sequence induced later by tumor-promoting 12-O-tetradecanoylphorbol-13-acetate in mouse osteoblastic cells (MC3T3-E1) and expressed constitutively in rastransformed cells. Cell Growth Differ 1990; 1(11):511-8.

82. Wetterwald A, Hoffstetter W, Cecchini MG, Lanske B, Wagner C, Fleisch $\mathrm{H}$, et al. Characterization and cloning of the Ell antigen, a marker expressed by the rat osteoblasts and osteocytes. Bone 1996; 18:125-32.

83. Kaneko MK, Kato Y, Kitano T, Osawa M. Conservation of a platelet activating domain of Aggrus/podoplanin as a platelet aggregationinducing factor. Gene 2006; 378:52-7.

84. Kato $Y$, Fujita $N$, Kunita A, Sato S, Kaneko $M$, Osawa $M$, et al. Molecular identification of Aggrus/Tlalpha as a platelet aggregationinducing factor expressed in colorectal tumors. J Biol Chem 2003; 278(51):51599-605.

85. Kato Y, Kaneko MK, Kunita A, Ito H, Kameyama A, Ogasawara S, et al. Molecular analysis of the pathophysiological binding of the platelet aggregation-inducing factor podoplanin to the C-type lectin-like receptor CLEC-2. Cancer Sci 2008; 99(1):54-61.

86. Suzuki-Inove K, Kato Y, Inoue O, Kaneko MK, Mishima K, Yatomi Y, et al. Involvement of the snake toxin receptor CLEC-2, in podoplaninmediated platelet activation, by cancer cells. J Biol Chem 2007; 282(36):25993-6001.

87. Martín-Villar E, Scholl FG, Gamallo C, Yurrita MM, Muñoz-Guerra M, Cruces J, et al. Characterization of human PA2.26 antigen (Tlalpha-2, podoplanin), a small membrane mucin induced in oral squamous cell carcinomas. Int J Cancer 2005; 113(6):899-910.

88. Ordonez NG. Podoplanin: a novel diagnostic immunohistochemical marker. Adv Anat Pathol 2006; 13(2):83-8.

89. Rishi AK, Joyce-Brady M, Fisher J, Dobbs LG, Floros J, VanderSpek J, et al. Cloning, characterization, and development expression of a rat lung alveolar type I cell gene in embryonic endodermal and neural derivatives. Dev Biol 1995; 167(1):294-306. 
90. Schacht V, Dadras SS, Johnson LA, Jackson DG, Hong YK, Detmar M. Upregulation of the lymphatic marker podoplanin, a mucin-type transmembrane glycoprotein, in human squamous cell carcinomas and germ cell tumors. Am J Pathol 2005; 166(3):913-21.

91. Breiteneder-Geleff S, Matsui K, Soleiman A, Meraner P, Poczewski H, Kalt R, et al. Podoplanin, novel 43-kd membrane protein of glomerular epithelial cells, is down-regulated in puromycin nephrosis. Am J Pathol 1997; 151(4):1141-52.

92. Schmid H, Henger A, Cohen CD, Frach K, Gröne HJ, Schlöndorff D, et al. Gene expression profiles of podocyte-associated molecules as diagnostic markers in acquired proteinuric diseases. J Am Soc Nephrol 2003; 14(1 1):2958-66.

93. Levidiotis $\mathrm{V}$, Power DA. New insights into the molecular biology of the glomerular filtration barrier and associated disease. Nephrology (Carlton) 2005; 10(2):157-66.

94. Schacht V, Ramirez MI, Hong YK, Hirakawa S, Feng D, Harvey N, et al. Tlalpha/podoplanin deficiency disrupts normal lymphatic vasculature formation and causes lymphedema. EMBO J 2003; 22(14):3546-56.

95. Ramirez MI, Millien G, Hinds A, Cao Y, Seldin DC, Williams MC. Tlalpha, a lung type I cell differentiation gene, is required for normal lung cell proliferation and alveolus formation at birth. Dev Biol 2003; 256(1):61-72.

96. Marks A, Bailey D, Iglesias J, Law J, Lei M, Yeger H, et al. Characterization and distribution of an oncofetal antigen ( M2A antigen ) expressed on testicular germ cell tumours. Br J Cancer 2000; 80:569-78.

97. Mäkinen T, Veikkola T, Mustjoki S, Karpanen T, Catimel B, Nice EC, et al. Isolated lymphatic endothelial cells transduce growth, survival and migratory signals via the VEGF-C/D receptor VEGFR-3. EMBO J 2001; 20(17):4762-73.

98. Ji RC, Eshita $Y$, Kato S. Investigation of intratumoural and peritumoural lymphatics expressed by podoplanin and LYVE-1 in the hybridomainduced tumours. Int J Exp Pathol 2007; 88(4):257-70.

99. Vanderbilt JN, Dobbs LG. Characterization of the gene and promoter for RTI40, a differentiation marker of type I alveolar epithelial cells. Am J Respir Cell Mol Biol 1998; 19(4):662-71.

100. Sipos B, Klapper W, Kruse ML, Kalthoff H, Kerjaschki D, Kloppel G. Expression of lymphangiogenic factors and evidence of intratumoral lymphangiogenesis in pancreatic endocrine tumors. Am J Pathol 2004; 165(4):1187-97. 
101. Rubbia-Brandt L, Terris B, Giostra E, Dousset B, Morel P, Pepper MS. Lymphatic vessel density and vascular endothelial growth factor- $C$ expression correlate with malignant behavior in human pancreatic endocrine tumors. Clin Cancer Res 2004; 10(20):6919-28.

102. Dumoff KL, Chu CS, Harris EE, Holtz D, Xu X, Zhang PJ, et al. Low podoplanin expression in pretreatment biopsy material predicts poor prognosis in advanced-stage squamous cell carcinoma of the uterine cervix treated by primary radiation. Mod Pathol 2006; 19(5):708-16.

103. Van Trappen PO, Pepper MS. Lymphangiogenesis in human gynaecological cancers. Angiogenesis 2005; 8(2):137-45.

104. Shepherd JH. Revised FIGO staging for gynaecological cancer. $\mathrm{Br} \mathrm{J}$ Obstet Gynaecol 1989; 96(8):889-92.

105. Tavassoli FA. Pathology \& genetics tumours of breast and female genital organs Lion. International Agency for Research on Cancer: IARC Press; 2003.

106. Weibel ER. Principles and methods for the morphometric study of the lung and other organs. Lab Invest 1963; 12:131-55.

107. Hall FT, Freeman JL, Asa SL, Jackson DG, Beasley NJ. Intratumoral lymphatics and lymph node metastases in papillary thyroid carcinoma. Arch Otolaryngol Head Neck Surg 2003; 129(7):716-9.

108. Pokkali S, Das RL. Expression of CXC and CC type of chemokines and its receptors in tuberculous and non-tuberculous effusions. Cytokine 2008; 41 (3):307-14.

109. Ran S, Volk L, Hall K, Flister MJ. Lymphangiogenesis and lymphatic metastasis in breast cancer. Pathophysiology. In press 2009.

110. Urabe A, Matsumoto T, Kimura M, Sonove H, Kinoshita K. Grading system of lymphatic invasion according to D2-40 immunostaining is useful for the prediction of nodal metastasis in squamous cell carcinoma of the uterine cervix. Histopathology 2006; 49(5):493-7.

111. Miyakuni Y, Matsumoto T, Arakawa A, Sonove H, Suzuki C, Takeda S. Lymphatic invasion according to D2-40 immunostaining is a predictor of nodal metastasis in endometrioid adenocarcinoma of the uterine corpus. Pathol Int 2008; 58(8):471-6.

112. Thierry J. Epithelial-mesenchymal transitions in tumor progression. Nature Rev Cancer 2002; 2:442-54. 
113. Guarino M, Rubino B, Ballabio G. The role of epithelial-mesenchymal transition in cancer pathology. Pathology 2007; 39(3):305-18.

114. Lee JM, Dedhar S, Kalluri R, Thompson EW. The epithelial-mesenchymal transition: new insights in signaling, development, and disease. J Cell Biol 2006; 172(7):973-81.

115. Wicki A, Lehembre F, Wick N, Hantusch B, Kerjaschki D, Christofori G. Tumor invasion in the absence of epithelial-mesenchymal transition: podoplanin-mediated remodeling of the actin cytoskeleton. Cancer Cell 2006; 9(4):261-72. 


\section{APÊNDICE A - PARECER ÉIICO}

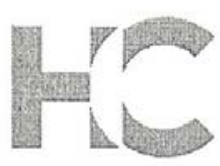

\section{APROVAÇÃO}

A Comissão de Ética para Análise de Projetos de Pesquisa CAPPesq da Diretoria Clínica do Hospital das Clíricas e ca Faculdade de Medicina da Universidade de São Paulo, em sessão de 10/09/2008, APROVOU O Protocolo de Pesquisa $n^{\circ}$ 0729/08, intitulado: "AVALIAÇĀO DA LINFANGIOGÊNESE EM CARCINOMA DE COLO DE ÚTERO" apresentado pelo Departamento de OBSTETRÍ́CIA E GINECOLOGIA.

Cabe ao pesquisador elaborar e apresentar à CAPPesq, os relatórios parciais e final sobre a pesquisa (Resoluçāo do Conselho Nacional de Saúde n¹96, de 10/10/1996, inciso (X.2, letra "c").

Pesquisador (a) Responsável: Jesus Paula Carvalho

Pesquisador (a) Executante: Fabrícia Leal Zaganelli

CAPPesq, 11 de Setembro de 2008

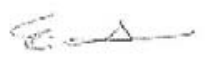

Prof. Dr. Eduardo Massad Presidente da Comissão de Ética para Análise de Projetos de Pesquisa 